UNIVERSIDADE DE SÃO PAULO

INSTITUTO DE QUÍMICA

\title{
DISTRIBUIÇÃO E REATIVIDADE DE ÍONS EM SOLUÇÕES DE MICELAS E VESÍCULAS
}

IDÉLCIO NOGUEIRA DA SILVA

\author{
IOLANDA MIDEA CUCCOVIA \\ (ORIENTADORA)
}

$-1995-$ 


\section{"DISTRIBUIÇÃO E REATIVIDADE DE ÍONS EM SOLUÇÕES DE MICELAS E VESÍCULAS"}

\section{IDÉLCIO NOGUEIRA DA SILVA}

Dissertação de Mestrado submetida ao Instituto de Química da Universidade de São Paulo como parte dos requisitos necessários à obtenção do grau de Mestre em Ciências - Área: Bioquímica.

Aprovada por:

\begin{tabular}{c}
\hline Profa. Dra. Iolanda Midea Cuccovia \\
IQ-USP \\
(Orientadora e Presidenta)
\end{tabular}

Profa. Dra. Ana Maria Carmona Ribeiro IQ-USP

Prof. Dr. João Baptista Sargi Bonilha

FFLCL-RP-USP

SĀO PAULO

31 DE JULHO DE 1995 
Dedico este trabalho:

Aos meus pais Osvaldo e Cecília.

Aos meus irmãos Izildinha, Itamiro, Ideli e Ivani. 
Agradecimentos:

- À prof. lolanda Midea Cuccovia pela orientação e oportunidade de trabalho.

- Ao prof. Hernan Chaimovich pelas discussões produtivas.

-Ao Xuds pelas discussōes e esclarecimentos atenciosos, batuques e cervejas.

- Ao prof. Pedro pelo profissionalismo e dicas de informática.

-À prof. Virgínia por ter permitido o uso do HPLC.

- Aos amigos do lab Palmira, Claudinha, Ana Paula, Fabinho, Fábio Jr., Walter, Boris, Márcia, Virgínia,TC, Neuza, Sílvia, Juliana, Flávio, Marcos e Priscila.

- Ao pessoal do B12S.

- Aos que saíram do laboratório e que deixaram saudades: Jacira, Hioka, Anselmo, Sérginho e Mauricinho.

- Ao CNPq pelo suporte financeiro. 
ÍNDICE

GLOSSÁRIO DE SÍMBOLOS E ABREVIAÇÕES

iii

LISTA DE FIGURAS

iv

RESUMO

vi

SUMMARY

vii

1 - INTRODUÇÃO

1.1 Agregados supramoleculares

1.1.1 Micelas

1.1.2 Vesículas

1.2 Reações em micelas e vesículas de anfifílicos sintéticos

1.3 Reações exo e endovesiculares

1.4 Controle da permeabilidade

1.5 Influência de micelas e vesículas nos produtos de reações 20

1.6 Análise quantitativa de reações em micelas e vesículas 22

1.7 OBJETIVOS 32

1.8 Reações estudadas $\quad 32$

1.8.1. Hidrólise alcalina do DTNB 32

1.8.2. Descarboxilação do NBOC 33

1.8.3 Decomposição do íon 2,4,6-trimetilbenzenodiazônio 37

2 - PARTE EXPERIMENTAL $\quad 40$

2.1. Materiais 40

2.2. Aparelhagem 41

2.2.1. Análise cromatográfica por HPLC 41

2.2.2. Cinéticas $\quad 45$

2.3. Métodos 45

2.3.1 Síntese do TMDBF4 45

2.3.2. Preparação do TMDCl 45 
2.3.3 Determinação da concentração de anfifílicos 46

2.3.4 Preparação de vesículas $\quad 46$

2.3.4.1 Vesículas sonicadas $\quad 46$

2.3.4.2 Vesículas injetadas $\quad 47$

2.3.5 Separação do TMDCI não incorporado 47

2.3.6 Reações do TMDCl em micelas e vesículas 48

2.3.7 Cinéticas $\quad 49$

2.3.7.1 Hidrólise alcalina do DTNB $\quad 49$

2.3.7.2 Decomposição do NBOC $\quad 50$

2.3.. Tratamento de dados 50

3 - RESULTADOS 51

3.1. Determinação do $\alpha$ em micelas e vesículas e de $\mathrm{K}_{\mathrm{Br} / \mathrm{Cl}}$

3.1.1 Micelas $\quad 51$

$\begin{array}{ll}3.1 .2 \text { Vesículas } & 60\end{array}$

3.2 Determinação de $\alpha_{i}$ de vesículas de DODAC 66

3.3 Efeito de micelas na descarboxilação do NBOC 69

3.4 Efeito de vesículas na velocidade de reações 72

3.4.1 Descarboxilação do NBOC $\quad 72$

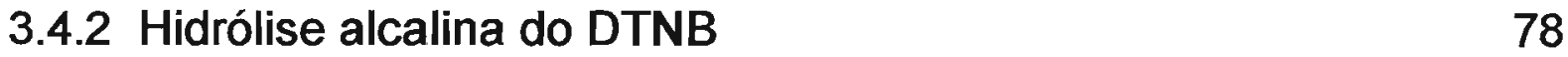

$\begin{array}{ll}\text { 4- DISCUSSÃO } & 87\end{array}$

$\begin{array}{ll}\text { CONCLUSÕES } & 98\end{array}$

$\begin{array}{ll}\text { BIBLIOGRAFIA } & 100\end{array}$ 
GLOSSÁRIO DE SÍMBOLOS E ABREVIAÇÕES

$\alpha \quad$ grau de dissociação iônica

$\mathrm{C}_{\mathrm{d}} \quad$ concentração de detergente micelizado

$\mathrm{C}_{\mathrm{t}} \quad$ concentração de detergente total

CMC concentração micelar crítica

CTACI cloreto de hexadecildimetilamônio

CTAB brometo de hexadecildimetilamônio

$D_{h} \quad$ diâmetro hidrodinâmico

DODAC cloreto de dioctadecildimetilamônio

DODAB brometo de dioctadecildimetilamônio

DTNB ácido 5,5'-ditiobis(2-nitrobenzóico)

$\mathrm{k}_{\Psi} \quad$ constante de velocidade observada

$\mathrm{k}_{2 \mathrm{v}} \quad$ constante de velocidade de $2^{\mathrm{a}}$ ordem na fase vesicular

$k_{2 w} \quad$ constante de velocidade de $2^{\mathrm{a}}$ ordem na fase aquosa

NBOC 6-nitrobenzisoxazol-3-carboxilato 


\section{LISTA DE FIGURAS}

Figura 1: Representação esquemática de agregados supramoleculares formados por anfifílicos.

Figura 2: Esquema da estrutura micela, em corte, segundo o modelo de Stigter.

Figura 4: Representação dos sítio reativos de uma vesícula em solução.

Figura 5: Reação de tiólise de éster por heptilmercaptana.

Figura 6: Reação de transaminação, catalisada por vesículas de $\mathrm{N}^{+} \mathrm{C}_{5} \mathrm{HisC}_{16}$.

Figura 7: Mecanismo da hidrólise alcalina do DTNB. 34

Figura 8: Decomposição do NBOC. $\quad$.. 36

Figura 9: Reação de decomposição do TMD. 38

Figura 10: Curva de calibração para o TMF. 42

Figura 11: Curva de calibração para o TMCl. $\quad 43$

Figura 12: Curva de calibração para o TMBr. 44

Figura 13: Formação de $\mathrm{TMBr}$ a partir da reação de TMD em presença de $\mathrm{NaBr}$ a baixas concentrações.

52

Figura 14: Formação de $\mathrm{TMBr}$ a partir da reação de TMD em presença de $\mathrm{NaBr}$ em altas concentrações.

Figura 15: Formação de $\mathrm{TMCl}$ a partir da reação de TMD em presença de $\mathrm{NaCl}$ a baixas concentrações.

Figura 16: Formação de TMCl a partir de reação de TMD em presença de $\mathrm{NaCl}$ em altas concentrações.

Figura 17: Efeito de micelas de CTACI na concentração de cloreto livre.

Figura 18: Efeito de micelas de CTABr na concentração de brometo livre.

Figura 19: Determinação da constante de troca $\mathrm{Br}^{-} / \mathrm{Cl}^{-}$em micelas de CTACI.

Figura 20: Efeito de vesículas de DODAC (preparadas por sonicador de banho) na concentração externa de cloreto.

Figura 21: Efeito de vesículas de DODAC sonicadas por tip na concentração externa de cloreto.

Figura 22: Efeito de vesículas de DODAC injetadas (DCM) na concentração externa de cloreto.

Figura 23: Determinação do grau de dissociação externo de vesículas de DODAB sonicadas (tip). 
Figura 24: Decomposição de NBOC em presença de micelas de CTACI.

Figura 25: Decomposição de NBOC em presença de micelas de CTAB.

Figura 26: Efeito da concentração do substrato na descarboxilação do NBOC em CTACI $5,64 \times 10^{-3} \mathrm{M}$.

Figura 27: Catálise da decomposicão de NBOC pela superfície externa de vesículas injetadas de DODAB.

Figura 28: Catálise da decomposição de NBOC pela superfície interna e externa de vesículas injetadas de DODAB.

Figura 29: Catálise da decomposição de NBOC pela superfície externa de vesículas injetadas de DODAC.

Figura 30: Catálise da decomposição de NBOC pela superfície interna e externa de vesículas injetadas de DODAC.

Figura 31: Efeito da concentração de substrato na descarboxilação do NBOC em DODAC (vesículas clorofórmicas).

Figura 32: Hidrólise alcalina de DTNB em vesículas sonicadas de DODAC.

Figura 33: Hidrólise alcalina de DTNB pela superfície interna de vesículas injetadas de DODAC.

Figura 34: Catálise da hidrólise alcalina de DTNB pela superfície externa de vesículas injetadas de DODAC.

Figura 35: Efeito da concentração de substrato na hidrólise alcalina do DTNB em DODAC $4,26 \times 10^{-3} \mathrm{M}$ (vesículas injetadas), 


\section{RESUMO}

A extensão relativa da dissociação iônica $(\alpha)$ de micelas de cloreto de hexadecildimetilamônio (CTACI), brometo de hexadecildimetilamônio (CTAB), vesículas de cloreto de dioctacecildimetilamônio (DODAC) e brometo de dioctadecildimetilamônio (DODAB) foram determinadas usando um método de dediazonização.

O método de dediazonização consiste na determinação de produtos resultantes da lenta decomposição espontânea de tetrafluorborato de 2,4,6-trimetilbenzenodiazônio, seguida pela reação rápida do cátion fenílico com nucleófilos presentes no meio. Foi demostrado que este método determina a composição relativa da pseudofase aquosa interagregado.

Os valores de $\alpha$ obtidos para CTACI e CTAB foram, respectivamente, 0,29 e 0,26 , em excelente concordância com valores previamente publicados. $\mathrm{O}$ coeficiente de troca iônica para brometo/cloreto, determinado através do mesmo método, foi de 2,65, coincidindo com dados publicados. Estes valores confirmam o uso deste método para se obter tanto grau de dissociação iônica relativo como coeficientes de seletividade. O método foi também aplicado para a determinação do grau de dissociação iônica externo $\left(\alpha_{e}\right)$ e interno $\left(\alpha_{i}\right)$ de vesículas de DODAC e DODAB. Para vesículas de DODAB sonicadas por tip obteve-se $\alpha_{e}$ de 0,20 ; para vesículas de DODAC sonicadas em banho $\alpha_{e}$ foi 0,20; para vesículas de DODAC sonicadas por tip $\alpha_{e}$ foi 0,25 e para vesículas de DODAC grandes $\alpha_{e}$ foi 0,11 . Foi também determinado, pela primeira vez, o valor de 0,07 para $\circ \alpha_{i}$ de vesículas grandes de DODAC.

O conjunto de valores obtidos para $\alpha_{i}$ e $\alpha_{e}$ permitiram a análise quantitativa da catálise pelo compartimento aquoso interno e externo de vesículas sem a utilização de $\alpha$ como parâmetro ajustável. Foi modelado com sucesso a decomposição espontânea do íon 6-nitrobenzisoxazol-3carboxilato e a hidrólise alcalina do ácido 5,5'-ditiobis(2-nitrobenzóico).

Este trabalho é a primeira análise quantitativa de reações modificadas por vesículas nos dois compartimentos usando dados independentes para dissociação iônica das superfícies vesiculares. 


\section{SUMMARY}

The relative extents of ion dissociation $(\alpha)$ from micelles of hexadecyltrimethylammonium (CTA) chloride (CTACl) and bromide (CTAB) and vesicles of dioctadecyldimethylammonium (DODA) chloride (DODAC) and bromide (DODAB) were determined using a dediazoniation method.

The dediazoniation method consists in the determination of the products resulting from the slow spontaneous decomposition of 2,4,6trimethylbenzene diazonium tetrafluoroborate, followed by fast reaction of the resulting phenyl cation with neighboring nucleophiles. This method was shown to determine the relative composition of the interaggregate aqueous pseudophase and, consequently, the degree of ion dissociation of the aggregate.

The values of $\alpha$ obtained for CTACl and CTAB were, respectively, 0.29 and 0.26 , in excellent agreement with previously published values. The ion exchange selectivity coefficient for bromide/chloride exchange, determined using the same method was 2.65 , coinciding with published data. These values lend confidence to the use of this method for obtaining both relative dissociation degrees and ion selectivity coefficients. The method was also applied for the determination of the external $\left(\alpha_{e}\right)$ as well as the internal $\left(\alpha_{i}\right) \alpha$ of DODAC and DODAB vesicles. For tip-sonicated DODAB vesicles $\alpha_{\mathrm{e}}$ was 0.20 , for bath-sonicated DODAC $\alpha_{\mathrm{e}}$ was 0.20 , for tip-sonicated DODAC $\alpha_{\mathrm{e}}$ was 0.25 
and for large DODAC vesicles $\alpha_{\mathrm{e}}$ was 0.11. We also determined, for the first time, the a value of 0.07 for $\alpha_{\mathrm{r}}$ of large vesicles.

The set of values obtained for $\alpha_{\mathrm{I}}$ and $\alpha_{\mathrm{e}}$ permitted quantitative analysis of two reactions in both the internal and external aqueous compartments of vesicles without recourse to ion dissociation adjustable parameters. We successfully modeled the spontaneous decomposition of 6-nitrobenzisoxazol-3carboxylate and the alkaline hydrolysis of 5,5'-dithiobis(2-nitrobenzoate).

This work is the first quantitative analysis of vesicle-modified reactions in both vesicle compartments using independent data for ion dissociation from vesicle's surfaces. 


\section{CAPÍTULO 1}

\section{INTRODUÇÃO}

\subsection{Agregados Supramoleculares}

Muitas das reações químicas em organismos vivos ocorrem em interfaces membrana-água. A simultaneidade de funções e a diversidade de componentes de uma membrana biológica dificultam a investigação de mecanismos de reação, transporte de íons, fusão, interação com mediadores a nível molecular. Modelos de membrana, mais simples do ponto de vista químico e estrutural, permitem o estudo isolado de cada fenômeno.

Agregados supramoleculares, tais como monocamadas, micelas aquosas ou reversas, lipossomos e vesículas (figura 1) modificam a velocidade e o mecanismo de reações químicas e são utilizados como modelos de membrana para se estudar as influências de diversos fatores em reações interfaciais (Fendler, 1982).

Os surfactantes que formam micelas têm em geral a fórmula $\mathrm{RX}$, onde $\mathrm{R}$ é uma cadeia hidrocarbônica e $\mathrm{X}$ é um grupo polar. As cadeias hidrocarbônicas contém, no mínimo, oito carbonos, apresentando ou não insaturações e ramificações. $O$ grupo polar $X$ na molécula de anfifílico pode ser não-iônico, zwitteriônico ou iônico. Os grupos não iônicos mais usados no estudo de surfactantes são 


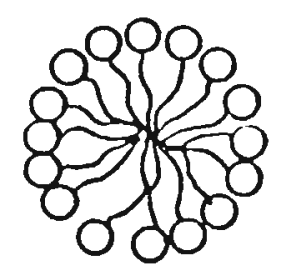

MICELA AQUOSA

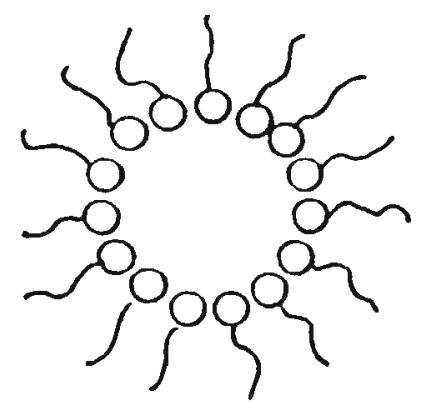

MICELA REVERSA

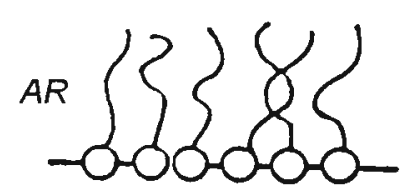

ÁGUA

MONOCAMADA
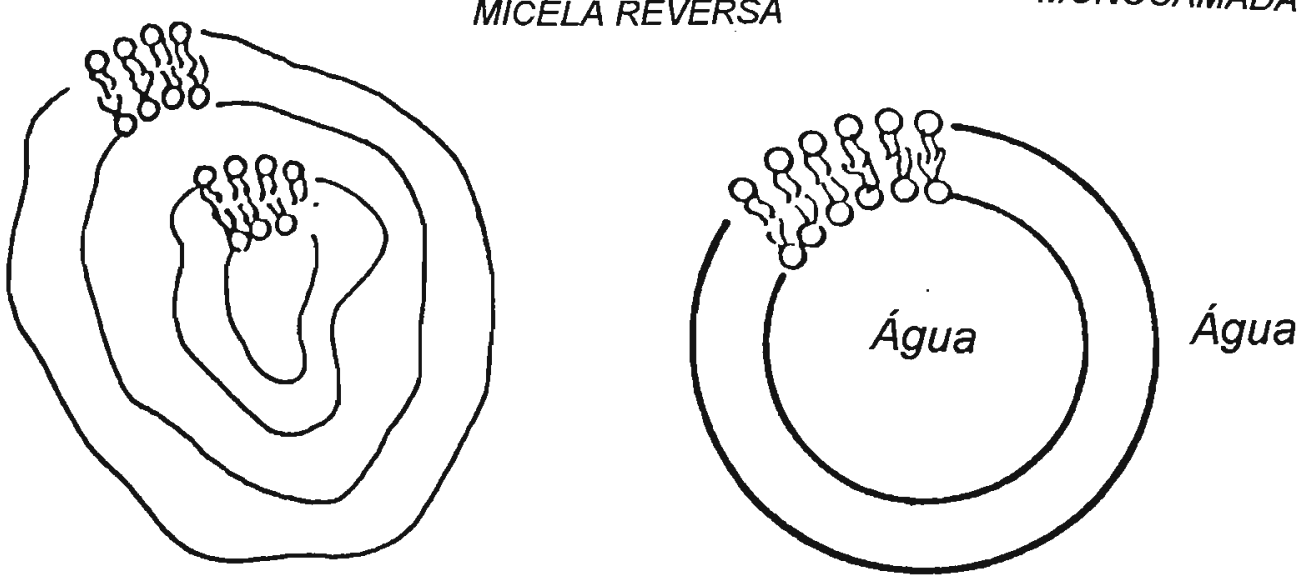

LIPOSSOMO

VESÍCULA

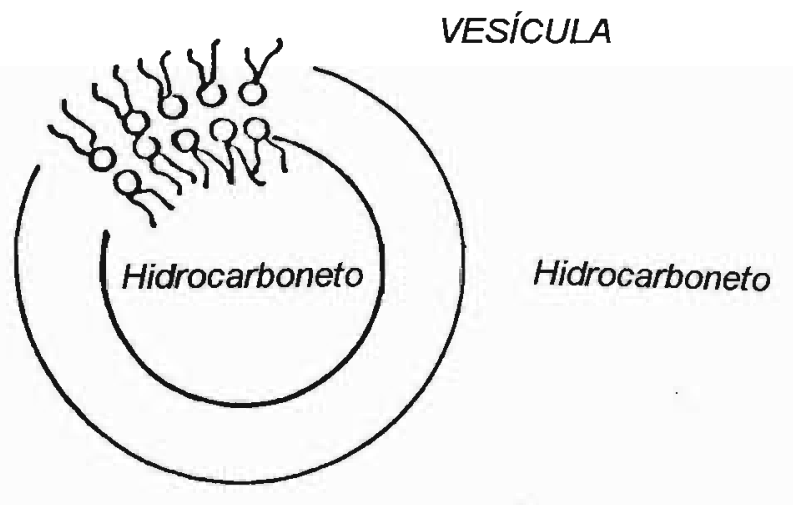

VESÍCULA REVERSA

Figura 1: Representação esquemática de agregados supramoleculares formados por anfifílicos. 
polioxietilenos de cadeia curta $-\left(\mathrm{C}_{2} \mathrm{H}_{4} \mathrm{O}\right)_{n}-$, nos quais $n$ varia de 3 ou 4 para 20 ou mais. Estes surfactantes são conhecidos como Brij e Tween (Israelachvili, 1991). Como grupos polares aniônicos, os grupos sulfato, sulfonato e carboxilato são os mais comuns, enquanto que os grupos contendo amônio quaternário são os mais comuns para surfactantes catiônicos. Os grupos polares zwitteriônicos possuem como grupo aniônico o fosfato, carboxilato ou sulfonato e como grupo catiônico o grupo amônio (Fendler e Fendler, 1975).

Os anfifílicos que formam vesículas têm, em geral, fórmula $R_{2} X$, onde $R$ é a cadeia hidrocarbônica e $X$ é um grupo polar. Anfifilicos como ácido fosfatídico, fosfatidilcolina, dihexadecilfosfato e sais de dialquildimetilamônio são os mais usados para a preparação de vesículas.

É possivel, através de considerações geométricas da estrutura do surfactante, explicar e, às vezes, predizer o tipo de agregado formado (Israelachvili, 1991). A geometria de uma molécula de anfifílico num agregado pode ser analisada em função de parâmetros como: a área ótima $\left(\mathrm{a}_{0}\right)$ que é a área na superfície do agregado ocupada pela cabeça polar quando a energia interfacial total por molécula no agregado é mínima, o volume (v) da cadeia hidrocarbônica e o comprimento máximo efetivo que as cadeias podem assumir $\left(I_{c}\right)$. Para moléculas se agregarem formando micelas, $a_{0}$ deve ser suficientemente grande e $v$ suficientemente pequeno de modo que o raio da micela não exceda o comprimento crítico da cadeia $I_{c}$. A partir destas considerações geométricas obtem-se que $v / a_{0} \cdot I_{c}=1 / 3$ para micelas. Para formar vesículas é necessário uma 
área $a_{0}$ pequena e uma cadeia hidrocarbônica relativamente volumosa $v$, o que resulta em $v / a_{0} \cdot I_{c} \sim 1$.

\subsubsection{Micelas}

Micelas são entidades dinâmicas, cuja cinética de formaçãodissolução é da ordem de milisegundos, enquanto que a troca de monômeros com o meio ocorre na escala de microsegundos (Fendler, 1982).

O modelo de Stigter para micelas é apresentado de forma esquemática na figura 2. A micela é aproximadamente esférica, possuindo uma região central constituída de hidrocarbonetos (desordenados e próximos ao estado líquido) com raio estimado de 10 a $28 \AA$. Ao redor do núcleo interno existe uma camada de poucos $\AA$ onde, no caso de anfifílicos iônicos, encontra-se a região iônica dos monômeros com parte de seus contraíons ligados, formando uma interface micela-água denominada de camada de Stern, seguida por uma camada externa, chamada de camada difusa de GouyChapman, onde, além de contra íons existem co-íons.

\subsubsection{Vesículas}

Vesículas são agregados cuja estrutura consiste numa bicamada de anfífilicos que envolve um determinado volume de água (figura 3). 


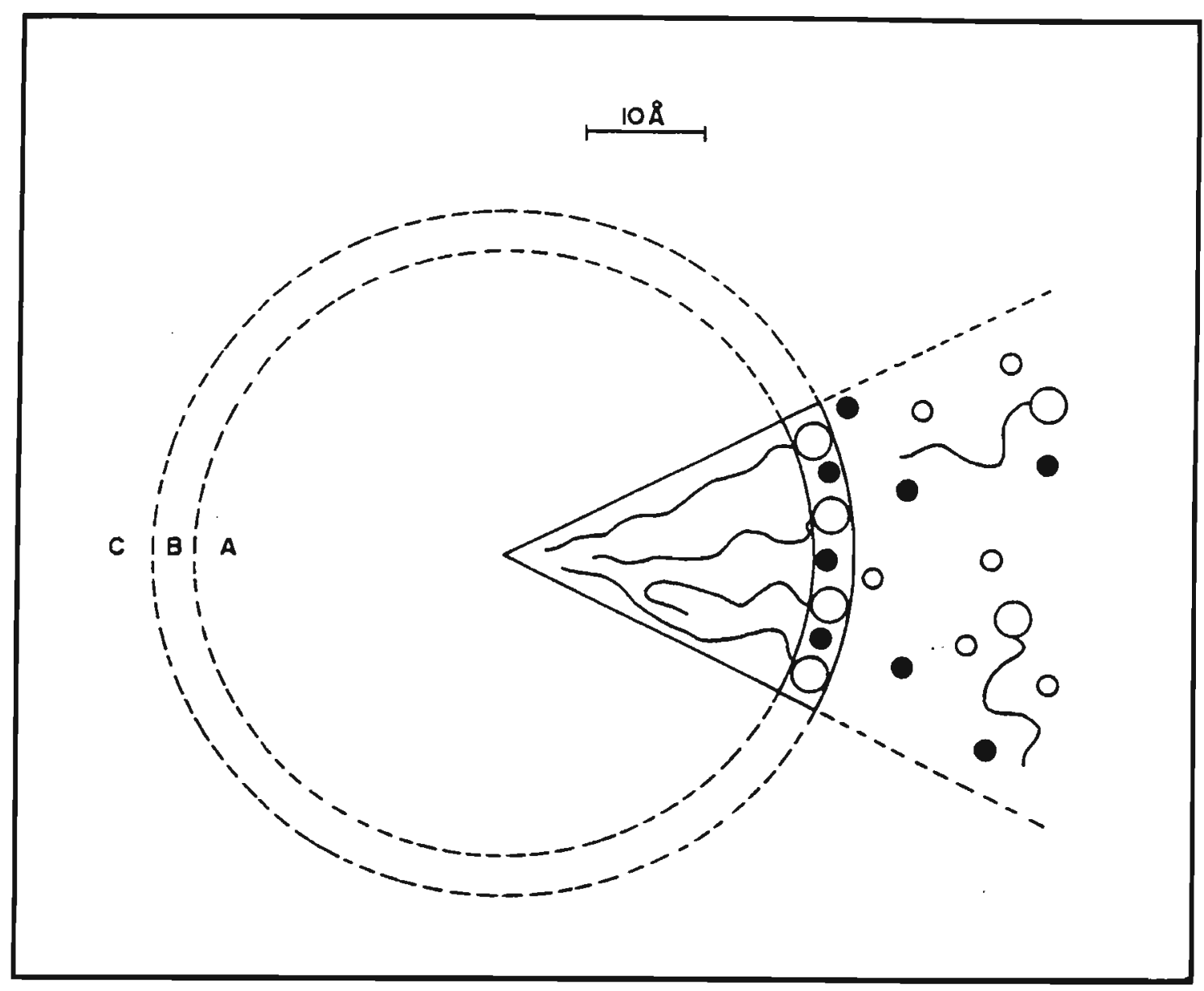

Figura 2: Esquema da estrutura micelar, em corte, segundo o modelo de Stigter, mostrando o caroço hidrofóbico (A), a camada de Stern (B) e a dupla camada de Gouy-Chapman (C). Os contra íons ( $\bullet$ ) podem ser encontrados nas camadas de Stern e Gouy-Chapman. Os co-íons (O) estão presentes na camada de Gouy-Chapman, pois são repelidos pelas cargas (de mesmo sinal) das cabeças polares na camada de Stern. A concentração de anfifílicos livres ( ح ) é da ordem da CMC. O esquema está em escala espacial, não havendo nehuma correlação entre a quantidade de monômeros ou íons das duas camadas. 


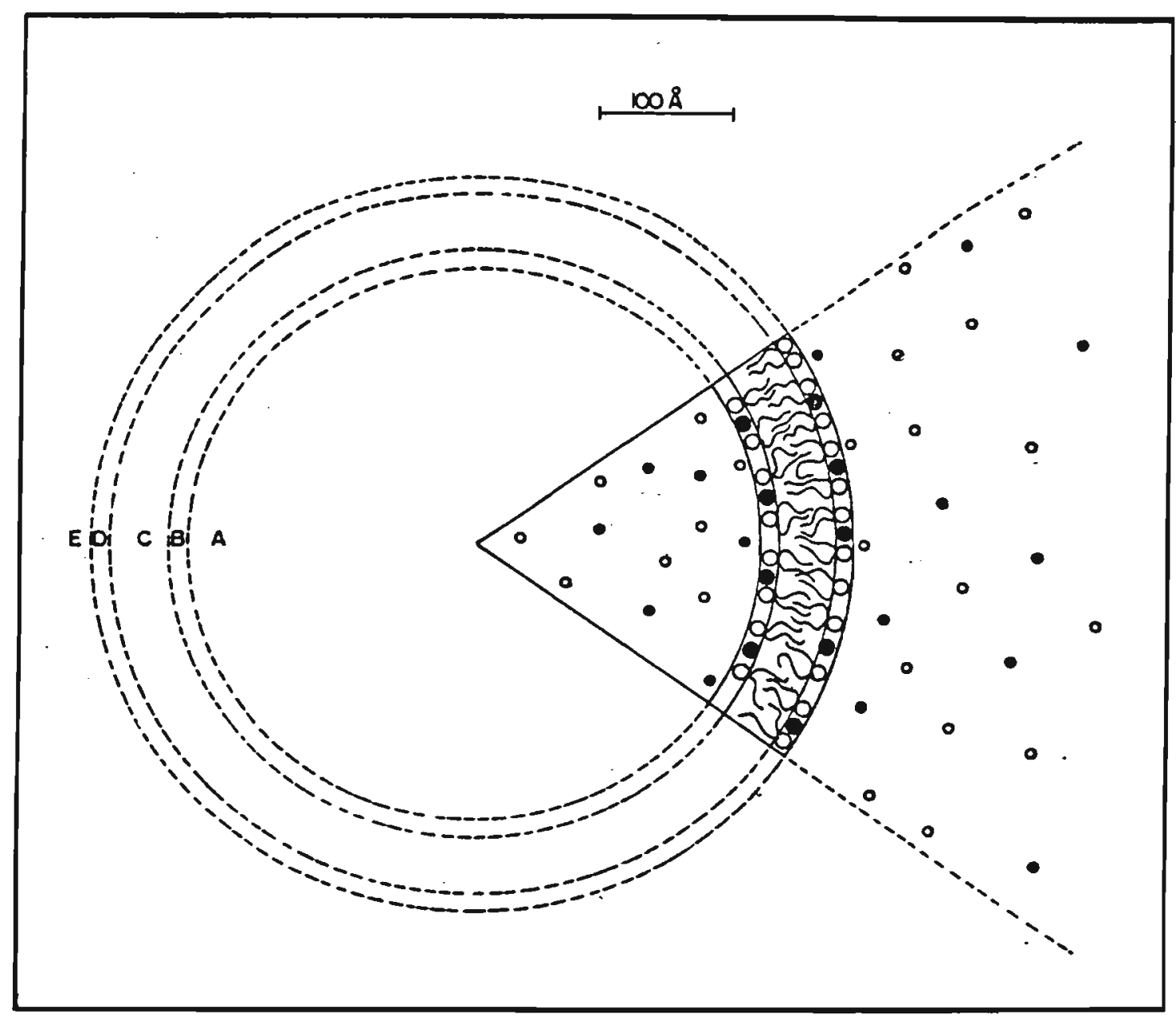

Figura 3: Modelo de Stigter aplicado a vesículas. Estrutura em corte, mostrando o anel hidrofóbico (C) e as camadas de Stern e Gouy-Chapman interna $(B, A)$ e externa $(D, E) .(\approx 0$ ) anfifílico; $(0)$, contra-íons; $(O)$, co-íons. 
Vesículas preparadas com anfifílicos são geralmente metaestáveis e revertem para estruturas multilamelares com o tempo (Lasic, 1988). Sais e aditivos orgânicos desestabilizam vesículas causando um aumento no diâmetro hidrodinâmico médio $\left(D_{h}\right)$ (Carmona-Ribeiro e Chaimovich, 1986; Madani e Kaler, 1990; Carmona-Ribeiro, 1992)

Vesículas têm sido utilizadas para se estudar propriedades de membrana com vantagens em relação aos demais agregados por possuirem compartimento aquoso interno, ideal para o estudo de permeabilidade.

Da mesma forma que micelas, vesículas são capazes de catalisar certas reações. Este efeito é devido principalmente à concentração de reagentes na bicamada, mudanças no $\mathrm{pK}_{\mathrm{a}}$ de nucleófilos derivados de ácidos fracos (Cuccovia et al, 1982; Chaimovich et al, 1984; Kawamuro et al, 1991) e, em alguns casos, diminuição na energia livre de ativação da reação (Kunitake et al, 1980; Cuccuvia et al; 1982; Kawamuro et al, 1991). Deste modo, vesículas são utilizadas como modelo para estudo tanto de fatores que influenciam na permeabilidade de membranas como na catálise de reações.

Existem vários métodos de preparação de vesículas, sendo que suas propriedades físicas e funcionais dependem do tamanho das vesículas obtidas (Lasic, 1988). Serão descritos brevemente alguns dos métodos mais comuns para a preparação de vesículas e lipossomos com anfíílicos sintéticos. 
O método mais simples de preparação de lipossomos consiste na deposição de um filme, obtido por evaporação do solvente de uma solução do anfifílico, hidratação com solução aquosa em excesso e agitação branda ou vigorosa. A distribuição dos tamanhos obtidos é larga, com $D_{h}$ variando de 0,1 a vários micrômetros.

A sonicação é amplamente usada para se obter vesículas unilamelares pequenas (small unilamellar vesicles, SUV). Vesículas sonicadas de cloreto de dioctadecildimetilamônio (DODAC) apresentam diâmetro hidrodinâmico de 380 a $530 \AA$ (Cuccovia et al, 1990), volume de incorporação de $0,13 \mathrm{~L} / \mathrm{mol}$ (Carmona-Ribeiro et al, 1983), temperatura de transição de fase $\left(T_{c}\right)$ de $37,5^{\circ} \mathrm{C}$ e grau de dissociação iônica externo em torno de 0,2 (Cuccovia et al, 1990). Como a incorporação de substratos solúveis em água no compartimento aquoso interno é pequena (Carmona-Ribeiro et al, 1985), é difícil afirmar se estes agregados são muito permeáveis ou são estruturas abertas. A formação de estruturas abertas que lentamente e espontaneamente formam vesículas fechadas maiores foi sugerida por Pansu et al (1990), baseado em experimentos de espalhamento de luz.

SUV's também podem ser obtidas por extrusão através de membranas de poro controlado e de passagem sob alta pressão através de orifícios pequenos (Lasic, 1988).

Vesículas unilamelares grandes (large unilamellar vesicles, LUV), $D_{h}>100 \mathrm{~nm}$, podem ser obtidas, entre outros métodos, por evaporação de fase reversa, injeção de solvente ou extrusão (Lasic, 1988). 
Vesículas unilamelares grandes de DODAC e DCP podem ser obtidas por injeção (lenta) de solução clorofórmica num meio aquoso termostatizado acima do ponto de ebulição do solvente (CarmonaRibeiro, 1992). As propriedades das vesículas de DODAC e DCP preparadas por injeção clorofórmica tem sido analisadas em detalhe e existem muitos resultados confirmando que estas vesículas são fechadas, retêm substratos solúveis em água, são impermeáveis a íons e apresentam comportamento osmométrico ideal (CarmonaRibeiro, 1992). Vesículas de DODAC preparadas por evaporação clorofórmica apresentam $D_{h}$ de 2850 a $5000 \AA$, volume de $9,7 \mathrm{~L} / \mathrm{mol}$, grau de dissociação externo de 0,04 e $\mathrm{T}_{\mathrm{c}}$ de $38,6^{\circ} \mathrm{C}$.

\subsection{Reações em Micelas e Vesículas de Anfifílicos Sintéticos}

Micelas apresentam sítios reativos em potencial, de polaridades diferentes, onde os substratos podem se ligar, dependendo do seu caráter hidrofóbico/hidrofílico. Entretanto, nos trabalhos de catálise de reações por micelas muito pouco é comentado sobre a localização do substrato.

A catálise por micelas ou vesículas $\left(k_{\Psi \text { máx }} / k_{0}\right)$ pode ser expressa como a relação entre a constante de velocidade máxima obtida em presença do agregado ( $k_{\Psi \text { máx }}$ ) a constante de velocidade obtida nas mesmas condições na sua ausência $\left(k_{0}\right)$.

A hidrólise alcalina do ácido 5,5'-ditiobis(2-nitrobenzóico) (DTNB) por micelas de brometo de hexadeciltrimetilamônio (CTAB) foi estudada por Fendler e Hinze (1981)(figura 7). Foi obtida uma 
constante observada de segunda ordem de $8,4 \mathrm{M}^{-1} \mathrm{~s}^{-1}$ a $26,4{ }^{\circ} \mathrm{C}$. $\mathrm{A}$ constante de segunda ordem em água é $0,54 \mathrm{M}^{-1} \mathrm{~s}^{-1}$. Micelas de CTAB catalisam a reação cerca de 15 vezes. A catálise é atribuída ao aumento da concentração de hidróxido e DTNB na superfície micelar.

A descarboxilação do íon 6-nitrobenzisoxazol-3-carboxilato (NBOC) (Bunton e Minch, 1970; Bunton et al, 1971) é aumentada cerca de 100 vezes por micelas de CTAB. Como a velocidade de descarboxilação é maior em meio apolar (Kemp e Paul, 1975), é sugerido que o NBOC esteja localizado na interface da micela com o grupo carboxilato direcionado para a camada de Stern.

Quando comparadas com micelas, vesículas contém um número muito maior de sítios reativos em potencial. Furhop e Mathieu (1984) propuseram uma classificação onde nove sítios potenciais de reação podem ser distinguidos numa solução contendo vesículas (figura 4): 1) parte intervesicular; 2) volume aquoso na vizinhança da cabeça polar e/ou camada de Gouy-Chapman se a vesícula for carregada; 3) cabeças polares externas; 4) membrana hidrofóbica perto das cabeças polares externas; 5) interior da membrana hidrofóbica e 6-9 as regiōes internas correspondentes às regiōes externas 4-1.

Em geral, os efeitos catalíticos de vesículas são mais significativos do que de micelas, sendo que nos dois sistemas a catálise pode ser atribuida: à ligação e concentração dos reagentes no agregado, ao aumento da dissociação dos reagentes ligados $\mathrm{e}$ efeitos intrínsecos na reatividade (Cuccovia et al, 1982). 


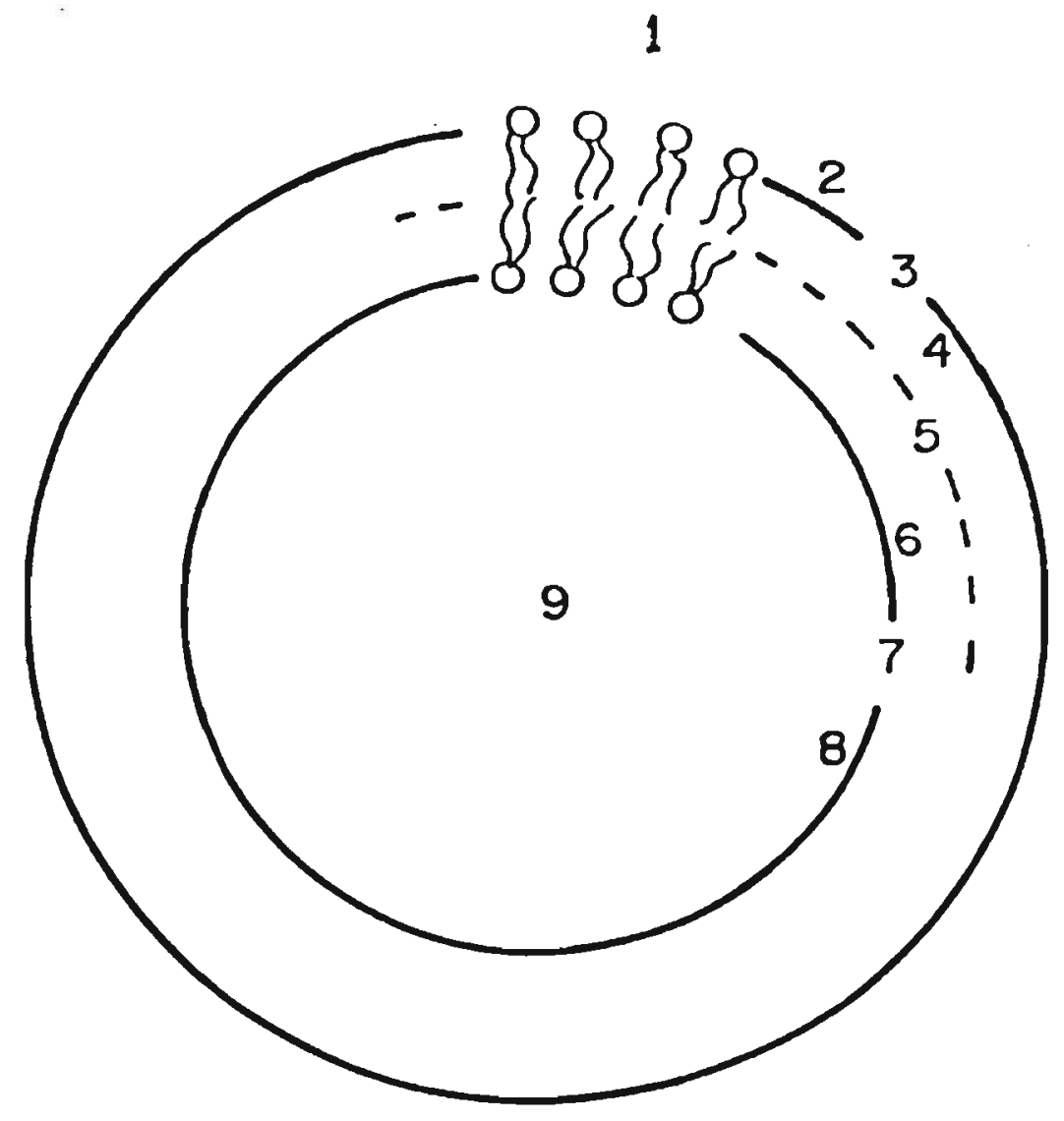

Figura 4: Representação dos sítios reativos de uma vesícula em solução: 1)-compartimento aquoso externo, 2)-esfera de hidratação próxima das cabeças polares, 3)-grupos polares da camada externa, 4)-membrana hidrofóbica próxima das cabeças polares externas, 5)-membrana hidrofóbica interna, 6)-membrana hidrofóbica próxima das cabeças polares internas, 7)-grupos polares da camada interna, 8)-esfera de hidratação das cabeças polares internas, 9)-espaço aquoso interno. 
O estudo de catálise de reaçōes por vesículas de anfifílicos sintéticos teve início com Kunitake e Sakamoto (1978). Desde então, o efeito de vesículas em uma enorme variedade de reações, tais como reações fotoquímicas, eletroquímicas, hidrólise de ésteres, estereoseletivas, entre outras, têm sido estudados.

Visto que a catálise por vesículas a aproxima às enzimas (Jencks,1987), nos estudos de catálise vesicular utilizou-se a priori reações enzimáticas muito conhecidas (hidrólise de ésteres), com grupos reativos de enzimas, como tiol e imidazol, covalentemente ligados ou não ao anfifílico vesicular.

Cuccovia et al (1979) obtiveram um aumento de velocidade de $7 \times 10^{4}$ na tiólise de acetato de p-nitrofenila (NPA) por heptilmercaptana (HM) em vesículas de DODAC (figura 5). Sob as mesmas condições, o aumento máximo na velocidade em presença de micelas de brometo de cetiltrimetilamônio (CTAB) é somente $4,0 \times 10^{3}$. Este aumento na velocidade é atribuído a um decréscimo no $\mathrm{pK}_{\mathrm{a}}$ da heptilmercaptana ligada ao agregado, à ligação e à concentração do ânion mercapteto e do NPA no agregado, possível efeito intrínseco sobre a reatividade do nucleófilo (ou seja, a constante de segunda ordem quando os reagentes estão ligados nas interfaces vesiculares $\left(k_{2 v}\right)$ é diferente da constante de segunda ordem nas mesmas condições em ausência de vesículas $\left(k_{2 w}\right)$ ) e aumento do $\mathrm{pH}$ na superfície positiva devido a ligação do hidróxido.

Prosseguindo com estudos de tiólise em vesículas, Cuccovia et al (1982) encontraram um fator de catálise acima de $10^{6}$ para a tiólise de octanoato de p-nitrofenila por n-heptilmercaptana (figura 5). A 


$$
\begin{aligned}
& \mathrm{R}^{\prime} \mathrm{H}=\mathrm{R}^{\prime}+\mathrm{H}^{+} \\
& R=-\mathrm{CH}_{3}(\mathrm{NPA}) ;-\left(\mathrm{CH}_{2}\right)_{6} \mathrm{CH}_{3}(\mathrm{NPO}) \\
& R^{\prime}=-\left(\mathrm{C} \mathrm{H}_{2}\right)_{6} \mathrm{CH}_{3}(\mathrm{HM})
\end{aligned}
$$

Figura 5: Reação de tiólise de éster por heptilmercaptana (HM). 
tiólise ocorre mesmo em $\mathrm{pH}$ 2, aproximadamente 6 unidades de $\mathrm{pH}$ abaixo do $\mathrm{pK}_{\mathrm{a}}$ do grupo $\mathrm{SH}$. A análise dos dados através do formalismo de Troca lônica (Quina e Chaimovich, 1979) mostrou que a aceleração na velocidade é devido principalmente concentração dos reagentes na vesícula, com pequena contribuição do aumento da dissociação e reatividade do nucleófilo.

Uma simulação de reação enzimática foi feita por Murakami et al (1989). Mostraram que vesículas formadas com brometo de N,Ndihexadecil-N ${ }^{\alpha}$-[6-(trimetilamônio)hexanoil]-L-histidinamida $\left(\mathrm{N}+\mathrm{C}_{5} \mathrm{His} 2 \mathrm{C}_{16}\right)$ catalisam a transaminação de $\alpha$-aminoácidos com ácido glioxilico em presença de $\mathrm{Cu}^{+2}$ (figura 6). Comparando as velocidades iniciais de transferência do aminogrupo dos aminoácidos L-alanina, ácido L-2-aminobutírico, L-norvalina, L-norleucina, ácido DL-2-aminooctanóico, L-leucina e fenilalanina para o ácido glioxílico em presença de vesículas de $\mathrm{N}+\mathrm{C}_{5} \mathrm{His} 2 \mathrm{C}_{16}$, a fenilalanina apresentou maior catálise ( 20 vezes em relação $s$ mesmas condições em ausência de vesículas). $\mathrm{O}$ aumento na velocidade foi atribuído ao efeito de coordenação exercido pelo $\mathrm{Cu}^{+2}$, catálise ácido-base do grupo imidazolil do lipídeo e ao efeito hidrofóbico da bicamada vesicular. Verificou-se uma correlação entre reatividade e a natureza do $\alpha$-aminoácido, observando-se um aumento da velocidade inicial de transaminação medida que a hidrofobicidade do grupo $\mathrm{R}$ do aminoácido aumentava. 

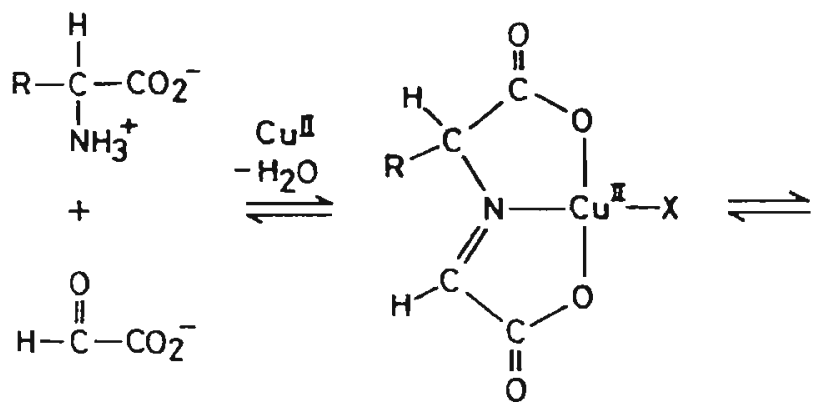<smiles></smiles><smiles>[R]C(=O)C(=O)[O-]</smiles>

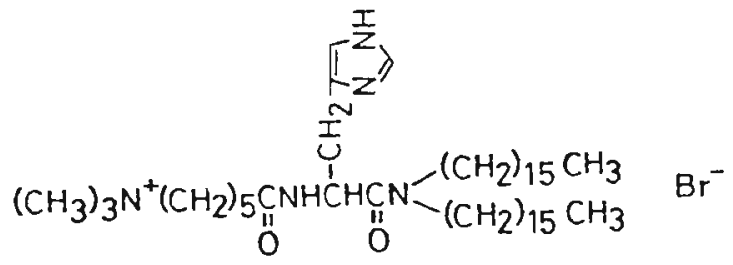

$$
\mathrm{N}^{+} \mathrm{C}_{5} \mathrm{His} 2 \mathrm{C}_{16}
$$

Figura 6: Reação de transaminação, catalisada por vesículas de $\mathrm{N}^{+} \mathrm{C}_{5} \mathrm{HisC}_{16}$ 


\subsection{Reaçōes Exo e Endovesiculares}

A observação dos efeitos da superfície interna e da superfície externa de vesículas separadamente na cinética e no mecanismo das reações permite se caracterizar e comparar a influência do empacotamento da bicamada e a diferença nas características eletrostáticas destas duas superfícies (Cuccovia et al ,1990; Feitosa et al, 1993).

Como o acesso a sítios de reação internos de vesículas é determinado por difusão, o estudo de transporte passivo é muito importante para se caracterizar estas superfícies.

Moss e Bizzigotti (1981), usando lipossomos de cloreto de N,Ndihexadecil-N-( $\alpha$-mercaptoetil)-N-metilamônio na tiólise do NPA conseguiu distinguir a reação que ocorre na superfície externa da que ocorre nas superfícies internas multilamelares. Os mesmos autores mostraram que a oxidação do ânion de Ellman em vesículas de brometo de dihexadecildimetilamônio (DHDA) por orto-iodobenzoato é limitada pela permeação. Obtiveram nitidamente um $\mathrm{k}_{2}$ fast ( constante de segunda ordem de reação rápida) devido reação na superfície externa e $k_{2}$ slow ( constante de segunda ordem da reação lenta) limitada pela permeação do iodobenzoato através da bicamada. Estas reações, limitadas pela difusão do reagente através da bicamada, foram chamadas de reações transvesiculares.

Visando o controle de reatividade pela permeação, Moss et al (1988) obtiveram um controle na reatividade por vesículas de DODAC superior ao obtido por vesículas de DHDA, na oxidação do 
ânion de Ellman por o-iodobenzoato. Estes reagentes quando incorporados separadamente em vesículas de DODAC são mantidos na mesma solução aquosa por horas com uma porcentagem mínima reação, enquanto que, no exterior da vesícula, o tempo total de reação é cerca de $10 \mathrm{~s}$. DTNB incorporado em vesículas de DODAC não reage com ditionito exovesicular, enquanto que em vesículas de DHDA a reação ocorre quantitativamente em cerca de $10 \mathrm{~s}$. A diferença de permeabilidade é devida ao aumento de 4 carbonos nas cadeias do DODAC em relação ao DHDA.

Para estudar o efeito da região hidrofóbica dos ésteres acetato de p-nitrofenila, hexanoato de p-nitrofenila, 4-acetoxi-3nitrobenzenosulfonato e palmitato de $p$-nitrofenila no acesso ao grupo tiol interno ou externo à vesícula, Moss et al (1986) utilizaram vesículas do surfactante cloreto de $\mathbf{N}, \mathbf{N}$-dihexadecil-N-metil-N-(2mercaptoetil) amônio, $16_{2} \mathrm{SH}$. Nestas tiólises, como o grupo tiol está covalentemente ligado ao surfactante (surfactante funcionalizado), as reatividades observadas foram devido exclusivamente à permeabilidade da vesícula aos ésteres. O efeito catalítico aumentou com a hidrofobicidade do éster. Os $k_{\Psi}$ máximos observados foram, $4,9,13,4,21,7$ e $7,3\left(\mathrm{~s}^{-1}\right)$ para acetato de p-nitrofenila, hexanoato de p-nitrofenila, palmitato de p-nitrofenila e 4-acetoxi-3nitrobenzenosulfonato, respectivamente.

$\mathrm{Na}$ clivagem do DTNB pelos tióis tiocolesterol, tiofenol, 2tionaftol, DL-cisteína, glutationa, 1-butanotiol e octanotiol em presença de vesículas sonicadas de DODAC, Moss e Swarup (1988) observaram uma diferenciação entre a reação exo e endovesicular. 
Para tióis estruturalmente semelhantes, a catálise também aumentou com a hidrofobicidade do éster. Para vesículas sonicadas de DODAC foi obtido $u m k_{\Psi}^{\text {lento }}$ (constante observada de primeira ordem limitada pela permeação do tiol) de $1,22 \mathrm{~s}^{-1}$ para tiofenol e $k_{\Psi}^{\text {lento }}$ de $46,3 \mathrm{~s}^{-1}$ para tionaftol. Este efeito é devido exclusivamente à permeabilidade da vesícula aos tióis, pois a permeabilidade ao DTNB é muito baixa.

Cuccovia et al (1989) demostraram que na hidrólise do DTNB em vesículas de DODAC, a relação entre as velocidades de reação na superfície interna e externa pode ser modulada pela composição do meio. A reação exovesicular é afetada pela adição na fase aquosa externa de brometo de sódio, que desloca o íon hidróxido da superfície vesicular e pela mudança no $\mathrm{pH}$, enquanto que a reação endovesicular é limitada pela difusão $\mathrm{H}^{+} / \mathrm{OH}^{-}$. Os valores de $\mathrm{k}_{2} / \mathrm{k}_{1}$, onde $k_{2}$ e $k_{1}$ são respectivamente a constante observada de primeira ordem para a reação exovesicular e endovesicular, podem variar de 90 a 0,6 dependendo da composição do meio.

\subsection{Controle da Permeabilidade}

Através do controle da permeabilidade de vesículas pode-se modular a velocidade de reações endovesiculares. Esta modulação é indispensável para o uso racional de vesículas sintéticas como catalisadores. Outra aplicação do controle da permeabilidade está no uso de vesículas e lipossomos como sistemas liberadores de drogas.

Em condições de permeabilidade muito baixa de uma vesícula funcionalizada é possivel obter vesículas assimétricas, vesículas onde 
o anfifilico da superfície interna é diferente do anfifilico da superfície externa, através da adição de um reagente que tenha acesso e modifique somente a superfície externa (Moss et al, 1987 e Moss et al, 1990). Estas vesículas tem um grande potencial de aplicação como catalisadores e sistemas liberadores de drogas (Lasic e Papahadjopoulos, 1995).

$\mathrm{Na} \mathrm{T}_{\mathrm{c}}$ de uma bicamada vesicular ocorre um grande aumento na permeabilidade. Como a $T_{c}$ aumenta com o comprimento da cadeia alquílica e com o grau de saturação do anfif́lico é possível modular a permeabilidade variando-se a estrutura do monômero ou através da mistura de diferentes anfifilicos (Moss et al, 1988; Moss et al , 1990; Moss et al, 1991).

A permeabilidade também pode ser controlada por: incorporação de colesterol na bicamada (Moss e Hui, 1983, Moss et al, 1989), adição de substâncias promotoras de fluxo, que aumentem a permeabilidade da membrana através da formação de poros ou de microfalhas (Moss e Swarup, 1986; Jayasuriya et al, 1990; Menger et al, 1990), mudança no pH (Maeda et al, 1988) e polimerização (Regen et al, 1983; Reed et al, 1984; Ishiwatari e Fendler, 1984; Stefely et al, 1988 e Frankel et al, 1989).

Um dos trabalhos de controle de permeação mais notável é o de Fuhrhop et al, 1988. As vesículas são preparadas com anfifílicos que são análogos dos constituintes de membrana da Archaebacteria. Com adição de uma oligoamina, que contem- grupos carboxilato ligados nos extremos da cadeia, formam-se poros na membrana vesicular que são permeáveis somente a íons metálicos. Estes poros 
podem ser fechados com várias moléculas aniônicas (stoppers) como ácido d-canforsulfúrico, taurina e EDTA. O EDTA pode ser retirado do poro através da adição de $\mathrm{Fe}^{+2}$ em excesso, sendo que um novo excesso de EDTA fecha outra vez os poros.

Stefely et al (1988) prepararam vesículas com um fosfolipídeo 1,2-bis[12-(lipoiloxi)dodecanoil]-sn-glicero-3-fosfocolina capaz de formar pontes de dissulfeto, misturado a 1-palmitoil-2-[12(lipoiloxi)dodecanoil]-sn-glicero-3-fosfocolina, fosfolipídio semelhante ao primeiro, mas que só fazia cadeias lineares com ligações dissulfeto. A permeabilidade da membrana depende do número de ligações dissulfeto ( lineares ou cruzadas), diminuindo com o aumento destas ligações. $O$ fato da quantidade de ponte dissulfeto ser controlada pela variação na proporção dos monômeros e a reversibilidade das ligações poliméricas de dissulfeto através da adição de redutores (Regen et al, 1983) tornam este sistema bastante eficiente no controle da permeabilidade.

\subsection{Influência de Micelas e Vesículas nos Produtos de Reações}

Algumas reações químicas podem ocorrer através de dois ou mais caminhos podendo levar a produtos diferentes. A presença de agregados supramoleculares, devido aos diversos microambientes existentes, podem influenciar diferentemente cada caminho da reação, resultando numa alteração na proporção dos produtos.

A hidrólise alcalina do íon $\mathbf{N}$-alquil-4-cianopiridínio produz, em pH 10, proporções semelhantes de piridona e carboxiamida (Kosower 
e Patton, 1966). Com a incorporação do ion $\mathbf{N}$-dodecil-4cianopiridínio em micelas de CTAB, a hidrólise alcalina produz quase exclusivamente a piridona correspondente (Politi et al, 1978).

Um efeito notável de micelas nos produtos da dediazonização foi obtido por Moss et al, 1982. Em solução aquosa, a dediazonização do brometo de (p-diazôniobenzil)dimetil-nhexadecilamônio em presença de micelas de CTAB e brometo em concentração $0,005 \mathrm{M}$ a $0,05 \mathrm{M}$ produziu acima de $95 \%$ do brometo de arila correspondente, enquanto que a dediazonização do brometo de (p-diazôniobenzil)trimetilamônio em solução aquosa, com as mesmas concentrações de brometo, resultou em mais de $95 \%$ do fenol correspondente.

A estereoquímica tem um papel fundamental no reconhecimento molecular, síntese de produtos naturais e processos bioquímicos. Muitas das reações catalisadas por enzimas são estereoespecíficas. Micelas e vesículas podem apresentar também certo grau de estereoseletividade, porém, em grau muitíssimo menor ao apresentado por enzimas.

A cloração ou bromação de fenil éteres ( Fenil-O-R, $\mathrm{R}=\mathrm{C}_{5} \mathrm{H}_{11}$, $\mathrm{C}_{9} \mathrm{H}_{19}, \mathrm{C}_{12} \mathrm{H}_{25}$ ) produz fenil éteres orto ou para-monossubstituídos (Jaeger et al, 1990). A relação para/orto obtida na monocloração do Fenil-O- $\mathrm{C}_{5} \mathrm{H}_{11}$ é 1,3 em água, 4,6 em micelas de dodecilsulfonato de sódio (SDS) e 4,0 em vesículas de 3-( (2,2-heptadecil-1,3-dioxalan-4il)metoxi-1-propano sulfonato de sódio (DHPS) e DPPC. Com um fenil éter mais hidrofóbico (fenil-O- $\mathrm{C}_{12} \mathrm{H}_{25}$ ) a relação para/orto é 7,0 em micelas de SDS, 6 em vesículas de DHPS e 9,0 em vesículas de 
DPPC. As diferenças nas relações para/orto podem ser atribuídas diferenças nos sítios de solubilização ou diferenças estruturais da interface no sítio reativo.

\subsection{Análise Quantitativa de Reações em Micelas e Vesículas}

Para se entender os mecanismos pelos quais as micelas e vesículas catalisam reações é necessário que os dados cinéticos sejam analisados através de um modelo que permita obter estimativas das velocidades de reação no agregado e na fase aquosa.

Os dados cinéticos deste trabalho serão analisados a partir da teoria de troca iônica de Quina e Chaimovich (1979), resumida a seguir.

Este modelo, baseado na consideração de que o conjunto das micelas pode ser tratado como uma pseudofase e na troca iônica, permite analisar adequadamente os efeitos interfaciais sobre a velocidade de reações em presença de micelas ou vesículas. Além disso, permite a análise de uma série de condições experimentais, tais como adição de sais, tampão e o efeito da concentração de detergente sobre a velocidade de reações.

Neste modelo são consideradas as seguintes suposições:

1) Para um detergente específico o grau de dissociação do agregado é essencialmente independente da natureza e concentração das espécies iônicas adicionadas (Romsted, 1975). 
2) As interações íon-íon e íon-"cabeça polar" da superfície do agregado não são cooperativas. Isto significa que a velocidade de troca iônica dependerá somente do número de íons em um agregado e da concentração de íons livres em solução (Chaimovich, 1979).

3) As velocidades de troca entre íons são rápidas quando comparadas com as escalas de tempo em que se processa a reação em estudo (Grunhagen, 1975).

4) $\mathrm{Na}$ presença de tampão, a concentração de hidróxido na fase aquosa é constante (Quina et al, 1980).

5) Tanto o hidróxido como as formas aniônicas do tampão e do nucleófilo trocam com o contra-íon do agregado positivo.

6) A ligação de um substrato neutro ao agregado pode ser caracterizada através de uma constante de ligação (Berezin et al, 1973).

7) A atividade das várias espécies presentes em solução é tratada em termos das suas concentrações analíticas (moles/litro de solução).

Com estas considerações, a troca de íons entre as fases aquosa e do agregado pode ser representada por:

$$
X_{f}+Y_{b} \stackrel{K_{x / y}}{\leftrightarrow} X_{b}+Y_{f}
$$

E caracterizada por:

$$
K_{x / y}=\frac{X_{b} \cdot Y_{f}}{X_{f} \cdot Y_{b}}
$$


Onde $K_{x / y}$ corresponde ao coeficiente de seletividade ou constante de troca entre os íons ligados e livres da solução, Y é a concentração de contra-íon do agregado, $X$ é a concentração de íon adicionado ao sistema, b e $f$ se referem aos íons ligados e livres, respectivamente.

Para um sistema formado por uma solução micelar que contém concentrações analíticas de detergente DY e de contra-íons reativos BX, com ou sem sal comum adicionado, na ausência de tampão, as seguintes equações são utilizadas:

$$
C_{t}=D Y=C_{d}+C M C
$$

Onde $C_{t}$ é a concentração total de detergente, $C_{d}$ é a concentração analítica de detergente que forma o agregado e CMC é a concentração micelar crítica do detergente.

$$
Y_{t}=D Y+B Y=Y_{b}+Y_{f}
$$

Onde $Y_{t}$ é a concentração total do contra-íon, que é igual soma de todos os contra-íons livres e ligados e BY é a concentração de sal comum adicionado ao sistema.

As concentrações de contra-íons livres e ligados são dadas pela equações 5 e 6 , respectivamente.

$$
Y_{f}=\alpha C_{d}+C M C+B Y+X_{b}
$$




$$
Y_{b}=(1-\alpha) C_{d}-X_{b}
$$

Onde $\alpha$ é o grau de dissociação iônica da micela.

Analogamente à equação (4) temos para a concentração total de íons reativos:

$$
X_{t}=B X=X_{f}+X_{b}
$$

Substituindo as equações 5, 6 e 7 na equação 2, obtém-se:

$$
K_{x / y}=\frac{X_{b}\left(\alpha C_{d}+C M C+X_{b}+B Y\right)}{\left(X_{t}-X_{b}\right)\left[(1-\alpha) C_{d}-X_{b}\right]}
$$

Rearranjando a equação 8 pode-se calcular $X_{b}$ quando se conhece $K_{x / y}$ :

$$
X_{b}=\frac{-\left(A_{1}+B Y\right)+\left[\left(A_{1}+B Y\right)^{2}+4\left(1-K_{x / y}\right) X_{t} K_{x / y}(1-\alpha) C_{d}\right]^{1 / 2}}{\left(1-K_{x / y}\right)}
$$

$$
\text { Onde } A_{1}=\alpha C_{d}+C M C+K_{x / y} \cdot X_{t}+(1-\alpha) C_{d} \cdot K_{x / y}
$$


Conhecendo-se os valores de $X_{t}, K_{x / y}, \alpha e$, no caso de micelas, também a CMC, pode-se estudar o comportamento de $X_{b}, X_{f}$ e $X_{b} / C_{d}$ (Chaimovich, 1979)

Se o sal adicionado for diferente, do tipo BZ, as equações 5 e 6 se transformam em:

$$
\begin{aligned}
& Y_{t}=\alpha C_{d}+C M C+X_{b}+Z_{b} \\
& Y_{b}=(1-\alpha) C_{d}-X_{b}-Z_{b}
\end{aligned}
$$

Para as ligações competitivas de mais de duas espécies iônicas $X, Y$ e $Z^{-}$na fase micelar ou vesicular, existem as constantes relativas às trocas $K_{x / y}, K_{x / z}$ e $K_{y / z}$. Pode-se calcular $X_{b}$ dispondo-se de $\alpha, \mathrm{CMC}, \mathrm{Z}_{\mathrm{t}}$ e qualquer duas das três constantes de troca $\mathrm{K}_{\mathrm{x} / \mathrm{y}}, \mathrm{K}_{\mathrm{x} / \mathrm{z}}$, $\mathrm{K}_{\mathrm{x} / \mathrm{z}}$ através da equação:

$$
K_{x / z}=\frac{X_{b} \cdot Z_{f}}{X_{f} \cdot Z_{b}}
$$

Substituindo $Z_{f}=Z_{t}-Z_{b}$ e $X_{f}=X_{t}-X_{b}$ e rearranjando, tem-se:

$$
Z_{b}=\frac{X_{b} \cdot Z_{t}}{K_{x / z} \cdot Z_{t}+X_{b}\left(1-K_{x / z}\right)}
$$


Deste modo, consegue-se exprimir $Z_{b}$ em função de $Z_{t}$ (conhecido) e $X_{b}$. Substituindo a equação 14 nas equações 11 e 12 e estas na equação 2 e rearranjando é obtida a equação:

$$
\begin{aligned}
& X_{b}^{3}\left(1-K_{x / z}\right)\left(1-K_{x / y}\right)+X_{b}^{2}\left[A_{1}\left(1-K_{x / z}\right)+\left(1-K_{x / z}\right)\left(X_{t} \cdot K_{x / z}+Z_{t}\right)\right]+ \\
& X_{b} X_{t}\left[K_{x / y}\left(Z_{t}-(1-\alpha) C_{d}\left(1-K_{x / z}\right)\right)+K_{x / z} A_{1}\right]-K_{x / y}(1-\alpha) C_{d} K_{x / z} X_{t}^{2}=0
\end{aligned}
$$

Onde $A_{1}$ é dado pela equação 10 . A resolução desta equação, onde aparecem as constantes de troca $K_{x / z}$ e $K_{x / y}$, fornece valores de $X_{b}$ para cada concentração de detergente presente no sistema.

O modelo acima descrito é valido para vesículas ressalvando-se que, no caso de vesículas impermeáveis a um dos reagentes, $C_{d}=$ $C_{t} / 2$ e, no caso de vesículas permeáveis, $C_{d}=C_{t}$. No caso de vesículas o termo BY é a concentração analítica de sal quando as vesículas são previamente preparadas nestas condições. $\mathrm{O}$ sal adicionado após o preparo de vesículas não terá acesso ao compartimento aquoso interno devido à baixa permeabilidade pelas vesículas de DODAC ao sal.

Neste trabalho serão analisadas quantitativamente dois tipos de reações: (A) reação unimolecular de um substrato de carga oposta à micela/vesícula em presença de tampão, $(B)$ reação bimolecular entre um substrato de carga negativa e um nucleófilo negativo (hidróxido) 
em meio tamponado. Por isso descrevemos abaixo os tratamentos matemáticos que serão utilizados nestes dois sistemas de reações.

A) Reação unimolecular de um substrato de carga oposta à micela/vesícula em presença de tampão.

A velocidade $(V)$ de uma reação unimolecular em presença de micelas/vesículas é descrita por:

$$
V=k_{\psi} \cdot X_{t}=k_{m} \cdot X_{b}+k_{w} \cdot X_{f}
$$

Onde as $k$ 's são constantes de velocidade, $X$ a concentração do substrato e os índices subscritos $\mathrm{m}, \mathrm{w}, \mathrm{f}$ e $\mathrm{b}$ indicam as fases micelar, aquosa, concentração total, livre e ligada, respectivamente. A constante de velocidade observada é:

$$
k_{\psi}=k_{m} \cdot \frac{X_{b}}{X_{t}}+k_{w} \cdot \frac{X_{f}}{X_{t}}
$$

Considerando que $X_{t}=X_{t}+X_{b}$ e substituindo a equação 2 na equação 17 temos:

$$
k_{\psi}=\frac{k_{w}+k_{m} \cdot K_{x / y} \cdot Y_{b} / Y_{f}}{1+K_{x / y} \cdot Y_{b} / Y_{f}}
$$

Onde: 


$$
\begin{aligned}
& Y_{b}=(1-\alpha) C_{d}-X_{b}-O H_{b}-Z_{b} \\
& Y_{f}=\alpha C_{d}+C M C+X_{b}+O H_{b}+Z_{b}
\end{aligned}
$$

e $Z_{b}$ é a concentração de sal devido à adição do tampão.

A equação 18 prevê que se $k_{m}=k_{w}$, a presença de detergente não interfere na reação. Se $k_{m}$ for menor que $k_{w}$ a reação será inibida e se $k_{m}$ maior que $k_{w}$ será catalisada.

Para altas concentrações de detergente, tem-se:

$$
\lim _{C_{d} \rightarrow \infty} K_{x / y} \cdot Y_{b} / Y_{f}=\frac{K_{x / y} \cdot(1-\alpha)}{\alpha}
$$

Isto implica que, independemente da relação $k_{m} / k_{w}, k_{\Psi}$ atingirá um valor constante com a concentração de detergente.

B) Reação bimolecular entre um substrato iônico e um íon reativo (hidróxido) de carga oposta à micela/vesícula em presença de tampão ou alta concentração de hidróxido.

Ambos as reagentes podem se ligar às micelas/vesículas de carga oposta. Suas ligações à interface são descritas pelas seguintes constantes de troca iônica: 


$$
K_{x / y}=\frac{X_{b} \cdot Y_{f}}{X_{f} \cdot Y_{b}}
$$

onde:

$$
\begin{aligned}
& X_{t}=X_{f}+X_{b} \\
& K_{O H / Y}=\frac{O H_{b} \cdot Y_{f}}{O H_{f} \cdot Y_{b}}
\end{aligned}
$$

Com $\mathrm{OH}_{t}=\mathrm{OH}_{f}+\mathrm{OH}_{b}$

Em condições de pseudo-primeira ordem, a equação de velocidade é:

$$
=k_{\psi} \cdot X_{t}=k_{2 w} \cdot O H_{f} \cdot X_{f}+k_{2 m} \cdot O H_{b} \cdot X_{b}
$$

Onde $k_{2 w}$ e $k_{2 m}$ são as constantes de velocidade de segunda ordem nas fases aquosa e micelar, respectivamente. $\mathrm{OH}_{b}$ é a concentração local de hidróxido, que se relaciona com a concentração analítica pela expressão:

$$
O H_{b}=\frac{O H}{C_{d} \cdot V}
$$

Onde Vé o volume efetivo por mol de detergente micelizado.

Rearranjando-se as equações 22 a 25 e substituindo na equação 26, obtém-se a equação: 


$$
k_{\psi}=O H_{f} \cdot \frac{k_{2 w}+\frac{k_{2 m}}{C_{d} \cdot V} \cdot K_{O H / y} \cdot K_{x / y} \cdot\left(\frac{Y_{b}}{Y_{f}}\right)^{2}}{1+K_{x / y} \cdot\left(\frac{Y_{b}}{Y_{f}}\right)}
$$

Esta equação foi obtida supondo-se um meio tamponado, de modo que o termo $\mathrm{OH}_{\mathrm{f}}$ colocado em evidência é constante. Para condições experimentais na ausência de tampão, mas em condições de pseudo-primeira ordem, $\mathrm{OH}_{\mathrm{t}}$ é considerado constante, sendo então este termo colocado em evidência, resultando na equação:

$$
k_{\psi}=O H_{t} \cdot \frac{k_{2 w} \cdot\left(\frac{Y_{f}}{Y_{b}}\right)^{2}+\frac{k_{2 m}}{V} \cdot K_{O H / y} \cdot K_{x / y} \cdot\left(\frac{1}{C_{d}}\right)}{\left[1+\left(\frac{Y_{f}}{Y_{b}}\right) \cdot\left(\frac{1}{K_{O H / y}}\right)\right]\left[1+\left(\frac{Y_{f}}{Y_{b}}\right) \cdot\left(\frac{1}{K_{x / y}}\right)\right] \cdot K_{x / y} \cdot \dot{K}_{O H / y}}
$$

Este tratamento matemático desenvolvido para analisar reações em fase micelar pode ser utilizado para vesículas com as ressalvas já feitas quanto à permeabilidade da bicamada aos íons.

A grande dificuldade na utilização deste tratamento matemático reside na falta de parâmetros físicos que são fundamentais para 0 tratamento dos dados, tais como $K_{\text {troca }}$ para os íons em questão, grau de dissociação iônica interno $\left(\alpha_{i}\right)$ e grau de dissociação iônica externo $\left(\alpha_{\mathrm{e}}\right)$ de vesículas. 


\subsection{Objetivos}

Este trabalho teve como objetivo:

1) testar um novo método na determinação do grau de dissociação iônica de micelas de CTACI e CTAB e das superfícies interna e externa de vesículas de DODAC e DODAB através da reação de decomposição do TMD.

2) Estudar a catálise das reações de descarboxilação do 6nitrobenzisoxazol -3-carboxilato (NBOC) e a hidrólise alcalina de 5,5'-ditiobis(2-nitrobenzoato) (DTNB) por micelas e pela superfície externa e interna de vesículas, a fim de caracterizar e comparar os fatores responsáveis pela catálise em cada sistema e analisar os resultados, de acordo com o modelo de troca iônica.

\subsection{Reações Estudadas}

\subsubsection{Hidrólise alcalina do DTNB}

A reação de hidrólise alcalina do DTNB (figura 7) foi escolhida por ter sido estudada em vários sistemas micelares e vesiculares (Fendler e Hinze, 1981; Moss e Shreck, 1985; Moss et al, 1988; Cuccovia et al, 1989).

O mecanismo de hidrólise geralmente aceito pode ser representado pelo ataque inicial do íon hidróxido no enxofre para dar um ânion tiolato e um ácido sulfênico (equação 1) 
lento

$\mathrm{RSSR}+\mathrm{OH}^{-}$

que rapidamente desproporciona em outro ânion tiolato e um sulfinato (equação 2):

rápido

$2 \mathrm{RSOH}-\left(---\mathrm{RS}^{-}+\mathrm{RSO}_{2}^{-}+2 \mathrm{H}^{+}\right.$

A estequiometria da reação total é mostrada na equação 3.

$$
2 \mathrm{RSSR}+4 \mathrm{OH}^{-}--->3 \mathrm{RS}^{-}+\mathrm{RSO}_{2}^{-}+2 \mathrm{H}_{2} \mathrm{O}
$$

Fendler e Hinze (1981) estudaram o efeito de micelas de CTAB e vesículas de DODAC na hidrólise alcalina do DTNB. Vesículas sonicadas de DODAC apresentaram um fator de catálise de 1500 , cerca de 100 vezes mais eficientes do que micelas de CTAB. Esta reação foi quantitativamente analisada, tendo-se atribuido a catálise exclusivamente concentração dos reagentes na superfície vesicular.

\subsubsection{Descarboxilação do íon 6-nitrobenzisoxazol-3-} carboxilato

O efeito de modificações na estrutura de interfaces sobre a reatividade química pode ser estudado através da análise do 


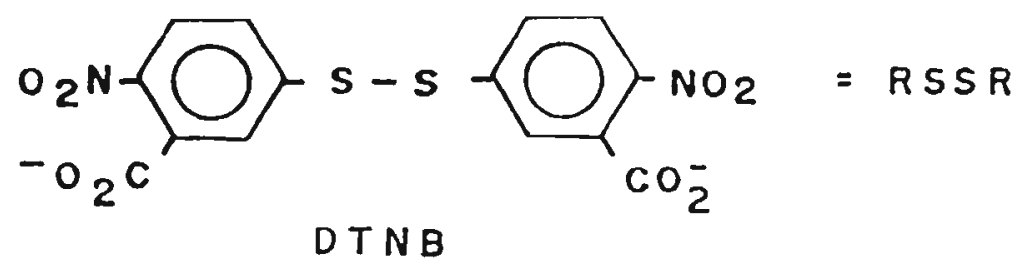

$\mathrm{RSSR}^{-} \mathrm{OH} \longrightarrow \mathrm{RS}^{-}+\mathrm{RSOH}$

$\mathrm{RSOH} \longrightarrow \mathrm{I} 2 \mathrm{RS}^{-}+1 / 2 \mathrm{RSO}_{2}^{-}+\mathrm{H}^{+}$

$\mathrm{RSSR}^{+} \mathrm{2}^{-\mathrm{OH}} \longrightarrow 3 / 2 \mathrm{RS}^{-}+1 / 2 \mathrm{RSO}_{2}^{-}+\mathrm{H}_{2} \mathrm{O}$

Figura 7: Mecanismo da hidrólise alcalina do DTNB. 
efeito do agregado na velocidade de decomposição espontânea do NBOC (figura 8). A velocidade de reação de descarboxilação do NBOC depende criticamente da estabilidade relativa do ânion carboxilato no estado inicial, que contém uma carga mais localizada quando comparado com o estado de transição. Esta é uma reação especialmente útil, pois a velocidade varia por mais de 106 vezes em diferentes solventes (Kemp et al, 1975). Esta reação também depende da capacidade do solvente em fazer pontes de hidrogênio.

A catálise por micelas da decomposição do NBOC é atribuída tanto a um decréscimo na polaridade local no sítio de reação como na relativa estabilização do estado de transição, com carga deslocalizada. A decomposição do NBOC em vesículas sonicadas de brometo de didodecildimetilamônio, brometo de ditetradecildimetilamônio, brometo de dihexadecildimetilamônio e brometo de dioctadecildimetilamônio e agregados de trioctilmetilamônio (TMAC) e micelas de CTAB foram comparadas por Kunitake et al (1980). A catálise obtida variou de 50 a 1300 vezes, em relação velocidade de reação em água. $\mathrm{O}$ efeito catalítico aumenta na ordem micelas<vesículas<agregado de TMAC. Os dados não foram analisados quantitativamente, portanto, efeitos catalítico não foram separados de possíveis diferenças em constantes de troca iônica do NBOC entre a fase aquosa e os agregados. 


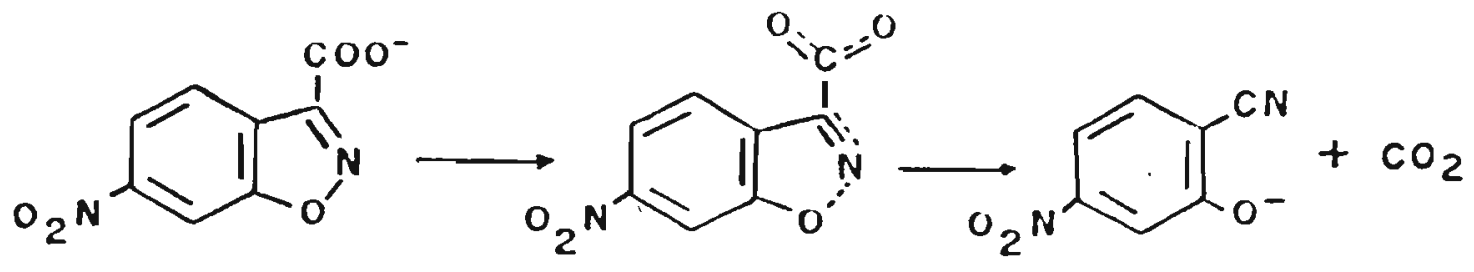

Figura 8: Decomposição do NBOC. 


\subsubsection{Decomposição do íon 2,4,6-Trimetilbenzenodiazônio}

A decomposição de íons arildiazônio tem sido utilizada como método analítico para estimar a concentração e composição de nucleófilos fracos na região interfacial de agregados de anfifílicos sintéticos como micelas (Loughlin e Romsted, 1990) e microemulsões ( Chaudhuri e Romsted, 1991, Chaudhuri et al, 1993).

Sais de arildiazônio sofrem decomposição térmica em solução aquosa ácida via formação de aril cátions intermediários (etapa determinante) seguido de reação controlada pela difusão com todos os nucleófilos disponíveis ( figura 9).

Assumindo-se que a seletividade da reação de diazonização é igual tanto em agregados de surfactantes como em solução aquosa, a distribuição de produtos de uma reação de um sal de diazônio ligado a um agregado (o qual deve estar com a cabeça polar voltada para a interface agregado-água) é proporcional quantidade de contraíons e água na superfície do agregado.

Loughlin e Romsted (1990) estudaram a decomposição do tetrafluorborato de 3-hexadeciloxicarbonilbenzenodiazôno (HBD) em presença de micelas de CTAX em 0,1M a 0,2M de HX com $\mathrm{NaX}\left(\mathrm{X}=\mathrm{Cl}^{-}\right.$ou $\left.\mathrm{Br}^{-}\right)$. Estes autores assumiram que os rendimentos dos produtos para a reação do HBD, (fenol ou o halobenzeno correspondente) na interface micelar são iguais aos rendimentos dos produtos para a dediazonização do 3- 


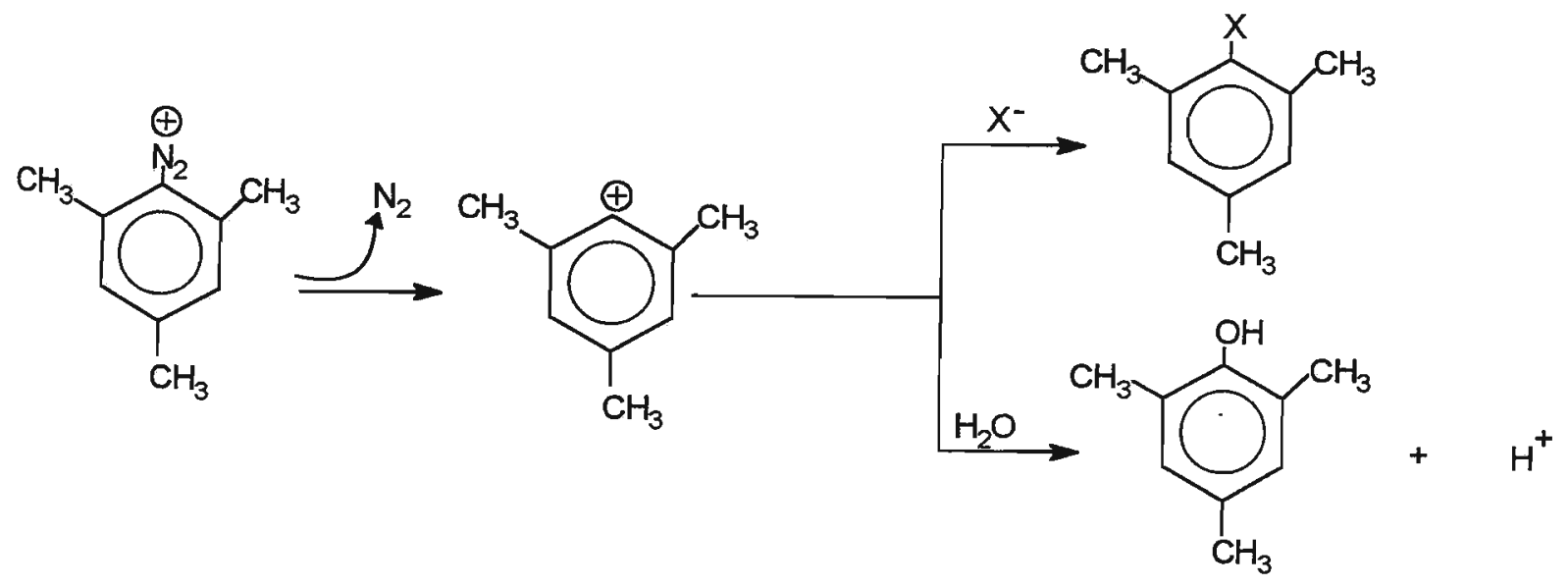

Figura 9: Reação de decomposição do TMD, utilizada como sonda para a determinação da concentração aquosa de haletos. TMD após perda de nitrogênio reage com água e haletos, dando fenol e halobenzeno, respectivamente. 
metiloxicarbonilbenzenodiazônio (MBD) em solução ácida aquosa em presença de NaX. A partir da curva de calibração com o rendimento do fenol e halobenzeno obtidos da reação do MBD em várias concentrações de sal, e dos rendimentos da dediazonização obtidos com o HDB em presença de micelas, estimaram a concentração interfacial de haleto e água.

A concentração interfacial de $\mathrm{Br}^{-}$variou de $3,3 \mathrm{M} \mathrm{em}$ presença de $0,12 \mathrm{M}$ de $\mathrm{NaBr}$ a $5,7 \mathrm{M}$, em presença de $\mathrm{NaBr}$ 3.12M. A concentração interfacial de $\mathrm{Cl}^{-}$variou de 2,6 M para $\mathrm{NaCl}$ 0,12 M a 6,0 M, para $\mathrm{NaCl} 4,12 \mathrm{M}$.

Loughlin e Romsted calcularam também a constante de troca $\mathrm{Br}^{-} / \mathrm{Cl}^{-}$na interface micelar através da relação dos produtos obtidos em 0,01M CTAX e HX 0,2M, contendo uma concentração total de haleto crescente, mas com uma proporção $\mathrm{Br}_{\text {total }} / \mathrm{Cl}_{\text {total }}$ igual a 1. Variando a concentração total de haleto de 0,21 até 3,21 obtiveram uma variação de $\mathrm{K}_{\mathrm{C} / \mathrm{Br}}$ de 2,55 a 3,06, dentro do erro experimental. 


\section{CAPÍTULO 2}

\subsection{Materiais}

Os compostos 2,4,6-trimetilclorobenzeno ( $\mathrm{TMCl}$ ), 2,4,6trimetilbromobenzeno (TMBr), 2,4,6-trimetilfenol (TMF), utilizados como padrão na cromatografia e o 6-nitrobenzisoxazol-3carboxilato (NBOC) foram gentilmente cedidos pelos professores. L.S.Romsted e C.A.Bunton.

O ácido 5,5'-ditiobisnitrobenzóico (DTNB), da Aldrich, foi utilizado sem purificação.

O cloreto de dioctadecildimetilamônio foi adquirido da Herga Indústrias Química e purificado como descrito em Cuccovia et al (1982). Para as determinaçōes de $\alpha$ interno e externo o DODAC foi preparado através de DODAB (KODAK), cujo brometo foi trocado por cloreto através de resina de troca iônica Dowex 21K.

Para eluição cromatográfica foi utilizado metanol padrão cromatográfico (Merck) e água MilliQ.

Brometo de dioctadecildimetilamônio (DODAB) e cloreto (brometo) de trimetilhexadecilamônio CTACI (Kodak) e CTAB (Merk) foram usados após recristalização em acetona/metanol 10/90 (v/v). 
Os demais reagentes empregados, de uso comum no laboratório eram de grau P.A. Para a preparação de soluçōes foi utilizada água bidestilada.

Os solventes orgânicos utilizados foram previamente secos e destilados.

\subsection{Aparelhagem}

\subsubsection{Análise cromatográfica por HPLC}

Utilizou-se um cromatógrafo Waters composto por bomba Waters 501, detector UV Waters 484, integrador Waters 746 e coluna de aço Microsorb-MV C18, 5micra, $100 \AA, 4,6$ × 250,0mm.

As amostras foram injetadas em loop fixo de $20 \mathrm{uL}$ ou $100 \mathrm{uL}$. A detecção foi feita a $225 \mathrm{~nm}$, fase móvel metanol $82 \%$ /água $18 \%$ (v/v). As curvas padrōes para os compostos TMF, $\mathrm{TMCl}$ e $\mathrm{TMBr}$ são apresentadas, respectivamente nas figuras 10,11 e 12 . Os tempos de retenção obtidos foram 4,28; 16,3 e 18,6 minutos, respectivamente, para $\mathrm{TMF}, \mathrm{TMCl}$ e $\mathrm{TMBr}$. Os coeficientes angulares obtidos foram, respectivamente, $1,63 \times 10^{10}, 2,05 \times 10^{10} \mathrm{e}$ $2,35 \times 10^{10}$ área/M. 


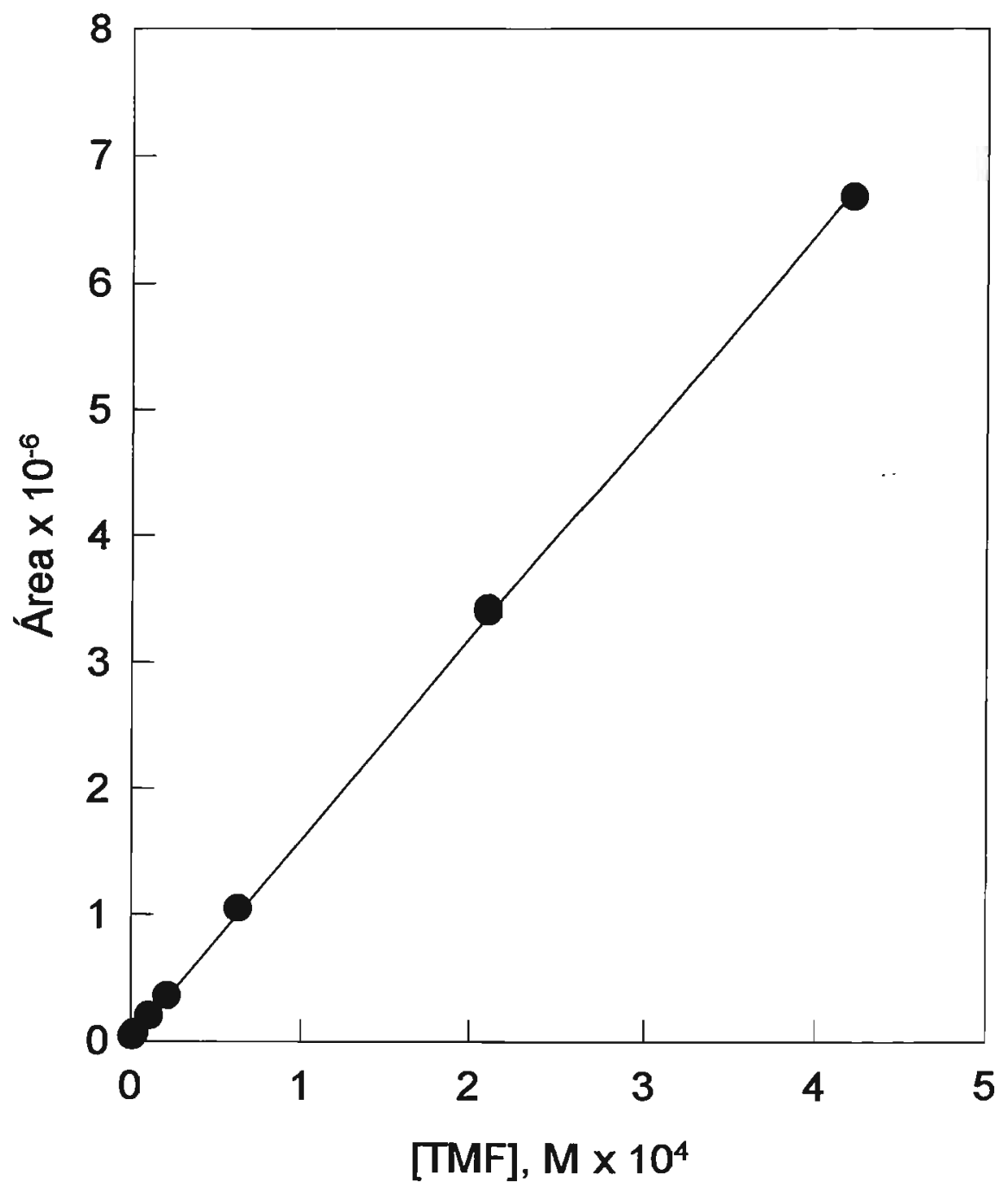

Figura 10: Curva de calibração para o TMF. 


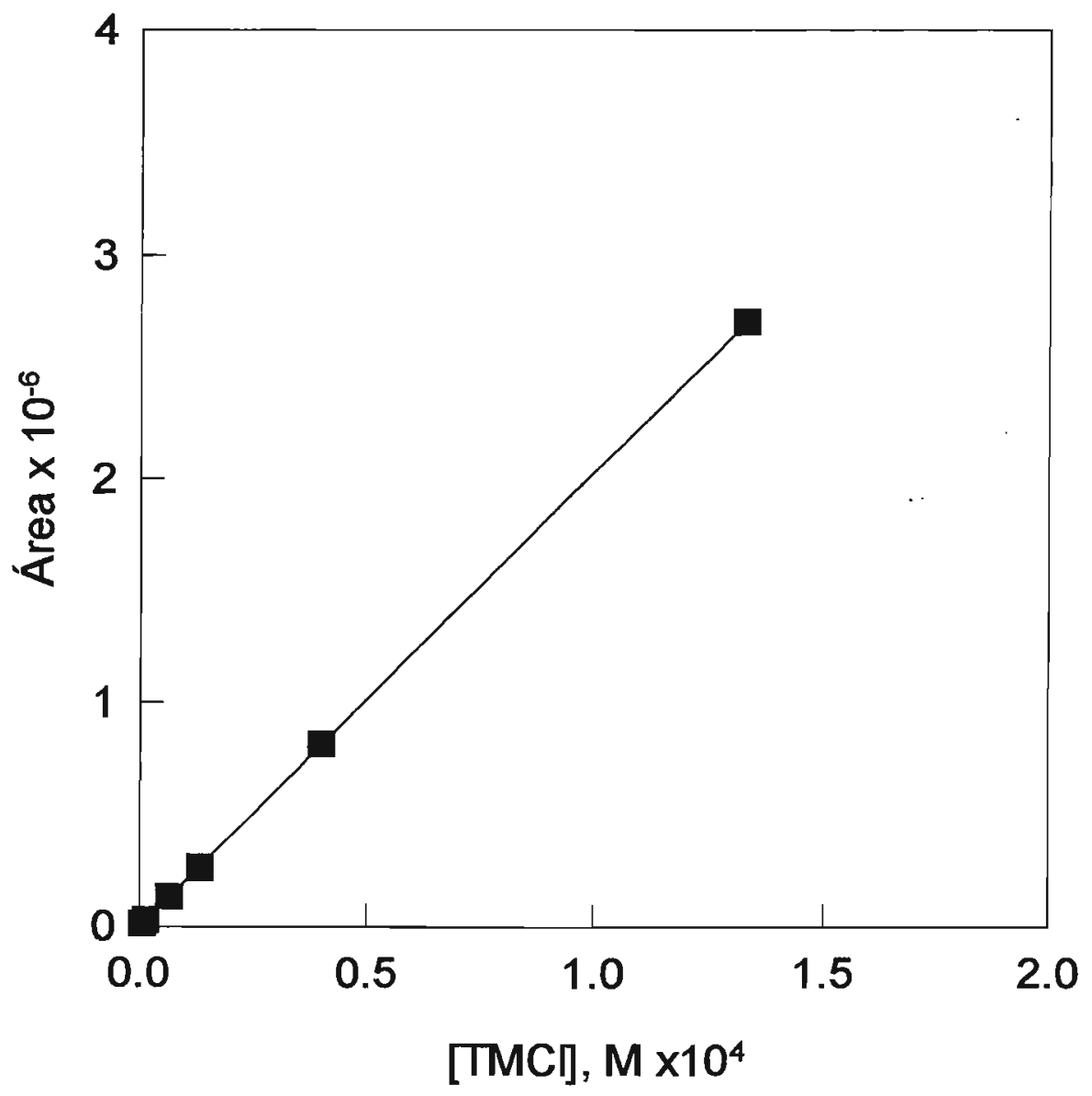

Figura 11:. Curva de calibração para o TMCl 


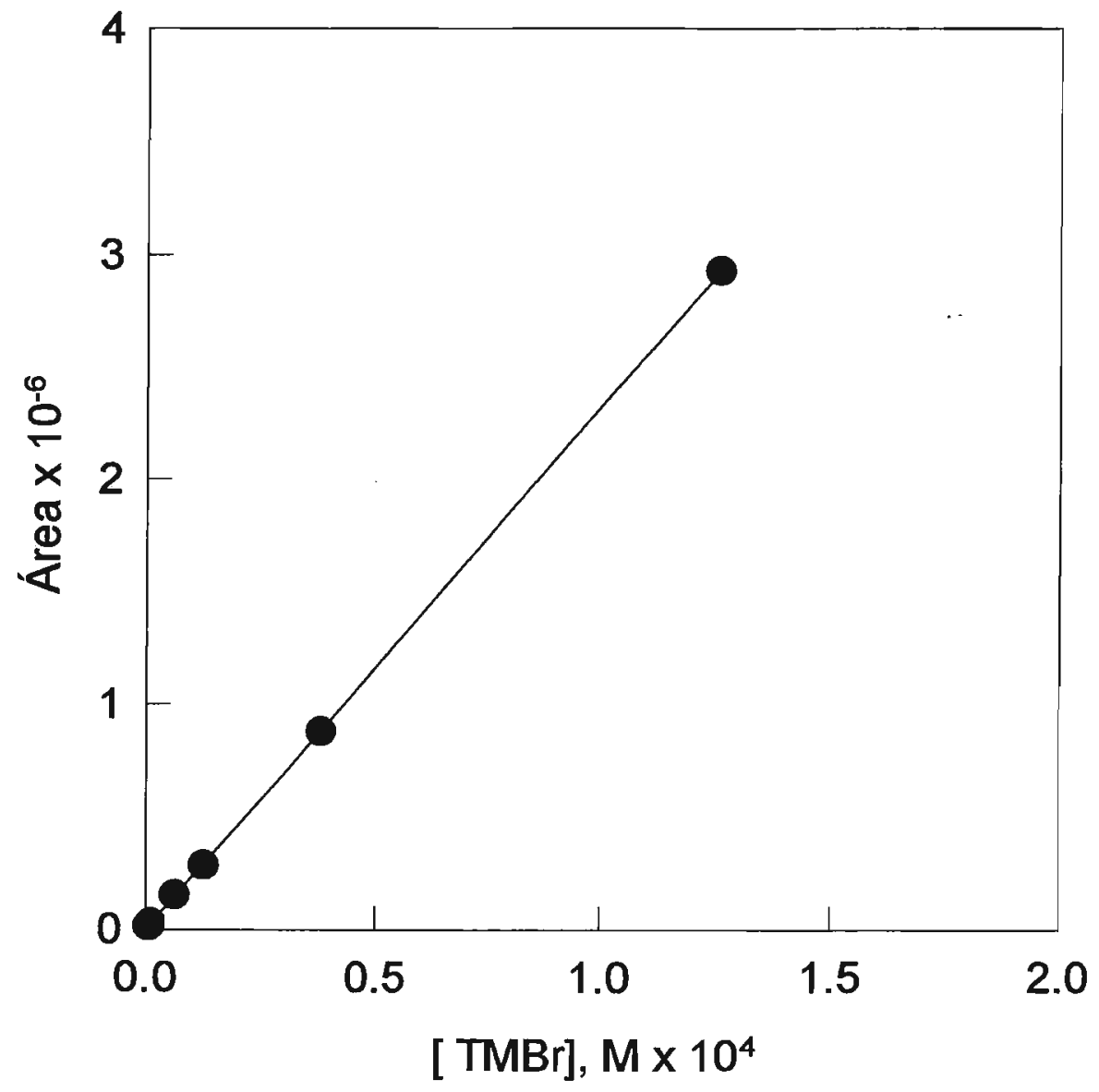

Figura 12: Curva de calibração para o TMBr. 


\subsubsection{Cinéticas}

As cinéticas foram monitoradas no espectrofotômetro Beckman DU-7, termostatizado em $30^{\circ} \mathrm{C}$. As medidas de $\mathrm{pH}$ foram feitas com pHmetro Incibrás.

\subsection{Métodos}

2.3.1 Síntese do tetrafluorborato de 2,4,6trimetilbenzenodiazônio (TMDBF 4 )

O $\mathrm{TMDBF}_{4}$ foi sintetizado conforme descrito por Vogel (1971), purificado através da dissolução num volume mínimo de acetonitrila, filtração e precipitação através da adição de éter etílico. O composto obtido fundiu a $78-80{ }^{\circ} \mathrm{C}$ (literatura: $88-89{ }^{\circ} \mathrm{C}$ ). A análise elementar resultou em.C $=46,08 \%, H=4,46 \%$ e $\mathrm{N}=12,31 \%$ (calculado $\mathrm{C}=46,19 \%, \mathrm{H}=4,70 \%$ e $\mathrm{N}=11,98 \%$ ). $\mathrm{A}$ reação do composto em água $\left(1 \times 10^{-4} \mathrm{M}\right)$ produziu 2,4.6trimetilfenol com $100 \%$ de rendimento.

2.3.2 Preparação do cloreto de 2,4,6-trimetilbenzenodiazônio (TMDCI)

O TMDCl foi obtido através da passagem do $\mathrm{TMDBF}_{4}$ através de uma coluna de troca iônica. Mediu-se a concentração 
de sal de diazônio através de seu $\varepsilon$ a $288 \mathrm{~nm}\left(\varepsilon=14200 \mathrm{M}^{-1} \mathrm{~cm}^{-1}\right)$. A concentração de cloreto foi determinada através de titulação pelo método de Schales e Schales (1941) e coincide com a calculada através da absorção.

2.3.3. Determinação da concentração de CTACI, CTAB, DODAC e DODAB

A determinação da concentração foi feita através da titulação do haleto utilizando-se o método de Schales e Schales (1941).

\subsubsection{Preparação de vesículas}

\subsubsection{Vesículas sonicadas}

Preparou-se vesículas através de sonicação por $30 \mathrm{~min}$ de solução 0,01M de DODAC em tampão. Utilizou-se sonicador de banho Branson com água em ebulição, esfriando durante a sonicação. A temperatura do banho após 30 minutos de sonicação era $50^{\circ} \mathrm{C}$.

Vesículas sonicadas em sonicador com tip foram preparadas através do aquecimento de uma suspensão de DODAC (10mM) por 10 minutos em banho a $60^{\circ} \mathrm{C}$. Esta solução foi submetida previamente a agitação intensa através de um 
vortex e depois sonicada por 15 minutos a $60{ }^{\circ} \mathrm{C}$ com sonicador Branson (tip de titânio) a 100 Watts. As partículas de titânio foram retiradas por centrifugação a 12000 G em centrífuga Sorvall RC2-B por 30 minutos.

\subsubsection{Vesículas injetadas}

Foram preparadas através de injeção de solução clorofórmica de DODAC $0,02 \mathrm{M}$ em tampão a $70{ }^{\circ} \mathrm{C}$ com borbulhamento de $\mathbf{N}_{2}$ (Carmona-Ribeiro et al, 1983). Após a preparação, as vesículas foram deixadas em annealing (Elamiani e Blume, 1983) por $1 \mathrm{~h}$ a $60 \circ \mathrm{C}$.

Para experimentos onde o sal de diazônio foi incorporado durante a preparação, injetou-se $1 \mathrm{~mL}$ de DODAC $0,04 \mathrm{M}$ dissolvido em diclorometano em $4 \mathrm{~mL}$ de solução de TMDCI $5 \mathrm{mM}$ e $\mathrm{HCl} 2 \times 10^{-4} \mathrm{M}$ a $42{ }^{\circ} \mathrm{C}$ com borbulhamento de $\mathrm{N}_{2}$. A duração da injeção foi de aproximadamente 5 minutos. Após a injeção e resfriamento, a preparação foi mantida a $4{ }^{\circ} \mathrm{C}$ até sua utilização. A quantidade de $\mathrm{TMDCl}$ que reagiu foi calculada a partir da determinação de TMF por HPLC.

\subsubsection{Separação do TMDCI não incorporado}

A separação foi feita através da eluição da solução de vesículas através de uma coluna Sephadex G-25 temperatura ambiente, com solução de $\mathrm{NaCl} 5 \mathrm{mM}, \mathrm{HCl} 2 \times 10^{-4} \mathrm{M}$. A uma 
coluna de Sephadex de $27 \times 1 \mathrm{~cm}$ adicionaram-se $1,5 \mathrm{~mL}$ de vesículas contendo TMDCl. Foram recolhidas alíquotas de $1 \mathrm{~mL}$. O tempo necessário para a eluição das vesículas foi cerca de 10 minutos. À $0,5 \mathrm{~mL}$ de cada tubo contendo vesículas adicionou-se 50ul de ciclohexano.

Com o restante das amostras determinou-se a concentração de $\mathrm{TMDCl}$ incorporada, diluindo-se uma alíquota com metanol e lendo a absorbância a $288 \mathrm{~nm}$. A concentração de DODAC foi determinada através de método descrito em Stelmo et al (1987). A a hidrólise inicial do TMD foi determinada passando-se uma alíquota por HPLC e quantificação do TMF formado. A porcentagem de hidrólise inicial era cerca de $5 \%$.

\subsubsection{Reação do TMDCl em presença de $\mathrm{NaCl}$, vesículas ou micelas}

A reação do $\mathrm{TMDCl}$ foi feita em tubos de tampa esmerilhada utilizando-se sempre $1 \mathrm{~mL}$ deTMDCI $5 \times 10^{-4} \mathrm{M}$ em $\mathrm{HCl} 2 \times 10^{-4} \mathrm{M}$ (ou $\mathrm{HBr} 2 \times 10^{-4} \mathrm{M}$ ) e concentraçōes variáveis de sal ou detergente a $30^{\circ} \mathrm{C}$ durante $18 \mathrm{~h}$. Para evitar a perda do $\mathrm{TMCl}$ ou $\mathrm{TMBr}$ formado por evaporação, em cada tubo foi adicionado 50ul de ciclohexano.

Após a reação, adicionou-se $0,95 \mathrm{~mL}$ de $\mathrm{n}$-propanol e se injetou 20uL da solução no cromatógrafo. 


\subsubsection{Cinéticas}

\subsubsection{Hidrólise alcalina do DTNB}

Mediu-se a velocidade da reação de hidrólise alcalina do DTNB $3 \times 10^{-5} \mathrm{M}$ em soluções de vesículas de DODAC em tampão borato. A cinética foi monitorada em $415 \mathrm{~nm}$.

Quando se pretendia que o substrato penetrasse no compartimento aquoso interno de vesículas grandes, a cubeta era deixada durante $5 \mathrm{~min}$ num banho a $45^{\circ} \mathrm{C}$. Em seguida, adicionava-se o substrato, mantendo-se a cubeta no banho por mais $40 \mathrm{~s}$, tranferindo-se em seguida para o espectrofotômetro termostatizado a $30^{\circ} \mathrm{C}$. Experimentos de incorporação de DTNB em pH 6,0 mostraram que 50\% do DTNB era incorporado.

Para melhor caracterização da catálise pela superfície interna das vesículas, após a distribuição do substrato pelas duas superfícies e esfriamento a $30{ }^{\circ} \mathrm{C}(\sim 5 \mathrm{~min})$ foi adicionado $\mathrm{Na}_{2} \mathrm{SO}_{3}$ suficiente para destruir $100 \%$ do substrato (proporção 1/1). Através da variação instantânea da absorbância observada em $415 \mathrm{~nm}$, foi estimada a concentração de DTNB externo não hidrolizado durante a incorporação para cada concentração de DODAC a porcentagem de DTNB externo não hidrolizado variou de $30 \%$ a $40 \%$. Numa segunda série de experimentos foi adicionado $\mathrm{Na}_{2} \mathrm{SO}_{3}$ suficiente para destruir apenas o substrato externo. 


\subsubsection{Decomposição do NBOC}

As reações foram feitas em vesículas ou micelas preparadas em tampão borato $\mathrm{pH} 9,18 / 10 \mathrm{mM}$. Monitorou-se a reação em 415nm. As concentrações de NBOC utilizadas foram de $1 \times 10^{-5}$ a $1 \times 10^{-4} \mathrm{M}$. Para penetração do NBOC no compartimento aquoso interno das vesículas procedeu-se como na reação do DTNB.

\subsubsection{Tratamento de dados}

Calculou-se as constantes velocidade de primeira ordem através do programa Enzfitter.

Os ajustes de $k_{\Psi} \times C_{d}$ foram feitos através do programa Micell, que ajusta os dados às equações resultantes do modelo de troca iônica, conforme citado na introdução. 


\section{CAPÍTULO 3}

\section{RESULTADOS}

3.1.Determinação do grau de dissociação iônica em micelas e vesículas e da constante de troca $\mathrm{Br}^{\top} / \mathrm{Cl}^{-}$

\subsubsection{Micelas}

A partir da curvas padrões obtidas do cromatógrafo foram determinadas as concentrações de $\mathrm{TMBr}$ formado na reação de decomposição do TMD em presença de $\mathrm{NaBr}$ em $\mathrm{HBr} 2 \times 10^{-4} \mathrm{M}$. Calculou-se a porcentagem de $\mathrm{TMBr}$ formado a partir da equação:

$\% \mathrm{TMBr}=[\mathrm{TMBr}] \times 100 /[\mathrm{MMD}]$

Onde [TMBr] e [TMD] são as concentrações de $\mathrm{TMBr}$ determinadas cromatograficamente e a concentração inicial de sal de diazônio no meio reacional, respectivamente.

A \% $T M B r$ formada na reação de decomposição de TMD depende da concentração de $\mathrm{NaBr}$ presente no meio. Na faixa de 0 a $100 \mathrm{mM}$ de $\mathrm{NaBr}$ a porcentagem de $\mathrm{TMBr}$ formado (figura 13) é linear, com um coeficiente angular $\mathrm{R}_{\mathrm{Br}}=45 \% \mathrm{M}^{-1}$. Em maiores concentrações de $\mathrm{NaBr}$ ocorre uma diminuição gradativa neste coeficiente (figura 14). 


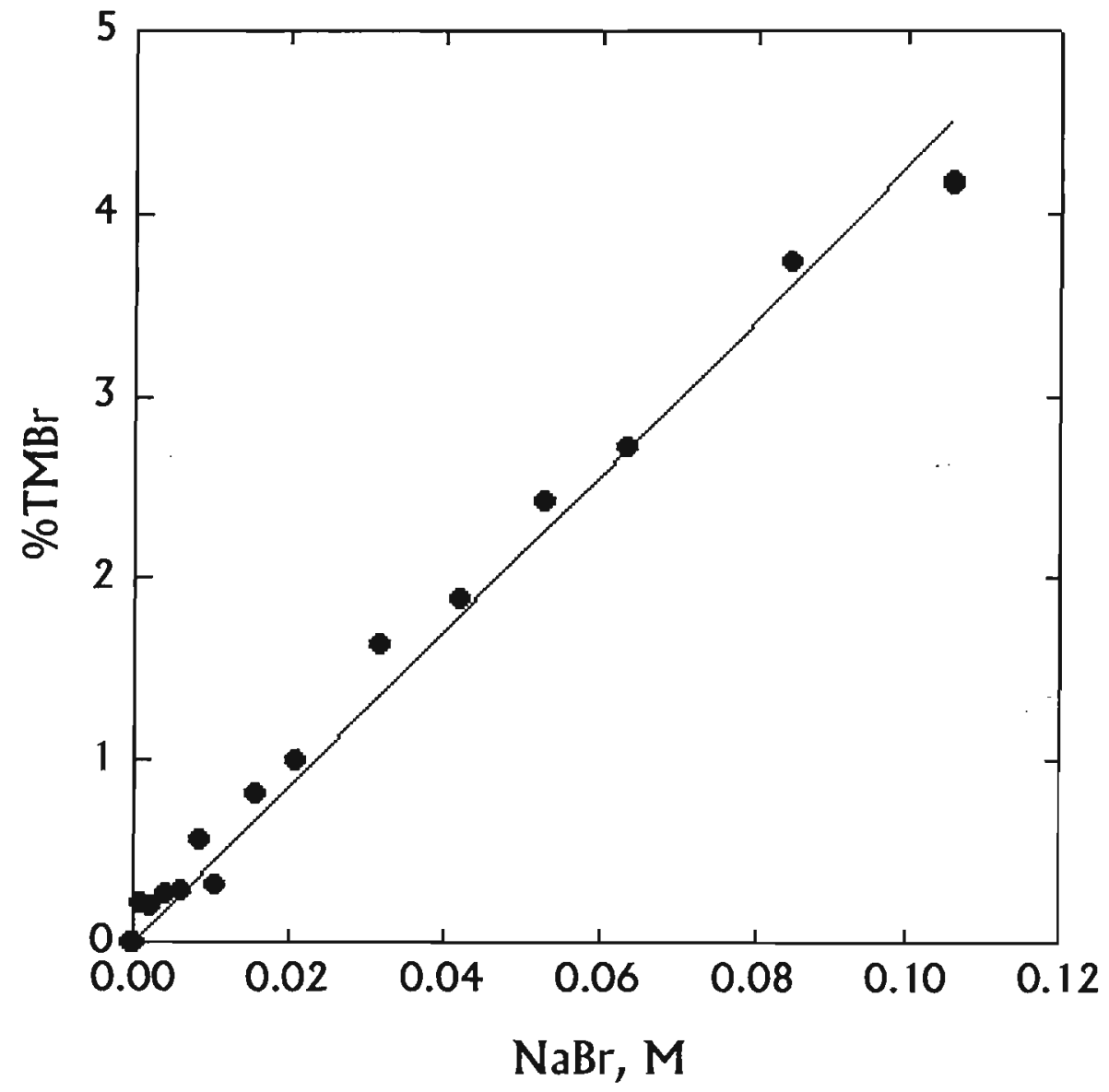

Figura 13: Formação de TMBr a partir da reação de TMD em presença de $\mathrm{NaBr}$ a baixas concentrações. 


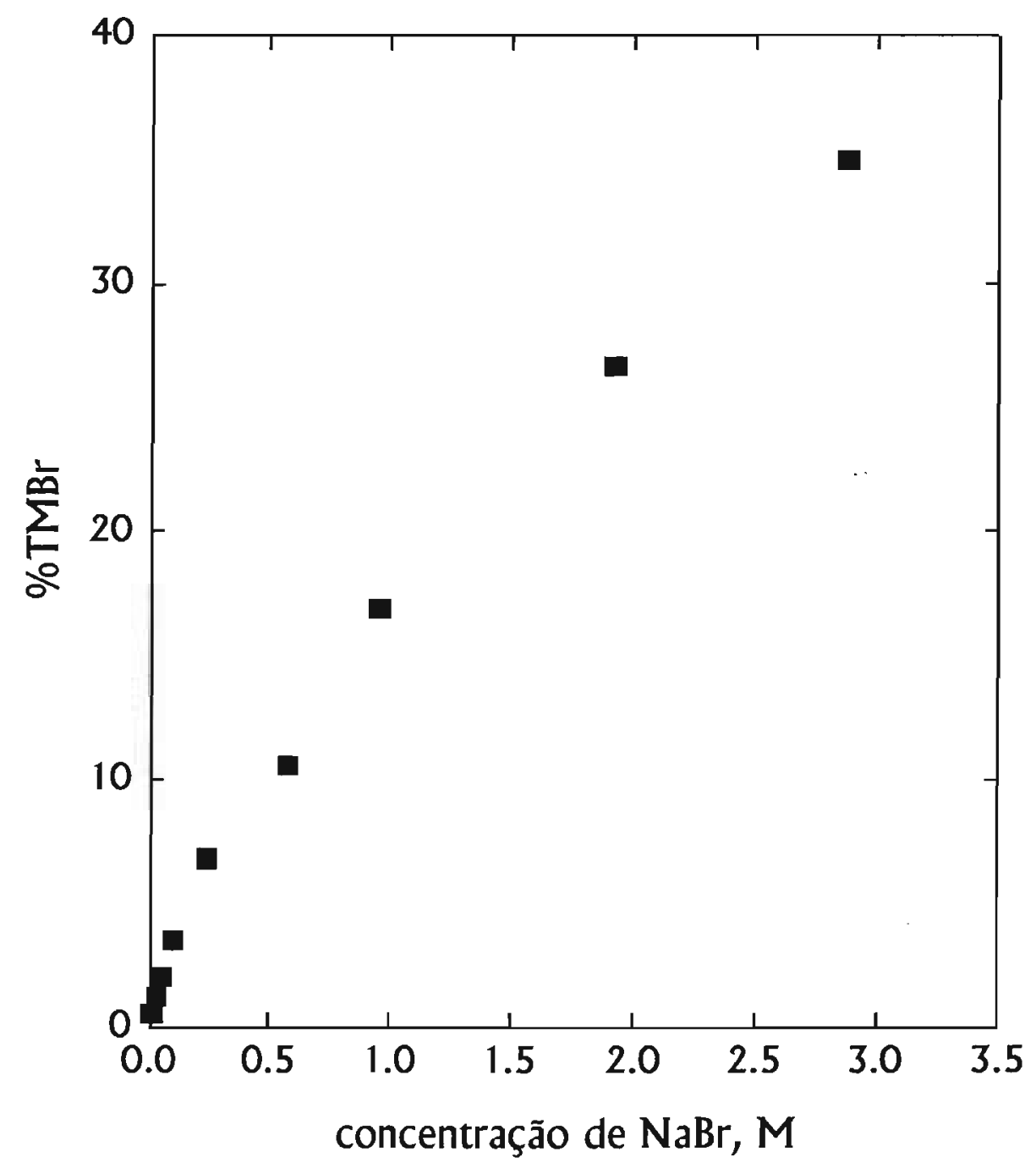

Figura 14: Formação de TMBr a partir da reação de TMD em presença de $\mathrm{NaBr}$ em altas concentrações. 
De maneira análoga foi calculada a porcentagem de $\mathrm{TMCl}$ formada na reação do TMD em presença de $\mathrm{NaCl}$ em $2 \times 10^{-4} \mathrm{M}$ de $\mathrm{HCl}$. O gráfico \% $\mathrm{TMCl} \times[\mathrm{NaCl}]$ é linear a baixas concentrações de sal (0 a $100 \mathrm{mM}$ ), com coeficiente angular de $R_{\mathrm{Cl}}=25 \% \mathrm{M}^{-1}$ (fig.15). Ocorre desvio da linearidade a partir de concentrações maiores que $0,1 \mathrm{M}$ de $\mathrm{NaCl}$ (fig.16).

O grau de dissociação $(\alpha)$ das micelas é definido como a relação entre concentração de contra-íon livre na fase aquosa e a concentração total de detergente micelizado. Para a determinação do $\alpha$ das micelas de CTAB e CTACI é necessário se determinar a concentração de contraíons livres em solução na presença de micelas. A partir da equação 5 a concentração de haleto livre para uma solução micelar é:

$$
\begin{aligned}
& C_{f}=\alpha C_{d}+C M C+B Y \\
& \text { Com } C_{d}=C_{t}-C M C
\end{aligned}
$$

Onde $Y_{f}, C_{d}, C_{t}, C M C$ e BY são, respectivamente, a concentração de haleto livre, concentração de detergente micelizado, concentração total de detergente, concentração micelar crítica e concentração de sal comum adicionado.

Determinou-se a concentração de haloderivado formado em concentrações variáveis de anfifílico. A partir da \%TMBr ou $\% \mathrm{TMCl}$ formado e se utilizando a curva padrão de NaY $x$ \%TMY determinou-se $Y_{f} . O$ coeficiente angular do gráfico $Y_{f} \times C_{d}$ é $o$ 


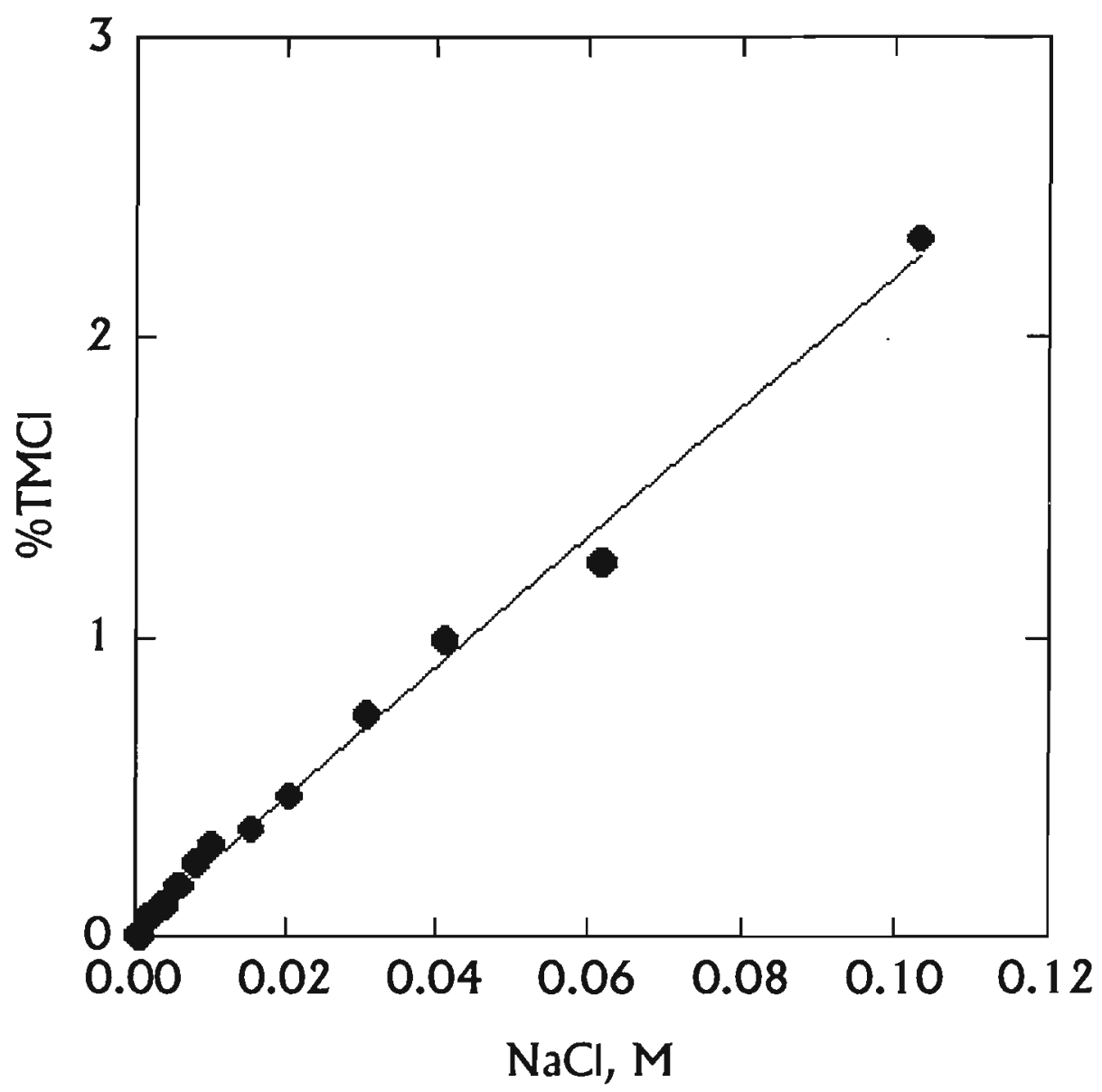

Figura 15: Formação de TMCl a partir da reação de TMD em presença de $\mathrm{NaCl}$ a baixas concentrações. 


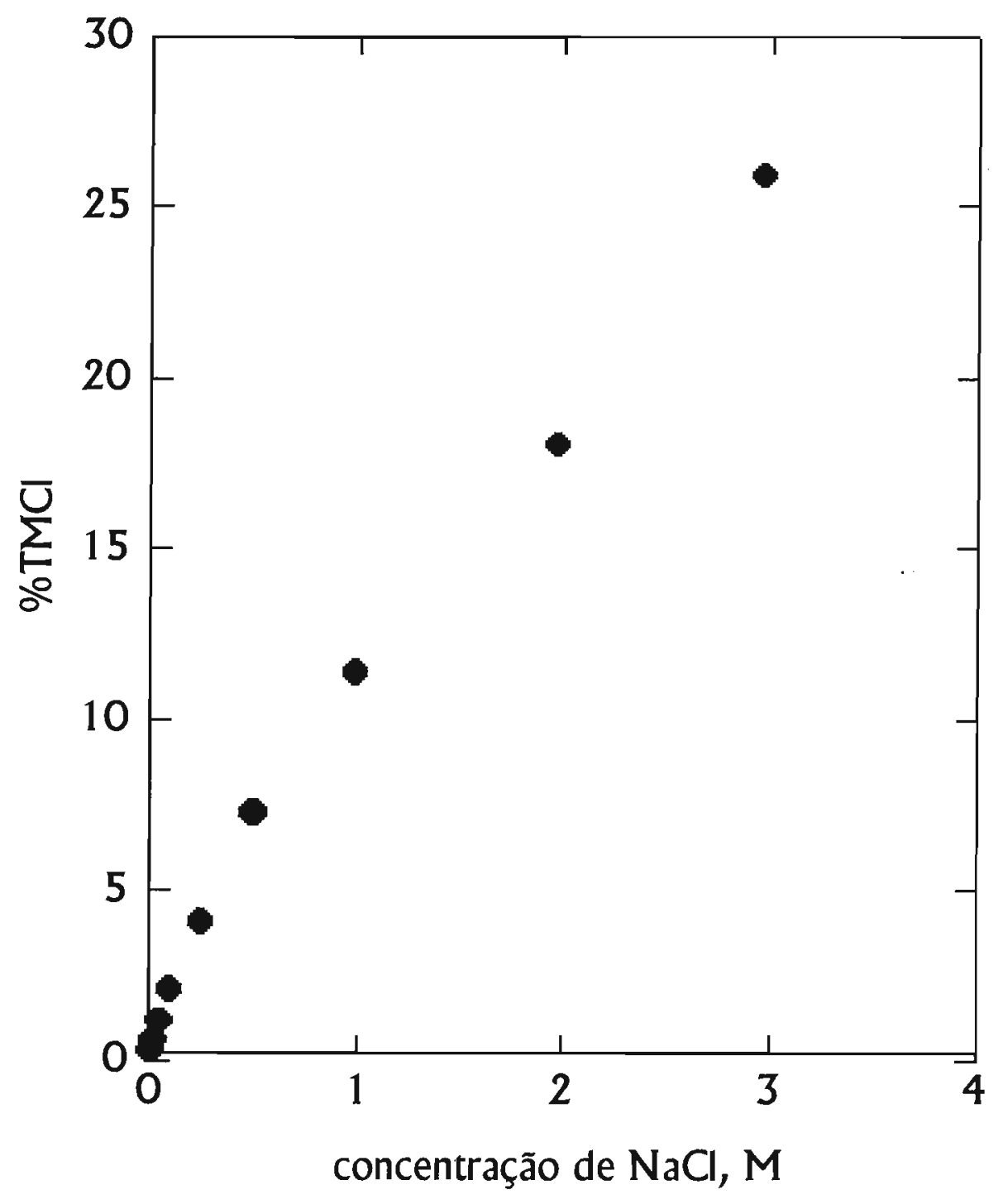

Figura 16: Formação de $\mathrm{TMCl}$ a parir de reação de $\mathrm{TMD}$ em presença de $\mathrm{NaCl}$ em altas concentrações. 
grau de dissociação iônica da micela. Para micelas de CTACI obteve-se um $\alpha=0,29$ (figura 17).

Foi determinada \% TMBr em presença de micelas de CTABr. Calculou-se $\mathrm{Br}_{\mathrm{f}}=\% \mathrm{TMBr} / \mathrm{R}_{\mathrm{Br}}$. A partir do gráfico $\mathrm{Br}_{\mathrm{f}} \times \mathrm{C}_{\mathrm{d}}$ (figura 18) calculou-se um $\alpha=0,26$.

Para determinar a constante de troca $\mathrm{Br}^{-} / \mathrm{Cl}^{-}$a uma concentração fixa de CTACl variou-se a concentração de $\mathrm{NaBr}$ e determinou-se $\mathrm{Cl}_{\mathrm{f}}$ e $\mathrm{Br}_{\mathrm{f}}$ que são dados por:

$$
\begin{aligned}
& \mathrm{Cl}_{\mathrm{f}}=\% \mathrm{TMCl} / \mathrm{R}_{\mathrm{Cl}} \\
& \text { e } \mathrm{Br}_{\mathrm{f}}=\% \mathrm{TMBr} / \mathrm{R}_{\mathrm{Br}}
\end{aligned}
$$

$\mathrm{Cl}_{\mathrm{b}}$ e $\mathrm{Br}_{\mathrm{b}}$ foram calculados a partir das equaçōes 35 e 36 respectivamente. Pela lei da conservação das massas:

$$
\begin{aligned}
& C l_{b}=C l_{t}-C l_{f}=C_{d}-C l_{f} \\
& B r_{b}=B r_{t}-B r_{f}
\end{aligned}
$$

onde o subscrito $t$ indica total $e C_{d}$ é a concentração de detergente micelizado.

A constante de troca $\mathrm{Br} / \mathrm{Cl}^{-}$é dada pela equação: 


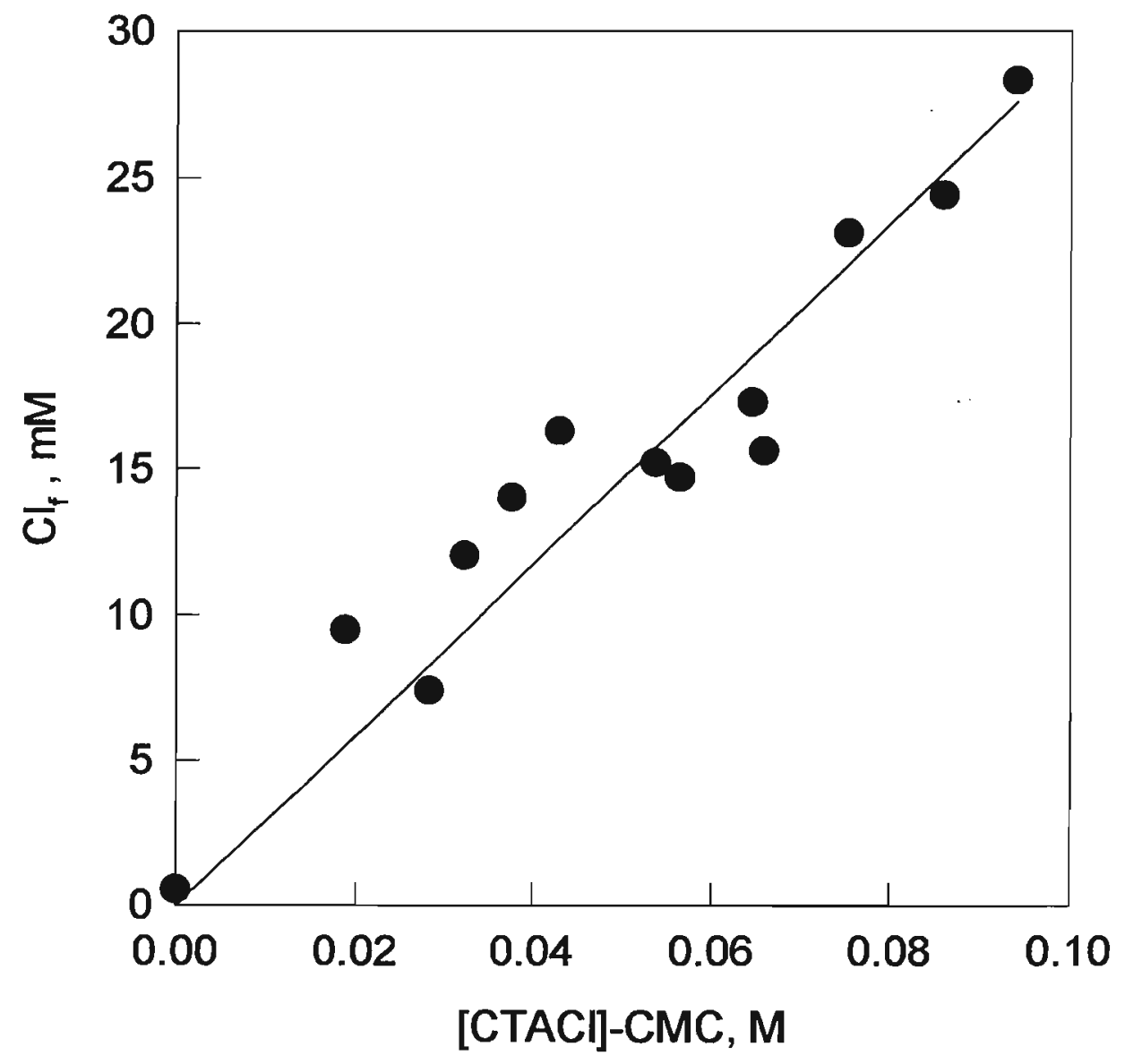

Figura 17: Efeito de micelas de $\mathrm{CTACl}$ na concentração de cloreto livre. 


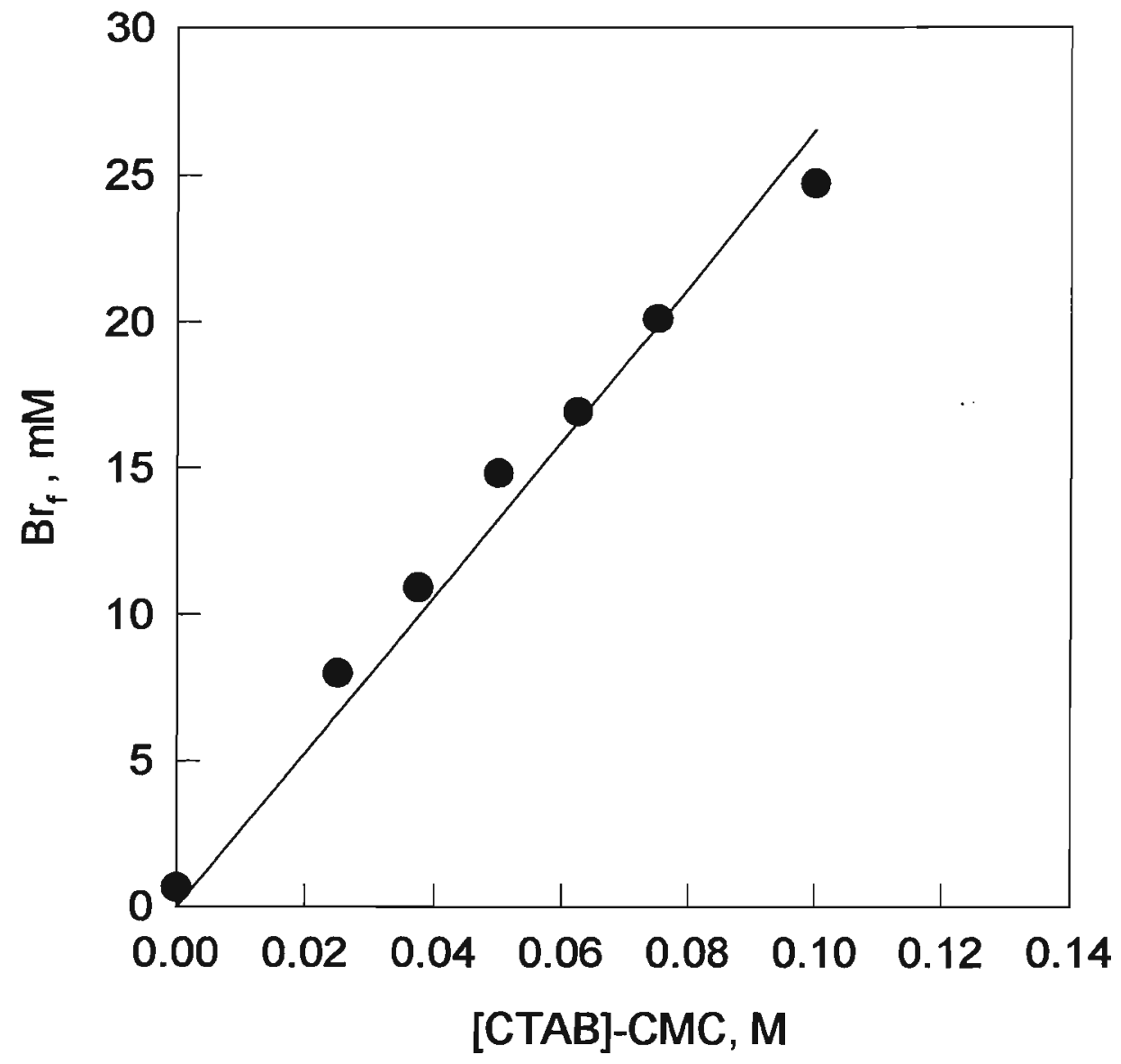

Figura 18: Efeito de micelas de CTABr na concentração de brometo livre. 


$$
K_{B r / C l}=\frac{B r_{b} \cdot C l_{f}}{B r_{f} \cdot C l_{b}}
$$

onde os subscritos b e f indicam ligado e livre, respectivamente.. Rearranjando a equação 1 temos:

$$
\frac{B r_{b}}{B r_{f}}=\frac{C l_{b}}{C l_{f}} K_{B r / C l}
$$

Fazendo-se o gráfico $\mathrm{Br}_{b} / \mathrm{Br}_{\mathrm{f}} \times \mathrm{Cl}_{\mathrm{b}} / \mathrm{Cl}_{\mathrm{f}}$ obtem-se como coeficiente angular $\mathrm{K}_{\mathrm{Br} / \mathrm{Cl} \text {. }} \mathrm{O} \mathrm{K}_{\mathrm{Br} / \mathrm{Cl}}$ obtido em micelas de CTACl foi de 2,65 (fig19) e está em ótima concordância com o valor obtido por Loughlin e Romsted (1990).

\subsubsection{Vesículas}

Procedeu-se como nas micelas para determinar $\alpha$ de vesículas. Variou-se a concentração de vesículas e foram determinadas as $\% \mathrm{TMBr}$ ou \% $\mathrm{TMCl}$. No caso de vesículas, visto que o TMD não penetra no compartimento aquoso interno da vesícula, a reação de decomposição do TMD é sensível somente à dissociação da fração (f) de anfifílicos que estão na superfície externa da vesícula:

$$
f=n_{e} / n_{t}
$$




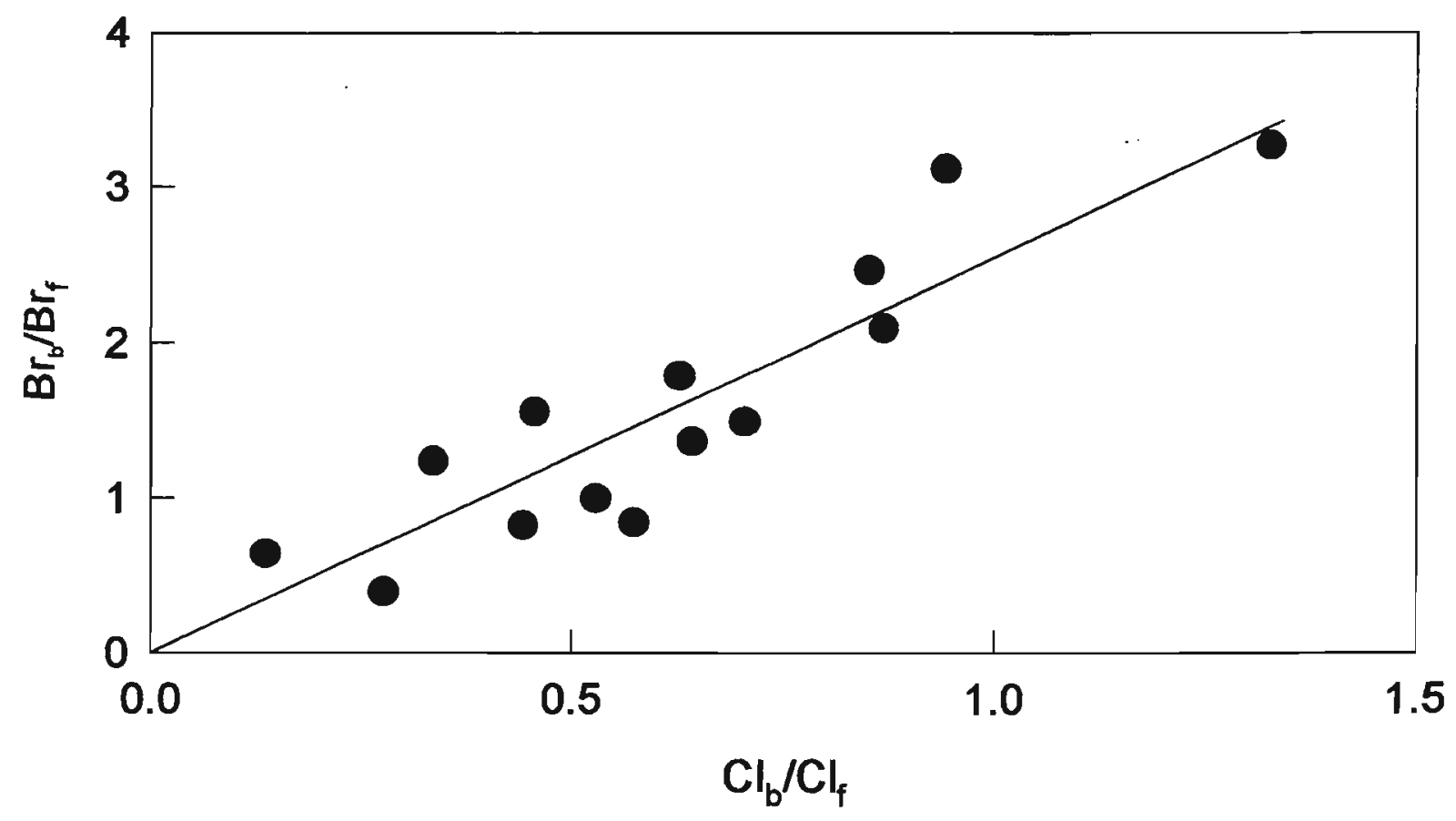

Figura 19: Determinação da constante de troca $\mathrm{Br} / \mathrm{Cl}$ em micelas de CTACl. 
Onde $n_{e}$ é o número de anfifílicos na superfície externa da vesícula e $n_{t}$ é o número total de anfifílicos na vesícula.

A partir da inclinação dos gráficos $Y_{f} \times C_{t}$ calcula-se $0 \alpha_{e}$ (grau de dissociação iônica externo) das vesículas através da equação:

$$
\alpha_{e}=\frac{Y_{f}}{C_{d} \cdot f}
$$

Para vesículas sonicadas de DODAC $\mathrm{f}=0,6$ (CarmonaRibeiro et al, 1984). Para vesículas sonicadas em banho $\alpha_{e}$ é 0,20 (figura 20) e para vesículas sonicadas por tip o $\alpha_{\mathrm{e}}$ é 0,25 (figura 21).

Cuccovia et al (1990) determinaram o $\alpha_{e}$ de vesículas por mobilidade eletroforética. Vesículas sonicadas de DODAC apresentaram $\alpha_{e}=0,21$ (em ausência de sal até $0,93 \mathrm{mM} \mathrm{NaCl}$, caindo para 0,11 em $\mathrm{NaCl} 9,27 \mathrm{mM}$.

Pode-se comparar o $\alpha_{\mathrm{e}}$ obtido por mobilidade eletroforética a $0,93 \mathrm{mM}$ de $\mathrm{NaCl}$ com o obtido na decomposição do TMD, pois a concentração de cloreto neste experimento, adicionada como contra-íon do TMD e $\mathrm{HCl}$ é $7 \times 10^{-4} \mathrm{M}$, bem próxima a $0,93 \mathrm{mM}$. Os $\alpha_{e}$ 's obtidos pela reação do TMD para vesículas sonicadas, independente do método de sonicação, estão em excelente concordância com o $\alpha_{e}$ obtido por mobilidade eletroforética.

Determinou-se $0 \alpha$ de vesículas injetadas de DODAC em diclorometano (figura 22). Levando em conta que a fração do 
63

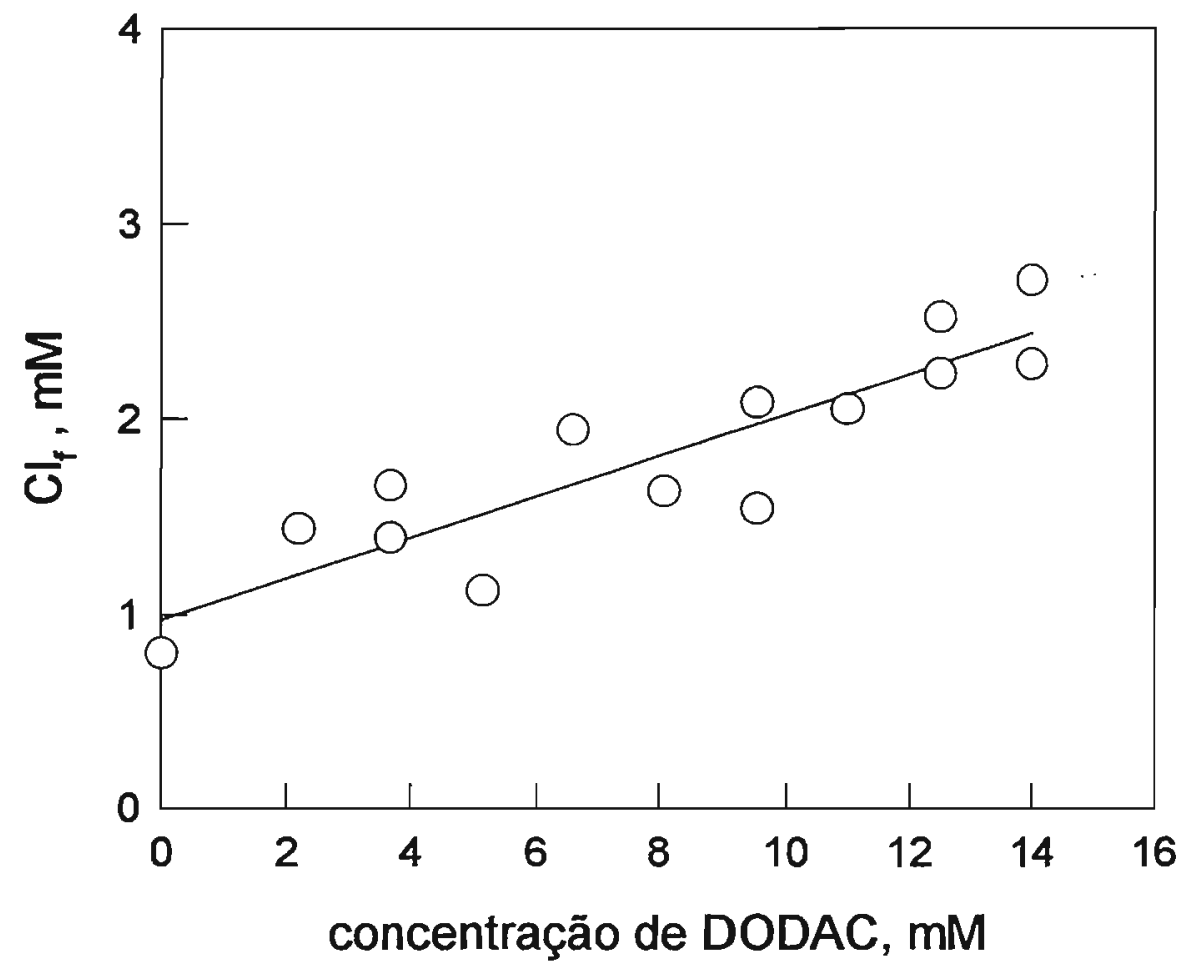

Figura 20: Efeito de vesículas de DODAC (preparadas por sonicador de banho) na concentração externa de cloreto. 


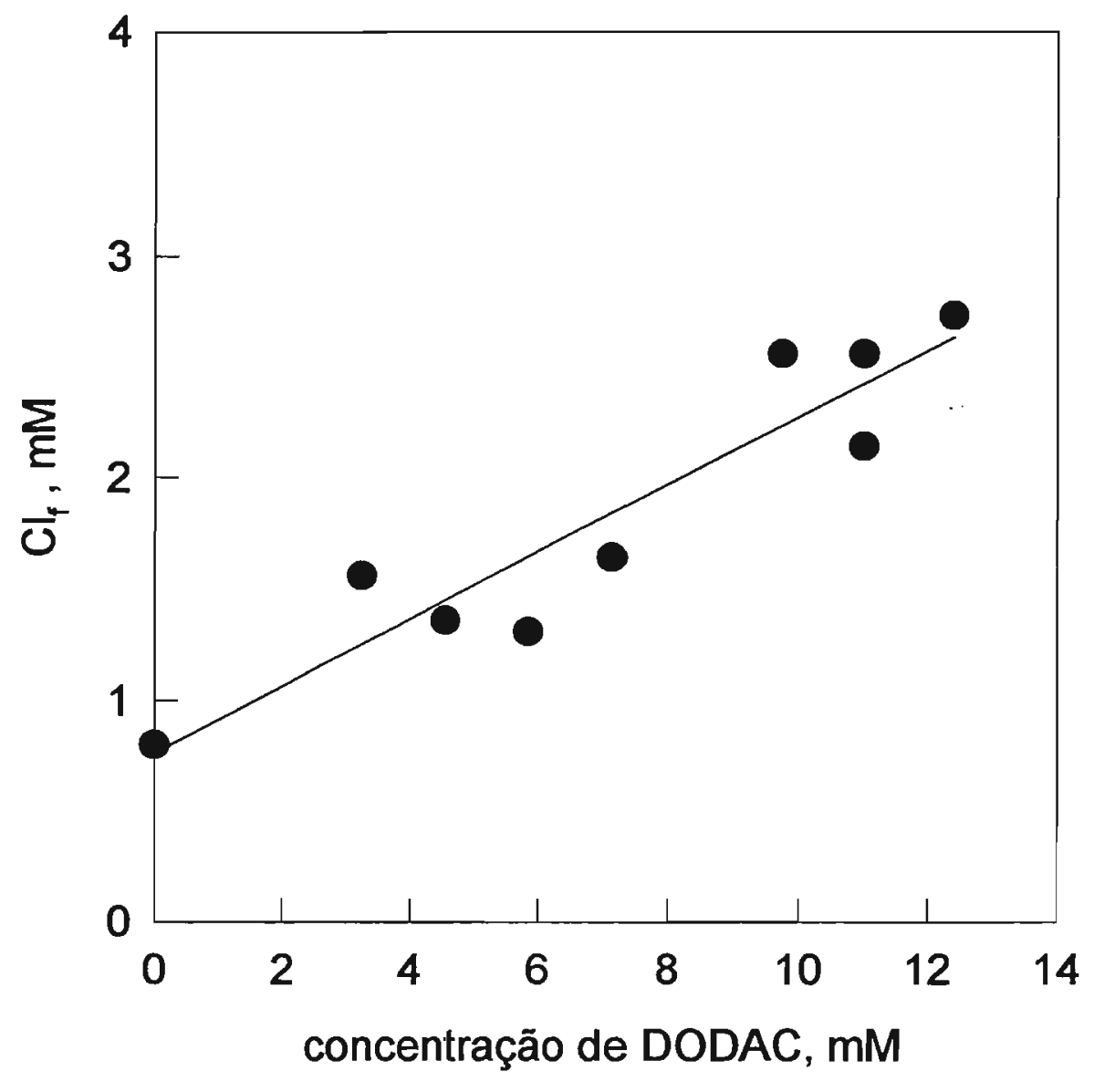

Figura 21: Efeito de vesículas de DODAC sonicadas por tip na concentração externa de cloreto. 


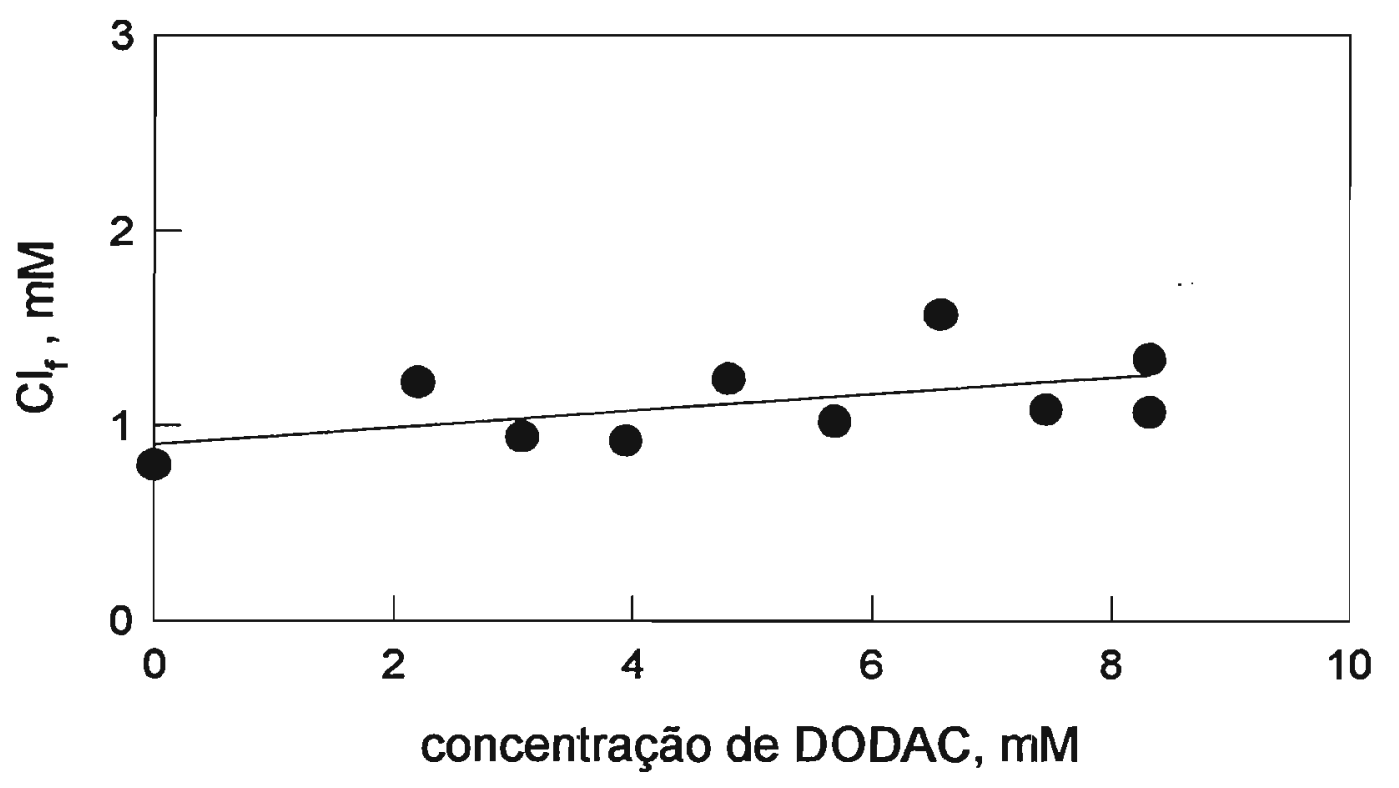

Figura 22: Efeito de vesículas de DODAC injetadas (DCM) na concentração externa de cloreto. 
anfifílico externa é 0,5 (Carmona-Ribeiro et al, 1984) tem se então $\alpha_{e}=0,11$. Cuccovia et al (1990) obtiveram $\alpha_{e}=0,044$ em ausência de sal para vesículas de DODAC clorofórmicas.

$O \alpha_{e}$ de vesículas de DODAB sonicadas com tip também foi determinado (figura 23). Levando em conta que $f=0,6$ obtem-se um $\alpha_{e}=0,2$. $O$ valor obtido por mobilidade eletroforética (Cuccovia et al, 1990) foi de 0,13, cerca de $65 \%$ do $\alpha_{e}$ determinado através da reação do TMD.

3.2 Determinação do grau de dissociação iônica interno de vesículas $\left(\alpha_{i}\right)$

O grau de dissociação interno de vesículas $\left(\alpha_{i}\right)$ não pode ser determinado como o grau de dissociação externo, através de um gráfico $\mathrm{Cl}_{\mathrm{f}} \times \mathrm{C}_{\mathrm{d}}$, visto que o TMDCl é incorporado às vesículas e depois separado do $\mathrm{TMDCl}$ externo através de cromatografia de exclusão.

Através da determinação da concentração de cloreto para uma concentração de vesículas pode-se calcular $0 \quad \alpha_{i}$ a partir das equações abaixo.

Uma vesícula de raio interno $r_{i}$ tem uma área interna $A_{i}=4 \pi r_{i}^{2} e$ volume interno $V_{i}=4 \pi r_{i}^{3} / 3$. Com a área ocupada por um monômero sendo $A_{m}$, o número de monômeros na monocamada interna de uma vesícula, $n_{m}=4 \pi r_{i}^{2} / A_{m}$. $O$ número de moles de cloretos dissociados no interior de uma vesícula é: 


$$
n_{C l_{f}}=\frac{\alpha_{i} 4 \pi r_{i}^{2}}{A_{m} n_{0}}
$$

Onde $\mathrm{n}_{0}=6,02 \times 10^{23}$ e $\alpha_{i}$ é o grau de dissociação interno. A concentração de cloreto livre no interior da vesícula, $\mathrm{Cl}_{\mathrm{f}}$, é:

$$
C l_{f}=\frac{n_{C l_{f}}}{V_{i}}=\frac{3 \alpha_{i}}{A_{m} n_{d} r_{i}}
$$

O grau de dissociação interno é entāo:

$$
\alpha_{i}=\frac{A_{m} n_{0} r_{i} C l_{f}}{3}
$$

A concentração interna de cloreto determinanda foi de $8,5 \mathrm{mM}$, onde $5,25 \mathrm{mM}$ é devido ao cloreto adicionado com o $\mathrm{TMDCl}$ em $\mathrm{HCl}$ $2 \times 10^{-4} \mathrm{M}$. A concentração de cloreto interno devido à dissociação é então 3,25mM. Substituindo este valor na equação 3 e assumindo $r_{i}=$ $1310 \AA=1,35 \times 10^{-6} \mathrm{dm}$ (Cuccovia et al, 1990), $A_{m}=80 \AA^{2}=8 \times 10^{-17} \mathrm{dm}^{2}$ (Souza, 1994) é obtido $\alpha_{\mathrm{i}}=0,070$. 


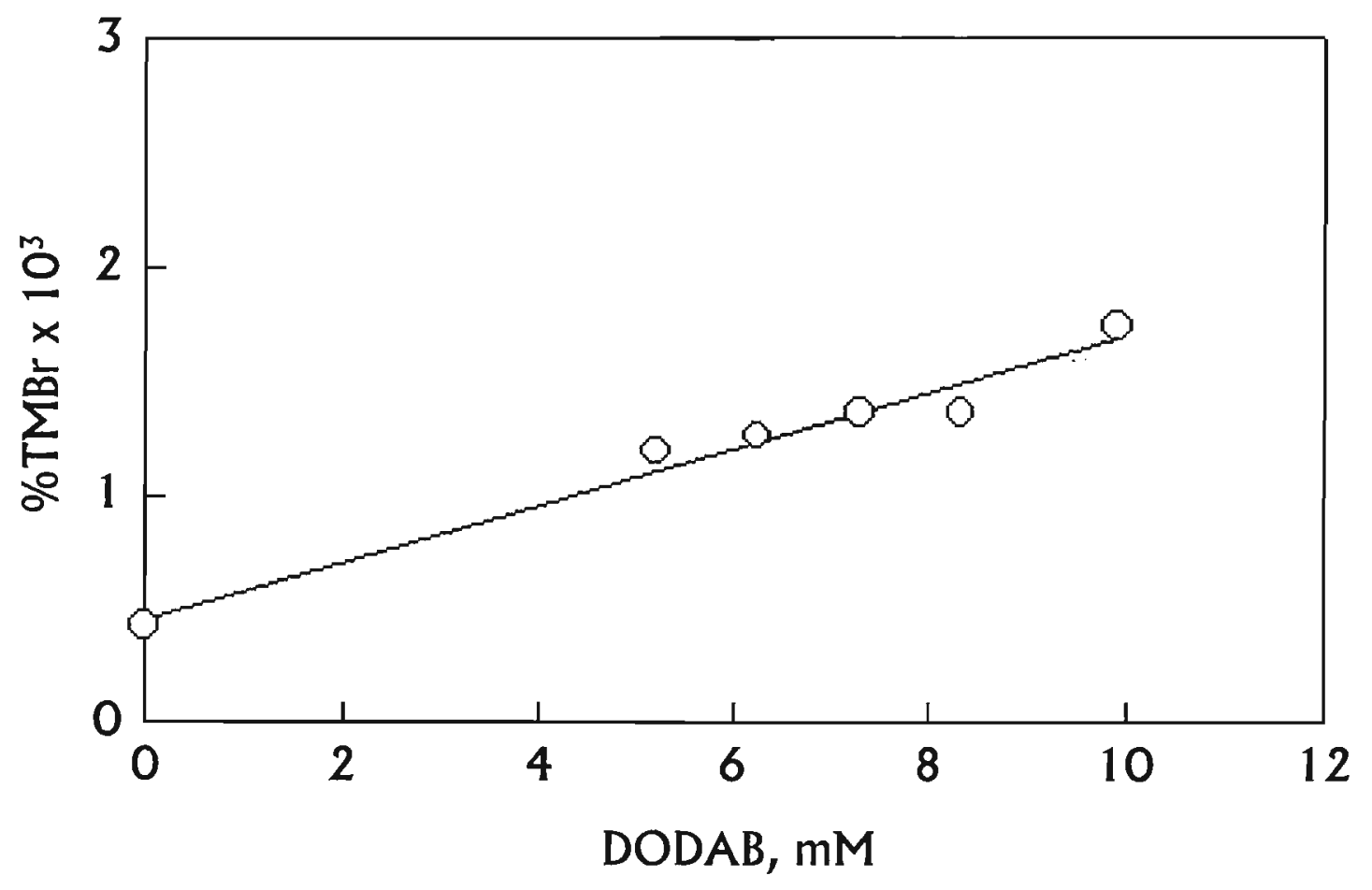

Figura 23: Determinação do grau de dissociação externo de vesículas de DODAB sonicadas (tip). 


\subsection{Efeito de micelas na descarboxilação do NBOC}

A reação de decomposição do NBOC foi estudada a várias concentrações de CTACl e CTAB em tampão borato $10 \mathrm{mM} \mathrm{pH}$ 9,20 .

$O k_{\Psi}$ de decomposição do NBOC em presença de micelas de CTACI (figura 24) aumenta com o aumento da concentração de detergente, atingindo um patamar. Os resultados podem ser analizados segundo a equação 19 , que prevê, para uma reação unimolecular, que $k_{\Psi}$ chega a um patamar.

A linha sólida na figura 24 foi obtida com ajuste segundo a equação $19 \mathrm{com} k_{m}=6,20 \times 10^{-4} s^{-1}, k_{w}=7,35 \times 10^{-6} s^{-1}, k_{N B O C / C l}=8$ (constante de troca $\mathrm{NBOC} /$ cloreto), $\mathrm{k}_{\mathrm{NBOC} / \text { borato }}=80$ (constante de troca NBOC/borato), $\alpha=0,29, \mathrm{CMC}$ de $1 \times 10^{-4} \mathrm{M}$, concentração de borato (BZ) de $5 \times 10^{-3} \mathrm{M}$ e concentração de NBOC de $1,13 \times 10^{-4} \mathrm{M}$.

Para micelas de CTAB (figura 25) obteve-se o mesmo perfil que em micelas de CTACI. A curva que melhor se ajustou aos dados experimentais foi obtida com os seguintes parâmetros: $\mathrm{K}_{\mathrm{m}}=7,15 \times 10^{-4} \mathrm{~s}^{-1}, \mathrm{~K}_{\mathrm{NBOC} / \mathrm{Br}}=4, \mathrm{~K}_{\mathrm{NBOC} / \mathrm{borato}}=80$ e demais parâmetros iguais ao do ajuste feito com micelas-de CTACI.

A relação entre $k_{\Psi \text { máx }} / k_{w}$ para micelas de CTAB é de 97. Para micelas de CTACl a relação é 84. As micelas de CTAB catalisam um pouco mais a reação do que as micelas de CTACI. Os dados obtidos estão de acordo com a literatura(Bunton e Minch, 1970; Bunton et al, 1971). 


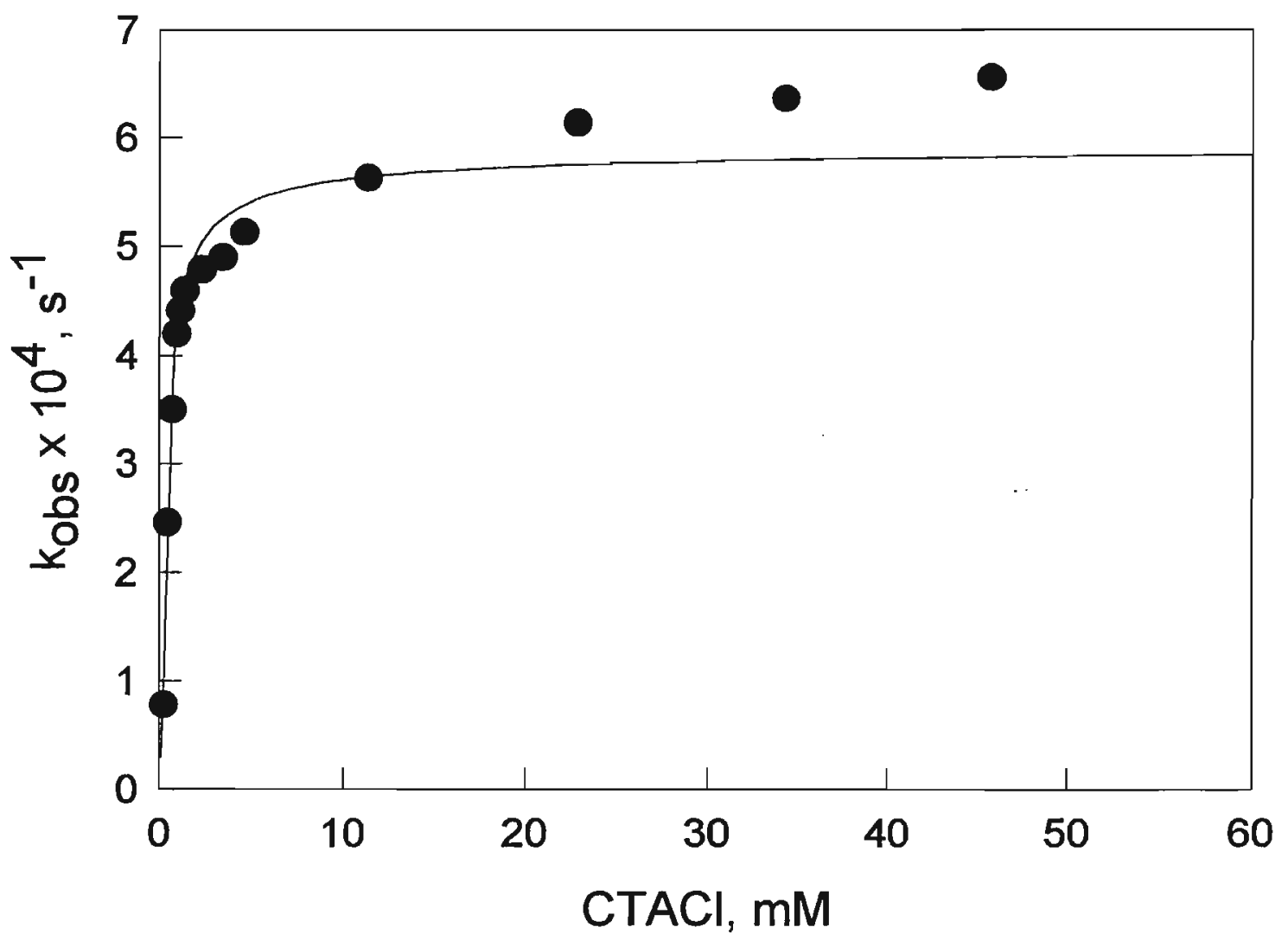

Figura 24: Decomposição de NBOC em presença de micelas de $\mathrm{CTACl}$ em tampão borato $0,010 \mathrm{M}, \mathrm{pH} 9,20$. [NBOC] $=1,3 \times 10^{-4} \mathrm{M}$. 


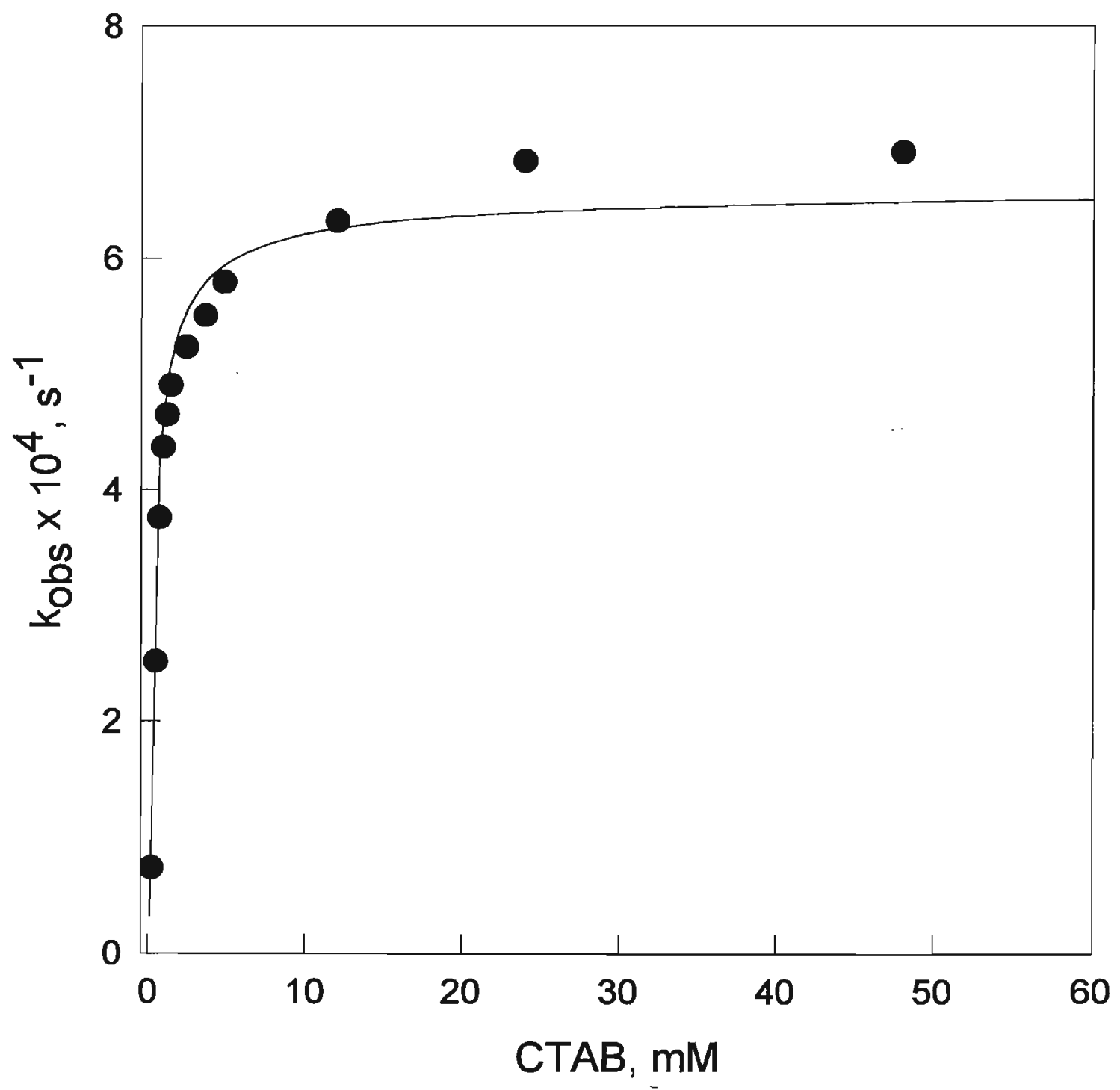

Figura 25: Decomposição de NBOC em presença de micelas de CTAB em tampão borato $0,010 \mathrm{M} \mathrm{pH} \mathrm{9,20.}[\mathrm{NBOC}]=1,13 \times 10^{-4} \mathrm{M}$. 
Com o objetivo de testar se a partir dos parâmetros obtidos no ajuste matemático de $k_{\Psi} \times C_{t}$ para NBOC era possível prever qual o perfil do gráfico $k_{\Psi} \times[N B O C]$, nas mesmas condições experimentais da figura 24 variou-se a concentração do substrato para uma concentração fixa de CTACI $=5,64 \times 10^{-3} \mathrm{M}$ (figura 26 ). $\mathrm{O} \mathrm{k} \Psi$ praticamente se manteve constante em $5,3 \times 10^{-4} \mathrm{~s}^{-1}$, na faixa de concentração utilizada.

Utilizando-se os parâmetros obtidos no ajuste teórico aos dados experimentais da figura 24 pode-se calcular os $k_{\Psi}$ esperados para as várias concentrações de substrato e comparálos aos obtidos experimentalmente (figura 26). Nota-se que há uma boa concordância para concentrações entre 2 a $4 \times 10^{-4} \mathrm{M}$ de substrato. Para concentraçōes fora desta faixa a diferença aumenta gradativamente.

\subsection{Efeito de vesículas na velocidade de reações}

\subsubsection{Descarboxilação do NBOC}

A reação de decomposição do NBOC foi estudada em presença de vesículas clorofórmicas de DODAC e DODAB. Numa primeira série de experimentos, $O N B O C$ foi adicionado às vesículas externamente a $30{ }^{\circ} \mathrm{C}$ e as constantes de velocidade foram determinadas. Numa segunda série de experimentos, as vesículas foram aquecidas a $46{ }^{\circ} \mathrm{C}$, o NBOC adicionado nesta 


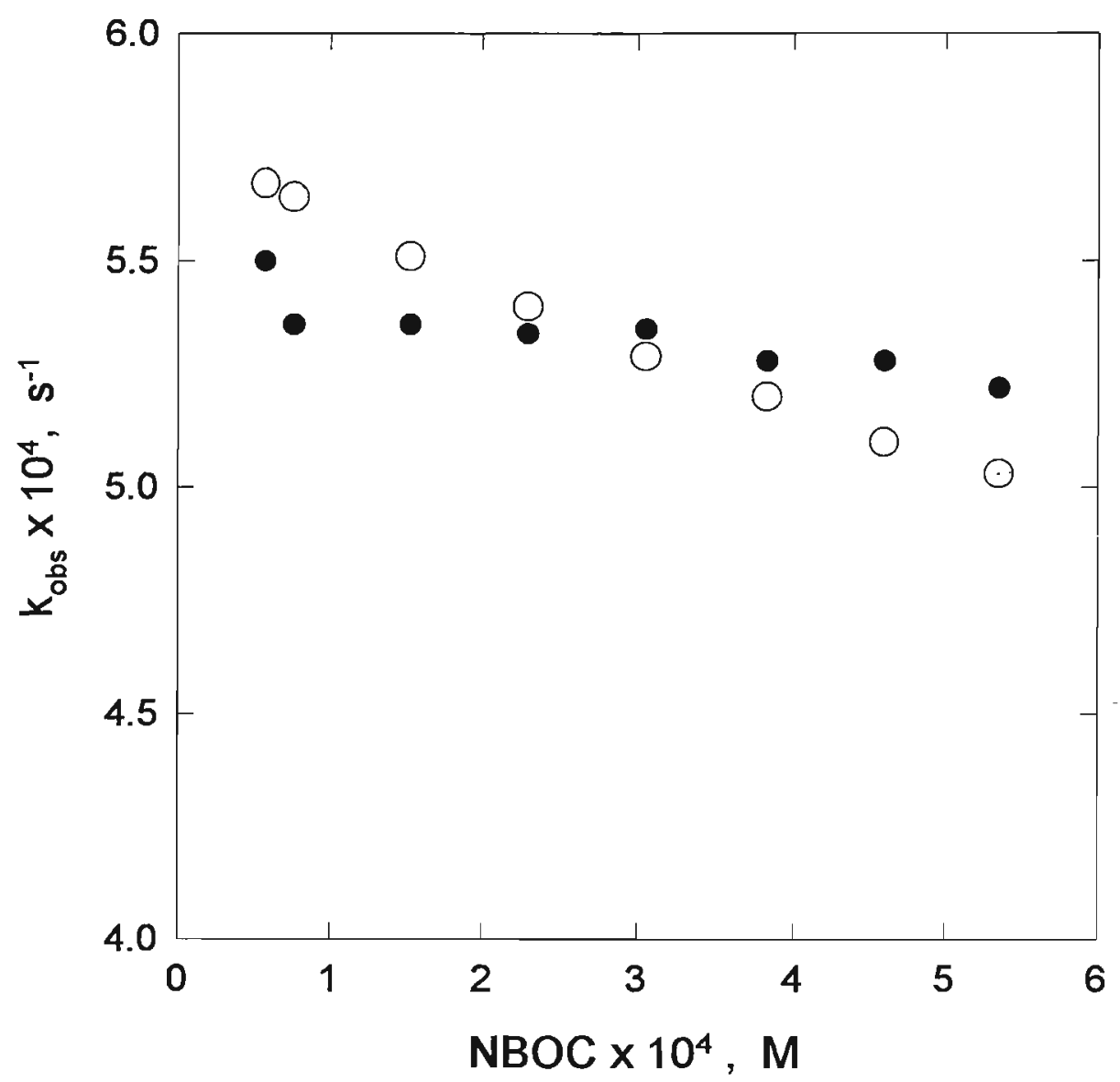

Figura 26 : Efeito da concentração do substrato na descarboxilação

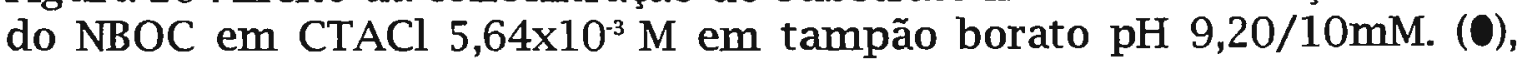
valores experimentais; $(0)$, valores calculados. 
temperatura (para penetração do NBOC no compartimento aquoso interno da vesícula), determinando-se as constantes de velocidade após termostatização a $30{ }^{\circ} \mathrm{C}$ do meio de reação.

Para evidenciar se através do aquecimento ocorria a penetração do NBOC na superfície interna das vesículas, determinou-se nos gráficos $k_{\Psi}$ vs. $C_{d}$ para as duas condições experimentais a concentração de detergente onde $k_{\Psi}=k_{\Psi \text { máximo }} / 2$ $\left(C_{1 / 2}\right)$. Para vesículas de DODAB aquecidas $C_{1 / 2}$ foi a metade do $\mathrm{C}_{1 / 2}$ para vesículas não aquecidas, indicando que a superfície de catálise havia dobrado. No ajuste das constantes de velocidade para o caso de vesículas sem aquecimento utilizou-se $C_{d} / 2$ (figura 27), visto que somente metade da superfície das vesículas tinha acesso ao substrato. Para vesículas aquecidas foi usado $\mathrm{C}_{\mathrm{d}}$ (figura 28) Os dados de $\mathrm{K}_{\Psi}$ foram ajustados com $\mathrm{C}_{\mathrm{d}}$ ou $\mathrm{C}_{d} / 2 \mathrm{e}$ $\alpha=0,11$, [Borato $]=5 \times 10^{-3} \mathrm{M},[\mathrm{NBOC}]=1.15 \times 10^{-4} \mathrm{M}, \mathrm{K}_{\mathrm{NBOC} / \mathrm{Br}}=3.5$, $\mathrm{K}_{\mathrm{NBOC} / \text { borato }}=100$ e $\mathrm{K}_{\mathrm{w}}=7,35 \times 10^{-6} \mathrm{~s}^{-1}$ para as duas curvas. Foi obtido $k_{m}{ }^{(i+e)}=1,43 \times 10^{-3} \mathrm{~s}^{-1}$ para vesículas aquecidas $e k_{m}{ }^{e}=$ $1.29 \times 10^{-3} \mathrm{~s}^{-1}$ para vesículas não aquecidas, onde $k_{m}{ }^{e} e k_{m}{ }^{(i+e)} s a ̃ o$ as constantes de velocidade de primeira ordem para a superfície interna e superfície interna e externa, respectivamente.

O mesmo procedimento para a penetração do NBOC foi feito para vesículas injetadas de DODAC, constatando-se que também ocorria penetração mediante aquecimento.

Para vesículas de DODAC sem aquecimento (figura 29) ajustou-se $\mathrm{k}_{\Psi}$ a $\mathrm{C}_{\mathrm{d}} / 2 \mathrm{com} \alpha=0,11, \mathrm{~K}_{\mathrm{NBOC} / \mathrm{Cl}}=7,0, \mathrm{k}_{\mathrm{m}}{ }^{\mathrm{e}}=2,10 \times 10^{-3} \mathrm{~s}^{-1}$, 


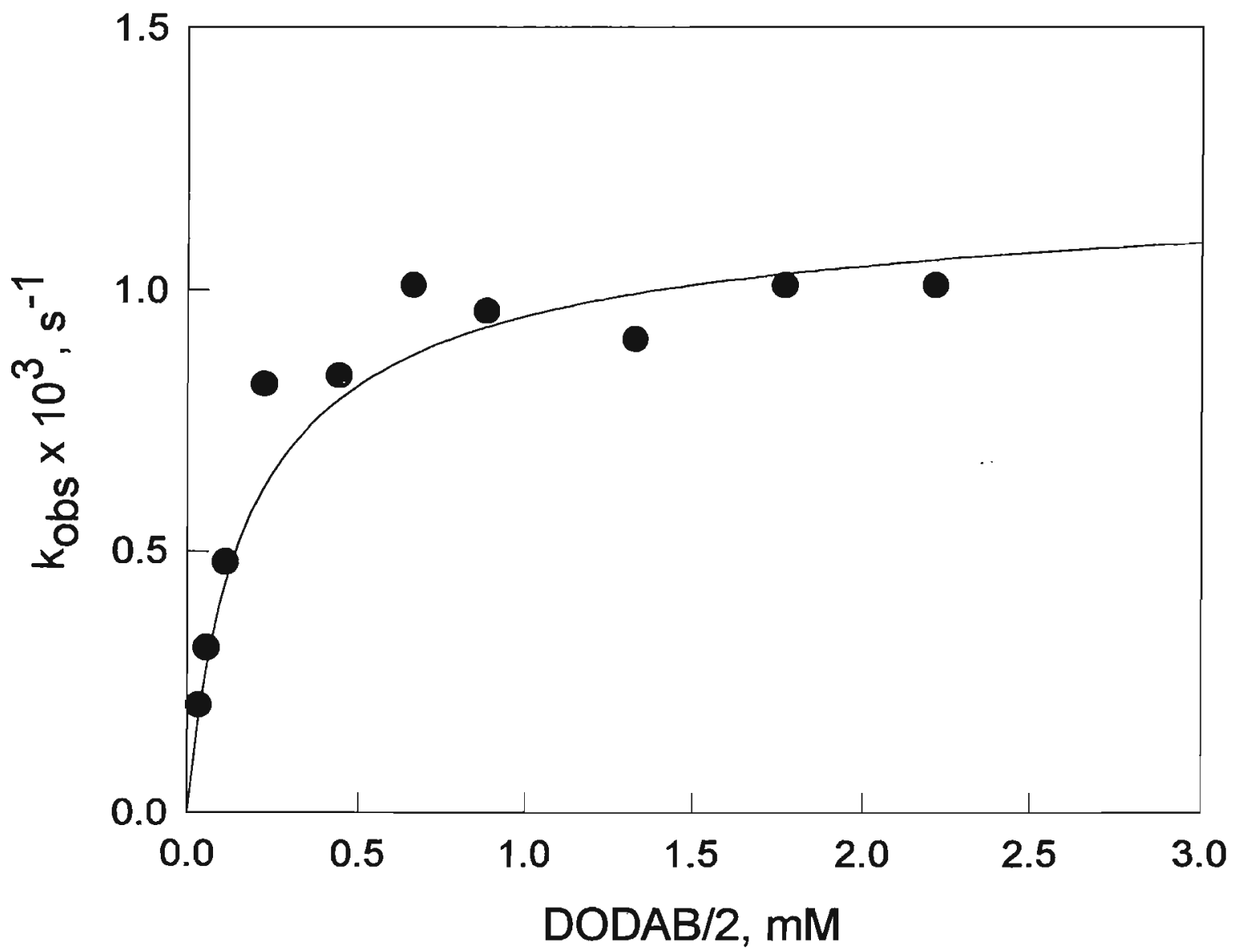

Figura 27: Catálise da decomposição de NBOC pela superfície externa de vesículas injetadas de DODAB em tampão borato 0,010M pH 9,20. [NBOC] $1,15 \times 10^{-4} \mathrm{M}$. 


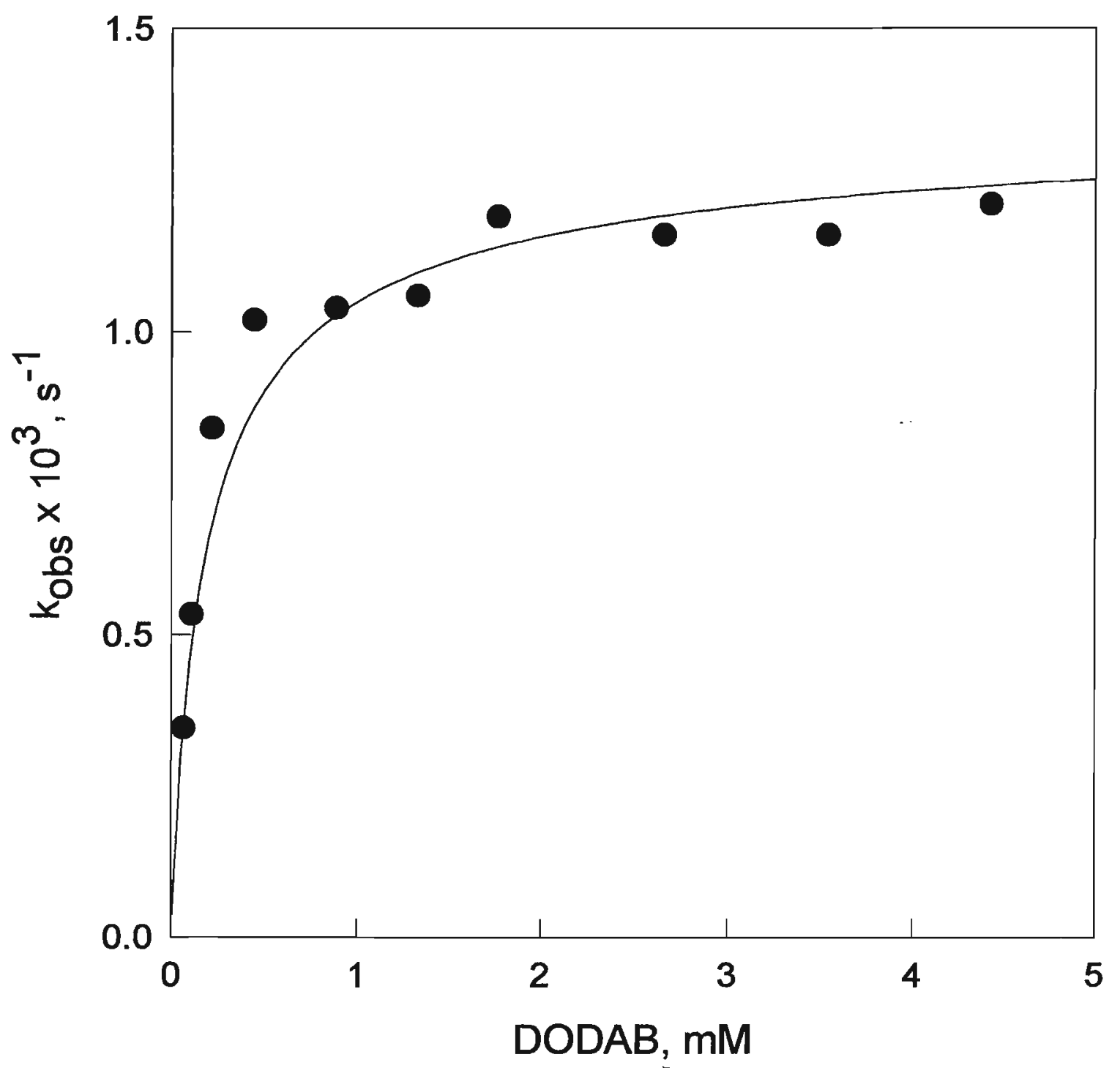

Figura 28: Catálise da decomposição de NBOC pela superfície interna e externa de vesículas injetadas de DODAB em tampão borato $0,010 \mathrm{M}$ $\mathrm{pH}=9,20 \mathrm{M}$. $[\mathrm{NBOC}]=1,15 \times 10^{-4} \mathrm{M}$. 


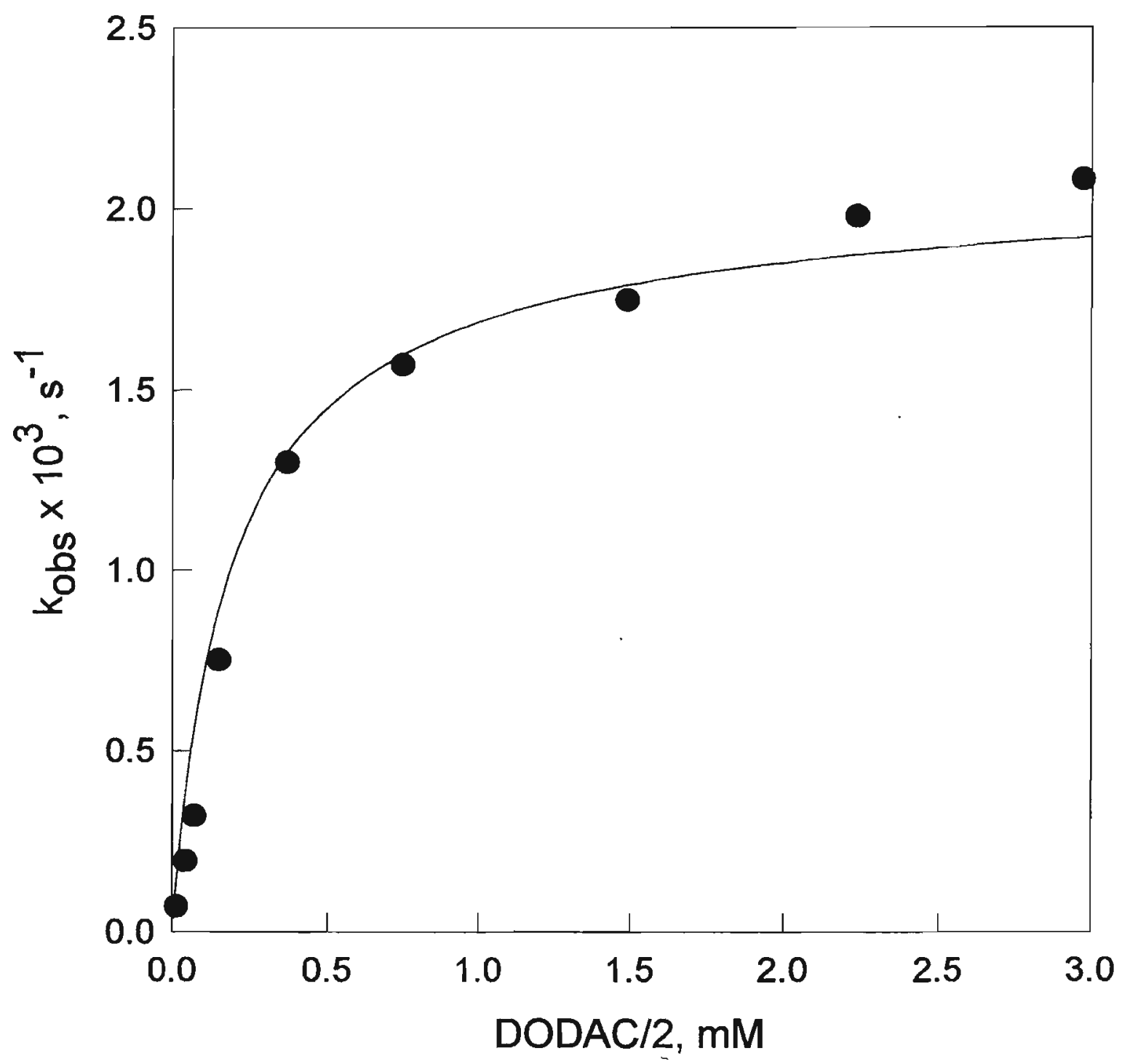

Figura 29: Catálise da decomposição do NBOC pela superfície externa de vesículas injetadas de DODAC em tampão borato $\mathrm{pH} 9,20 / 10 \mathrm{mM}$. $[\mathrm{NBOC}]=1,13 \times 10^{-4} \mathrm{M}$. 
$\mathrm{K}_{\mathrm{NBOC} / \text { borato }}=80$ e demais parâmetros iguais aos utilizados para vesículas de DODAB.

Para vesículas de DODAC aquecidas (figura 30 ) ajustou-se $k_{\Psi}$ a $C_{d}$ com $\alpha=0,11, k_{m}^{(i+e)}=3,35 \times 10^{-3} s^{-1}, K_{N B O C / C I}=7$, $\mathrm{K}_{\mathrm{NBOC} / \text { borato }}=10$ e demais parâmetros iguais aos utilizados para vesículas de DODAB.

Para uma concentração fixa de vesículas de DODAC variou-se a concentração de NBOC para testar se a catálise vesicular era dependente da concentração de substrato. $O$ efeito da concentração de substrato no $k_{\Psi}$ da descarḅoxilação do NBOC para vesículas clorofórmicas de DODAC (figura 31) mostra que a catálise depende da concentração de substrato, o que não ocorre com micelas (figura 26). Com vesículas injetadas, fixou-se a concentração de DODAC a $4,5 \times 10^{-3} \mathrm{M}$ e a concetração de $\mathrm{NBOC}$ foi variada de $2 \times 10^{-5} \mathrm{M}$ a $3 \times 10^{-4} \mathrm{M}$ (figura 31). Ocorreu uma redução no $k_{\Psi}$ de $40 \%$, enquanto que para micelas de CTACl, variando-se a concentração de NBOC de $5 \times 10^{-5} \mathrm{M}$ a $5 \times 10^{-4} \mathrm{M}$ o $\mathrm{K}_{\Psi}$ se manteve em torno de $5,3 \times 10^{-4} \mathrm{~s}^{-1}$.

\subsubsection{Hidrólise alcalina do DTNB}

A hidrólise alcalina do DTNB foi estudada em presença de vesículas sonicadas de DODAC variando-se a concentração de vesículas.

$\mathrm{Na}$ hidrólise alcalina de DTNB por vesículas sonicadas (figura 32) ocorre primeiramente um aumento no $k_{\Psi}$ com o 


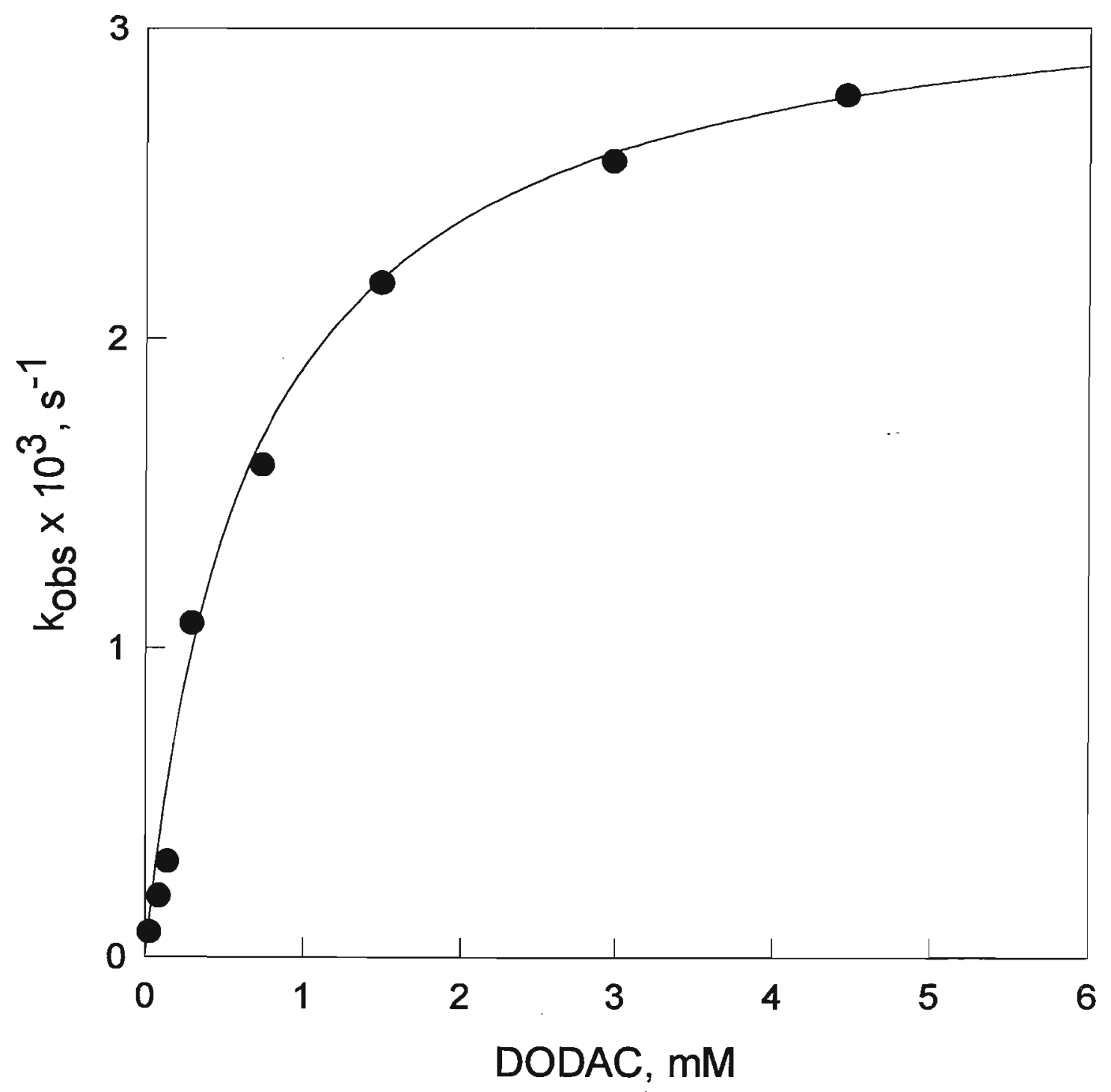

Figura 30: Catálise da decomposição do NBOC pelas superfícies interna e externa de vesículas injetadas de DODAC em tampão borato $\mathrm{pH} \mathrm{9,20/}$ $10 \mathrm{mM}$. $[\mathrm{NBOC}]=1,13 \times 10^{-4} \mathrm{M}$. 


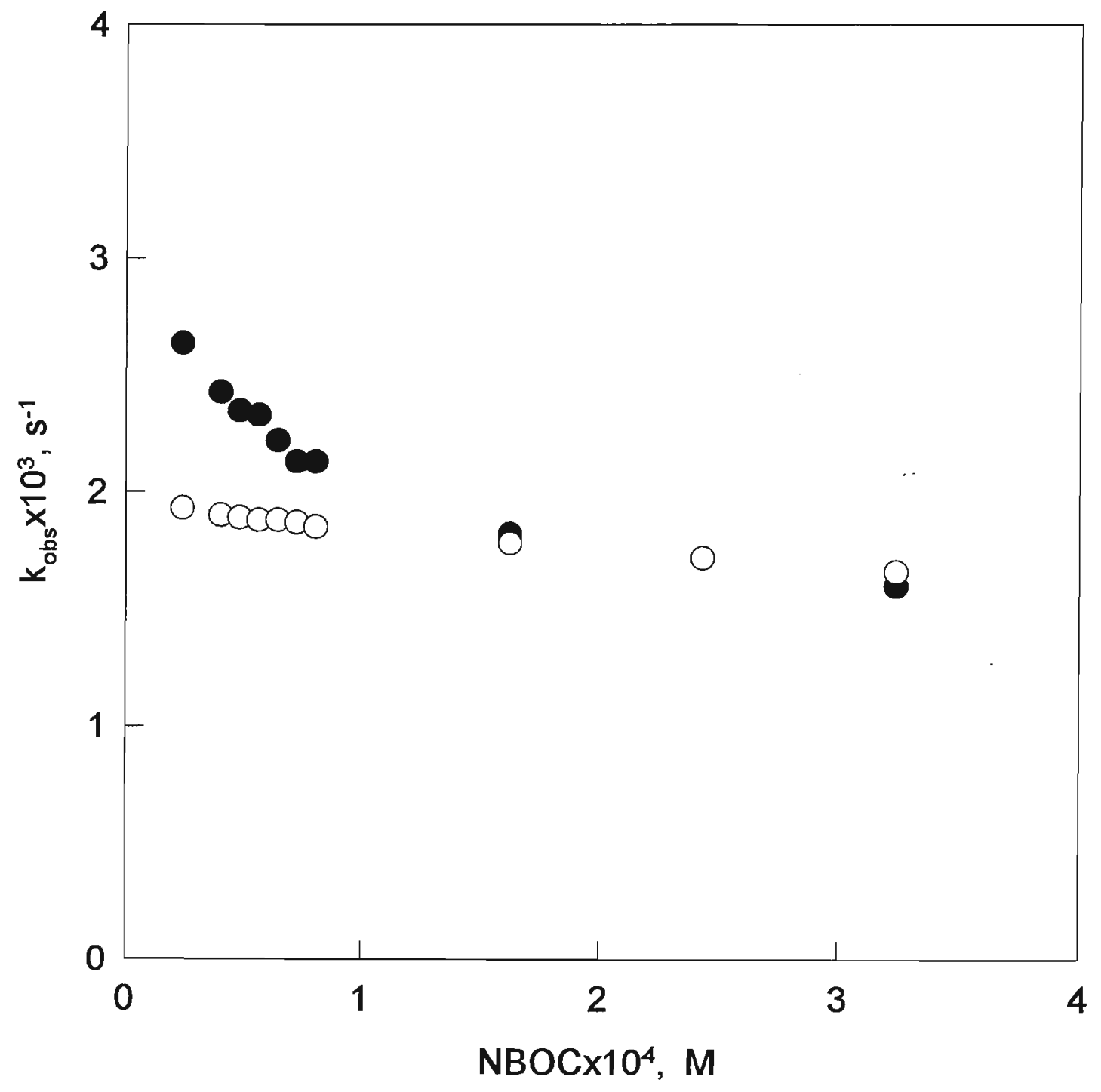

Figura 31: Efeito da concentração de substrato na descarboxilação do $\mathrm{NBOC}$ em DODAC (vesículas clorofórmicas). [DODAC] $=4,50 \times 10^{-3} \mathrm{M} .(\bullet)$, valores experimentais; $(\mathrm{O})$, valores calculados. 


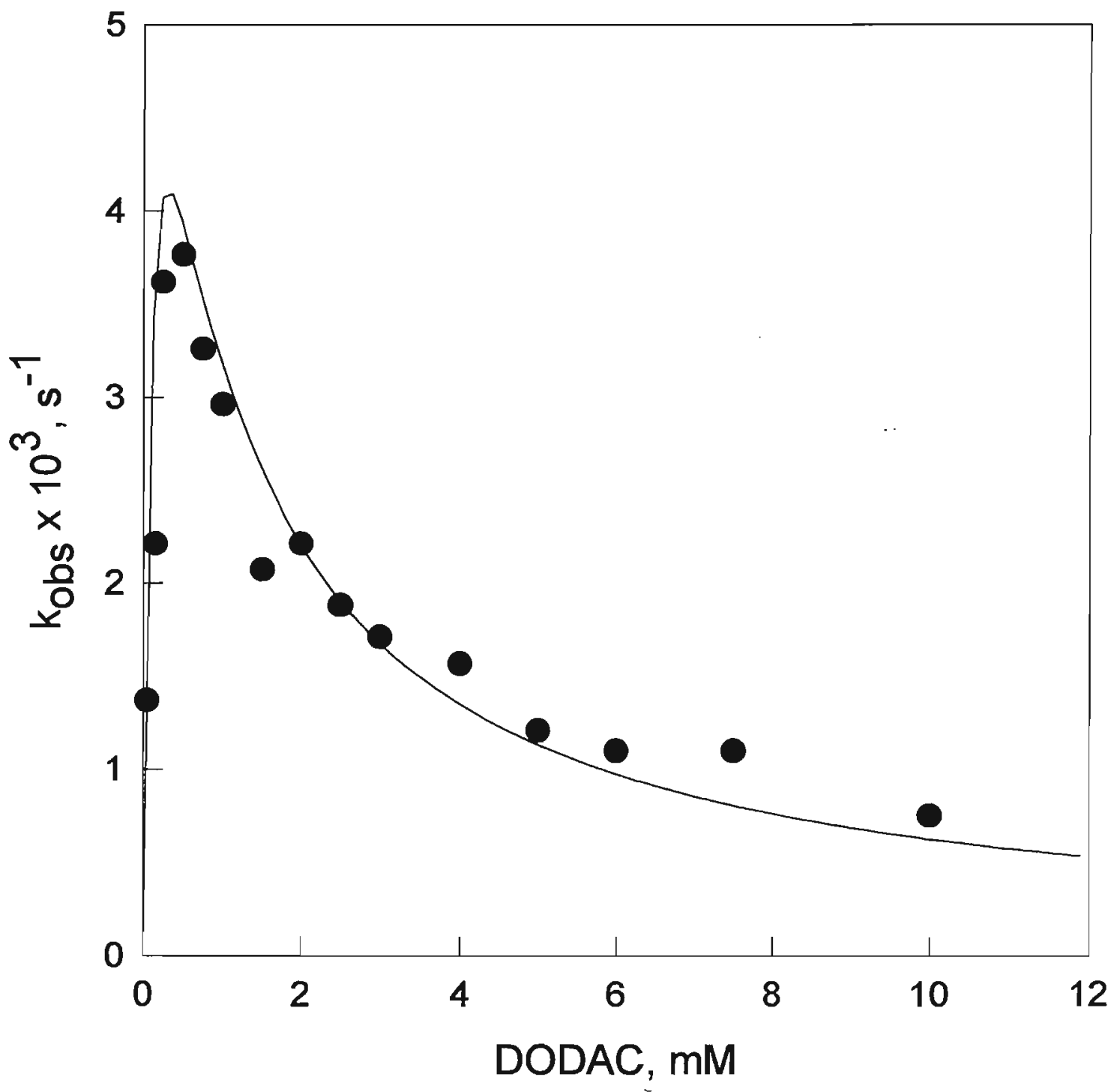

Figura 32: Hidrólise alcalina de DTNB em vesículas sonicadas de DODAC em tampão borato $\mathrm{pH} 8,9 / 0,020 \mathrm{M}$. [DTNB] $=3,61 \times 10^{-5} \mathrm{M}$. 
aumento da concentração de anfifílico. Este aumento é devido à ligação do substrato à vesícula. A diminuição no $K_{\Psi}$ é devido à expulsão do hidróxido e DTNB pelo cloreto. Estes dados foram melhor ajustados com $\alpha=0,20, \mathrm{~K}_{\mathrm{OH} / \mathrm{Cl}}=1.48 \times 10^{-1} ; \mathrm{K}_{\text {OH } / \mathrm{DTNB}}=$ $1.50 \times 10^{-2}, \mathrm{~K}_{2 \mathrm{~m}}=8.80 \times 10^{-1} \mathrm{M}^{-1} \mathrm{~s}^{-1}, \mathrm{k}_{2 \mathrm{w}}=5,40 \times 10^{-1} \mathrm{M}^{-1} \mathrm{~s}^{-1}, \mathrm{CMC}=$ $1 \times 10^{-8} \mathrm{M}$, [Borato] $=1,70 \times 10^{-4} \mathrm{M},\left[\mathrm{OH}^{-}\right]=7,94 \times 10^{-6} \mathrm{M}$, [DTNB] = $3,61 \times 10^{-5} \mathrm{M} \mathrm{e} \mathrm{V}=5,8 \times 10^{-1} \mathrm{~L} / \mathrm{Mol}$.

Para verificar se o DTNB tinha acesso à superfície interna de vesículas clorofórmicas injetadas de DODAC, procedeu-se do seguinte modo:

Após o aquecimento para a penetração do DTNB, esfriamento da amostra, adicionou-se ditionito para eliminar o DTNB externo e monitorou-se a catálise devido exclusivamente à superfície interna da vesícula (figura 33). Para a hidrólise alcalina do DTNB observou-se que somente com a adição do substrato quando a solução de vesículas estava a $46^{\circ} \mathrm{C}$ este tinha acesso à superfície interna da vesícula.

$\mathrm{O}$ ajuste matemático foi feito com $\alpha=0,07, \mathrm{BY}=2,3 \times 10^{-4}$ $\mathrm{M}$, DTNB $=3,43 \times 10^{-5} \mathrm{M}, \mathrm{K}_{\mathrm{OH} / \mathrm{Cl}}=1,6 \times 10^{-1}, \mathrm{~K}_{\mathrm{OH} / \mathrm{DTNB}}=1,7 \times 10^{-2}$, $\mathrm{OH}^{-}=2,5 \times 10^{-6} \mathrm{M}, \mathrm{CMC}=1 \times 10^{-8} \mathrm{M}, \mathrm{k}_{2 \mathrm{~m}}=2,2 \mathrm{M}^{-1} \cdot \mathrm{s}^{-1} \mathrm{k}_{2 \mathrm{w}}=0.54 \mathrm{M}^{-1}$ .$s^{-1}$ e $V=0,58$ L/mol. Para condições experimentais idênticas, mas com o DTNB tendo acesso só à superfície externa (figura 34) obteve-se 0 ajuste com $\alpha=0,11, C M C=1 \times 10^{-8} \mathrm{M}$, $B Y=1,2 \times 10^{-5} M, \quad$ DTNB $=3,43 \times 10^{-5} \quad M, \quad O^{-}=2,5 \times 10^{-6} \quad M$, $\mathrm{K}_{\mathrm{OH} / \mathrm{Cl}}=1,6 \times 10^{-1} \quad \mathrm{~K}_{\mathrm{OH} / \mathrm{DTNB}}=1,7 \times 10^{-2} \quad \mathrm{M}, \quad \mathrm{K}_{2 \mathrm{~m}}=8 \times 10^{-1} \mathrm{M}^{-1} \mathrm{~s}^{-1}$ e $\mathrm{K}_{0}=5,4 \times 10^{-1} \mathrm{M}^{-1} \mathrm{~s}^{-1} . \mathrm{e} \mathrm{V}=0,58 \mathrm{~L} / \mathrm{Mol}$. 
Para testar o efeito da concentração de DTNB no $k_{\Psi}$ em presença de vesículas injetadas, foi fixada a concentração DODAC em 4,26 × 10 $0^{-3} \mathrm{M}$ e foi variada a concentração de DTNB.

O gráfico $k_{\Psi} \times$ DTNB (figura 35 ) apresenta a baixas concentrações de substrato um aumento no $\mathrm{k} \Psi$, atingindo um máximo em 2,5×10-5M de DTNB, diminuindo com aumento da concentração de DTNB, estabilizando em torno de 4,6 $\times 10^{-3} \mathrm{~s}^{-1}$.

Visando testar se com os parâmetros obtidos através do ajuste de $k_{\Psi}$ vs $C_{d}$ podia prever o perfil do gráfico $k_{\Psi} \times[D T N B] ~ d a$ figura 33, através dos parâmetros obtidos com um ajuste (nas mesmas condições em que foi feito o experimento de $k_{\Psi} v s C_{d}$ ) calculou-se valores de $k_{\Psi}$ introduzindo as mesmas concentrações de substrato do experimento da figura 33. Observando-se os valores calculados (também apresentados na figura 33) nota-se que a equação prevê para a concentração mais baixa de substrato o maior $k_{\Psi}$, diminuindo com o aumento da concentração de substrato. Para concentrações na faixa de $1,5 \times 10^{-5}$ a $1 \times 10^{-4} \mathrm{M}$ os valores obtidos experimentalmente estão paralelos aos calculados, dando uma boa previsão, visto que os dados experimentais e os valores calculados não são de uma mesma preparação de vesículas. 


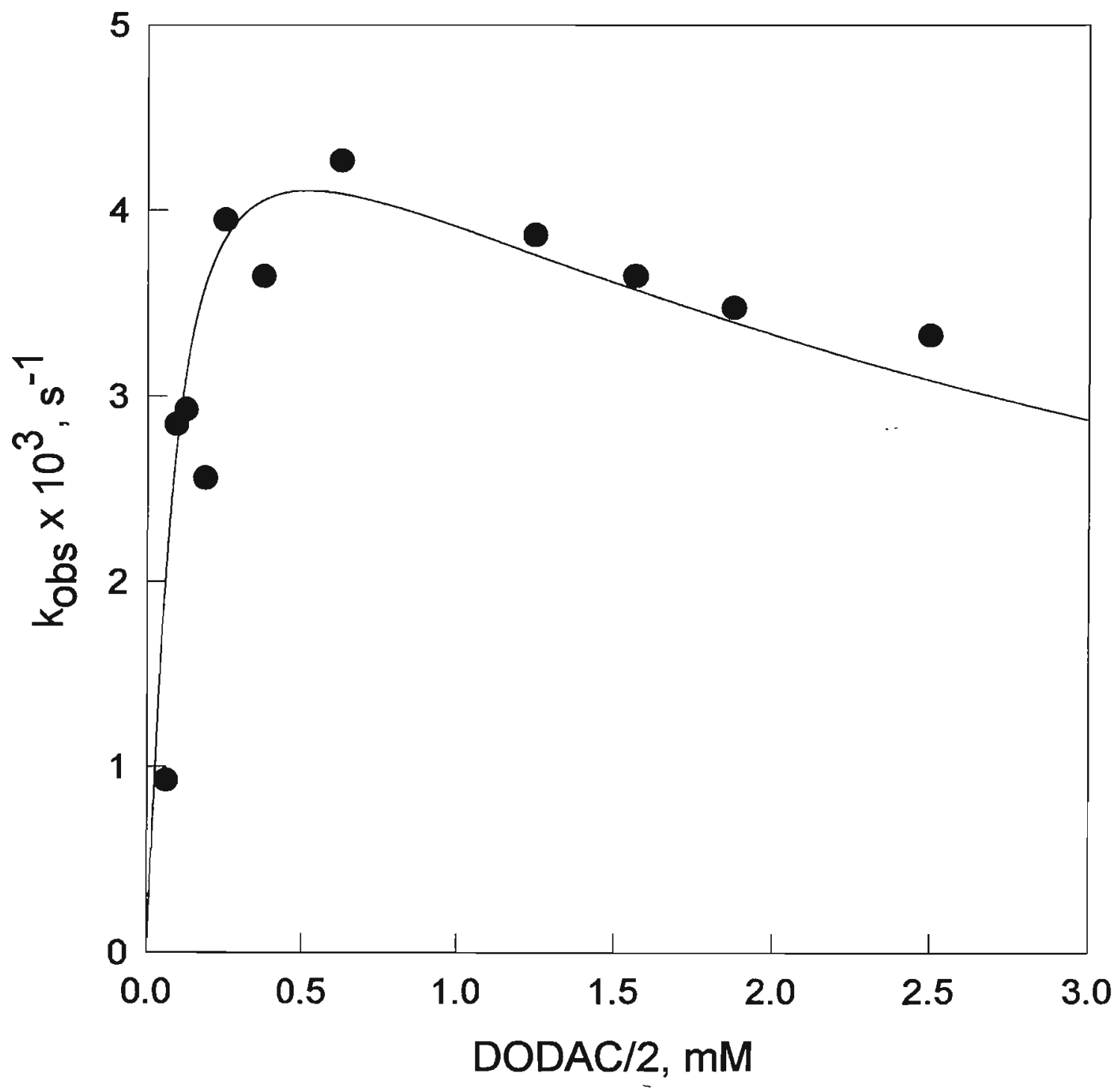

Figura 33: Catálise da hidrólise alcalina de DTNB pela superfície interna de vesículas injetadas de DODAC em tampão borato $\mathrm{pH}$ 8,4/0,025 M. $[\mathrm{DTNB}]=3,46 \times 10^{-5} \mathrm{M}$. 


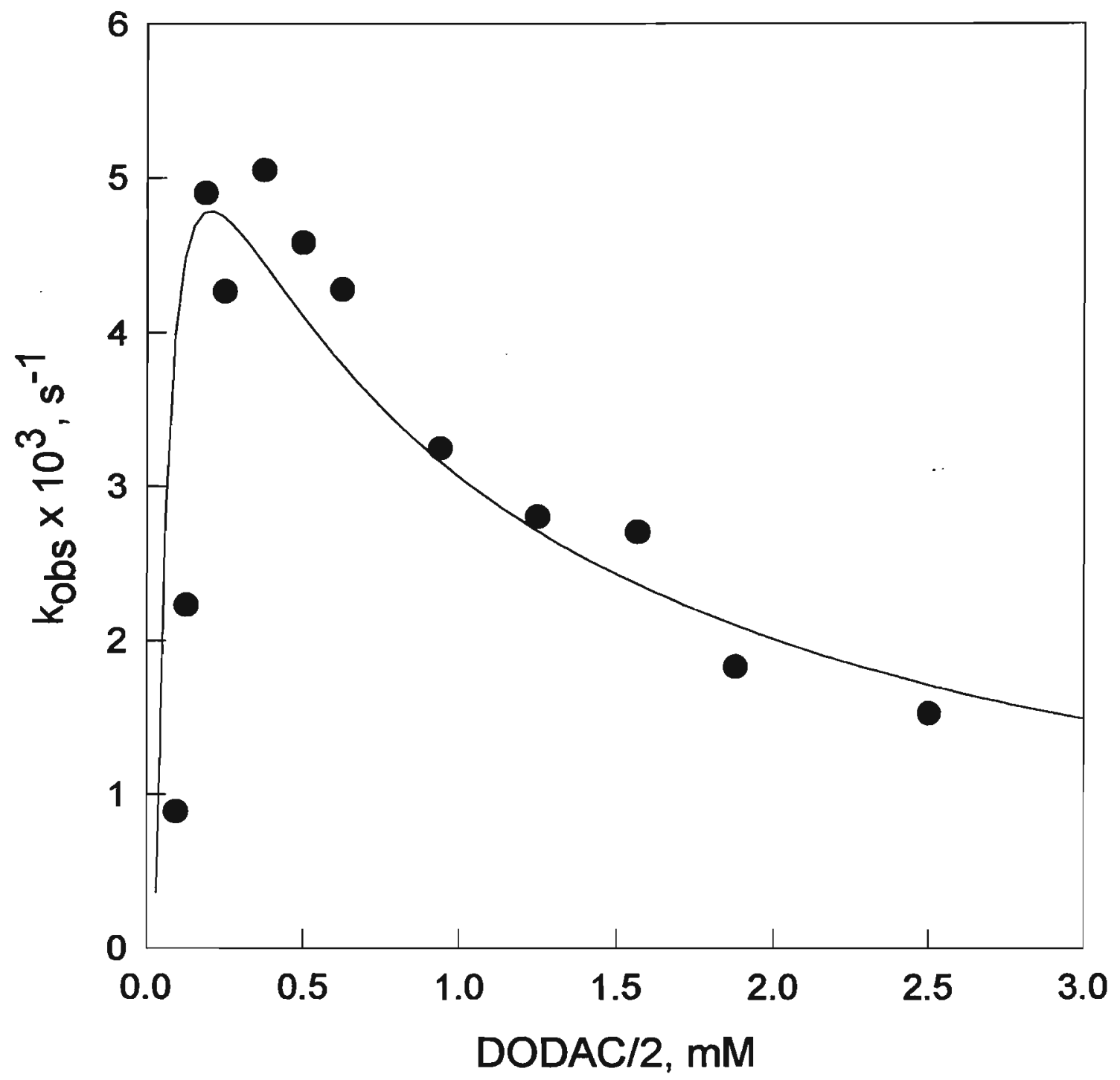

Figura 34: Catálise da hidrólise alcalina de DTNB pela superfície externa de vesículas injetadas de DODAC em tampão borato $\mathrm{pH} 8,40 / 0,025 \mathrm{M}$. $[\mathrm{DTNB}]=3,43 \times 10^{-5} \mathrm{M}$. 


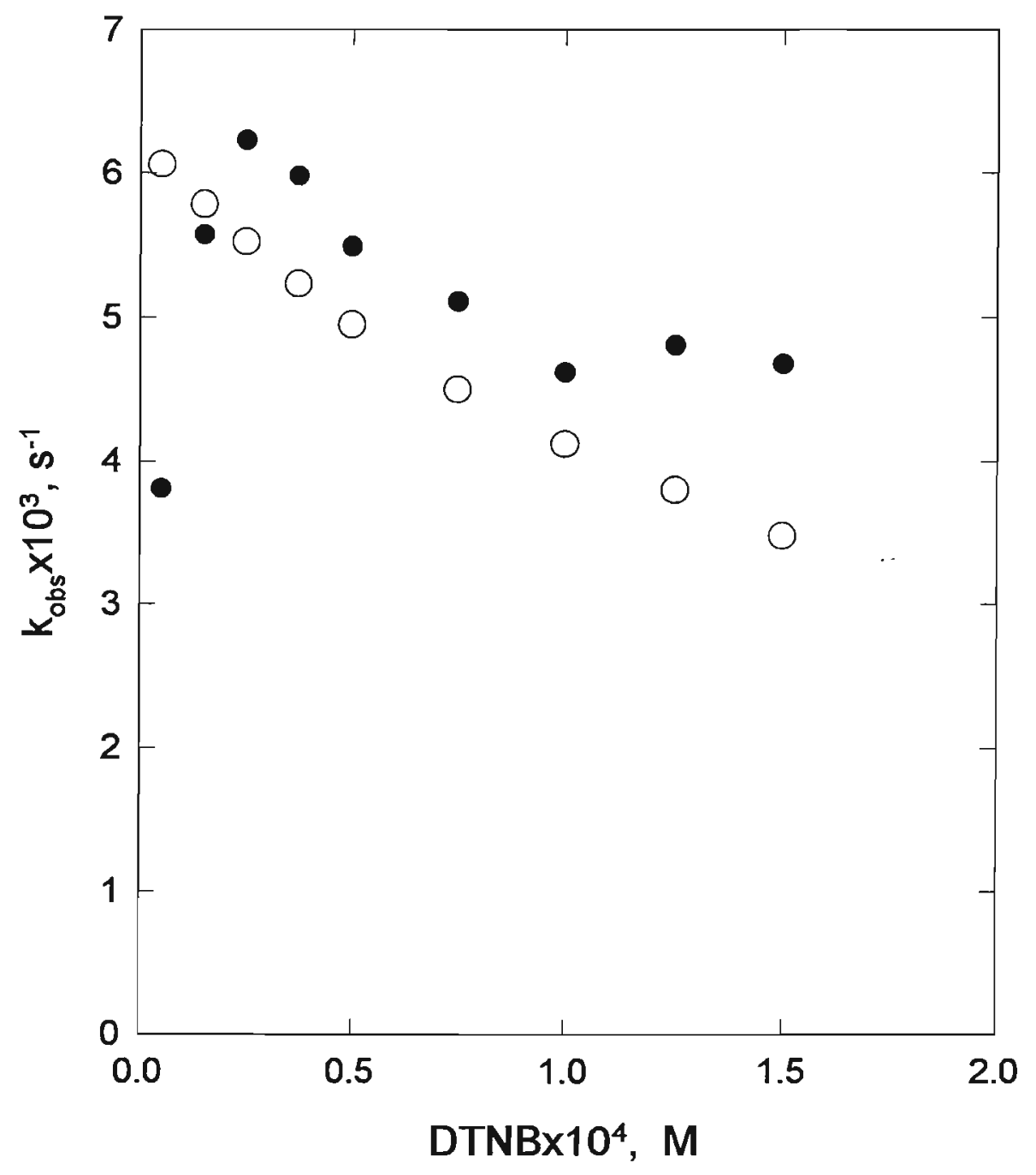

Figura 35: Efeito da concentração de substrato na hidrólise alcalina do DTNB em vesículas injetadas de DODAC $4,26 \times 10^{-3} \mathrm{M}$ em tampão borato $\mathrm{pH}$ 8,9/0,02M.(0), valores experimentais; $(\mathrm{O})$, valores calculados. 


\section{CAPÍTULO 4}

\subsection{Discussão}

Na primeira parte desta dissertação determinamos $0 \alpha$ de micelas e vesículas através do uso da reação do TMD com os haletos que são contra-íons dos anfifílicos.

Uma variedade de métodos experimentais tem sido usada para a determinação do $\alpha$ de micelas (principalmente) e vesículas (Romsted, 1975), como CMC (Corrin e Harkins, 1947), espalhamento de luz (Geer et al, 1971; Jones e Piercy, 1972), medidas de condutância (Barry e Russel, 1972), mobilidade eletroforética (Cuccovia et al, 1990), medidas potenciométricas com eletrodos ion-seletivos de vidro ou membranas (Mathews et al, 1972; Larsen e Magid, 1974) e difusão iônica (Lindman e Brun, 1973). Os valores de $\alpha$ determinados dependem do método empregado. Romsted (1975) comparou os $\alpha$ 's para micelas de dodecilsulfato de sódio (SDS) determinados por diversos métodos na literatura. Os valores de $\alpha$ determinados por espalhameto de luz foram os menores obtidos. Já os valores de $\alpha$ obtidos por condutância ou métodos potenciométricos deram valores intermediários, enquanto que métodos utilizando CMC ou difusão de sódio deram os valores mais altos. Os métodos dão valores diferentes porque são sensíveis à diferentes regiões da micela, monitorando, portanto, concentrações 
diferentes de íons ligados/desligados do agregado. É difícil definir experimentalmente $\alpha$, já que é arbitrário definir a distância entre os contra-íons e as cabeças polares do anfifilico a partir da qual se considera o contra-íon livre ou ligado.

No método empregado neste trabalho, a distribuição dos produtos da reação de decomposição do TMD é sensível apenas ao haleto dissociado do agregado. O TMD, por ser um cátion pequeno, de carga igual à dos agregados não se liga à micelas ou vesículas (Resultados de fluorescência, não mostrados, indicam que o TMD se encontra somente na fase aquosa quando em presença de micelas de CTACl). Em vesículas injetadas foi mostrado que não ocorria vazamento do TMD através do seguinte experimento: após incorporação do TMD nas vesículas e eluição em coluna Sephadex G-25, uma nova eluição da alíquota que continha vesículas manteve o TMD incorporado.

Existe uma dificuldade analítica na determinação do grau de dissociação iônica em vesículas, devido ao limite de concentração vesicular $(10 \mathrm{mM})$ que pode ser usada, já que acima desta concentração ocorre floculação das vesículas. Para a concentração máxima de DODAC utilizada $(10 \mathrm{mM})$ e supondo $\alpha=0,11$ obtém-se uma concentração de $5 \times 10^{-4} \mathrm{M}$ de cloreto livre. A reação de $5 \times 10^{-4} \mathrm{M}$ de $T M D$ em presença desta concentração de cloreto produz $6,80 \times 10^{-8} \mathrm{M}$ de $\mathrm{TMCl}$, que está próximo do limite de deteç̧ão do método, que é cerca de $3 \times 10^{-8} \mathrm{M}$ de TMY. Outro problema encontrado foi o fato de que tanto o $\mathrm{TMCl}$ como o $\mathrm{TMBr}$ serem pouco solúveis em água e voláteis. Para evitar a 
sua perda foi necessário colocar uma camada de ciclohexano sobre a solução onde ele está sendo formado e após a reação o ciclohexano é diluído no meio reacional com a adição de npropanol. Por isto, o grau de dissociação determinado por este método é passível de erros devido ao fato de se trabalhar no limite de detecção. Entretanto, no caso do $\alpha_{1}$ é o único método descrito para esta determinação.

$\mathrm{Na}$ tabela I estão listados os $\alpha$ 's determinados para micelas e vesículas através da reação de decomposição do TMD e por mobilidade eletroforética. Os valores de $\alpha$ para $\mathrm{CTACl}$ e CTAB obtidos estão de acordo com a literatura. São encontrados na literatura $\alpha$ para $C T A C I$ de 0,1 a 0,4 e para CTAB, de 0,15 a 0,2 (Cuccovia et al, 1990; Romsted, 1975; Fabre et al, 1980). Em geral, os valores de $\alpha$ para CTAB são menores que os obtidos para CTACI.

$O \propto$ para vesículas sonicadas de DODAC obtido foi igual tanto para vesículas sonicadas em banho como para vesícula sonicadas por tip. Dados de espalhamento de luz, determinados em nosso laboratório, de vesículas preparadas por sonicação mostram que o diâmetro de vesículas sonicadas com tip é $430 \AA$ e para vesículas sonicadas em banho é de $460 \AA$, sendo então preparações de vesículas semelhantes.

A maior diferença entre os $\alpha$ 's determinados por reação e o determinado por mobilidade eletroforética está nas vesículas de DODAC injetadas em diclorometano. Estas vesículas, tomando como base $0 \alpha$ obtido por mobilidade eletroforética, são as que 
Tabela I : Valores de grau de dissociação iônica determinados.

\begin{tabular}{|c|c|c|c|}
\hline Vesículas/micelas & $\begin{array}{l}\text { Método de } \\
\text { preparação }\end{array}$ & $\alpha_{e}$ & $\alpha_{i}$ \\
\hline DODAC & sonicadas por tip & 0,25 & \\
\hline DODAC & sonicadas em banho & $0,20(0,21)^{a}$ & \\
\hline DODAC & injetadas com DCM & $0,11(0,044)^{a}$ & 0,07 \\
\hline DODAB & sonicadas tip & $0,20(0,13)^{a}$ & \\
\hline CTACl & & $0,29(0,25)^{b}$ & \\
\hline CTAB & & $0,26(0,20)^{\mathrm{a}}$ & \\
\hline
\end{tabular}

a : Cuccovia et al (1990); b: Romsted (1975). 
possuem menor grau de dissociação, que junto com o limite máximo da concentração de vesículas $(\sim 10 \mathrm{mM})$ dá uma concentração baixa de cloreto, de detecção mais difícil.

Não é possivel determinar $\alpha_{i}$ para vesículas injetadas com clorofórmio com o método do TMD porque durante a preparação destas vesículas a temperatura é mantida a $70{ }^{\circ} \mathrm{C}$ para a evaporação do solvente. A esta temperatura o TMD se decompõe rapidamente, não sendo possível incorporá-lo significativamente, já que durante a injeção ( cerca de 2 a 3 minutos) uma fração significativa (cerca de 50\%) se decompõe. Através da preparação de vesículas injetadas por injeção com diclorometano, a $42{ }^{\circ} \mathrm{C}$, pode-se incorporar o TMD e separá-lo do TMD externo, sem muita perda devido à sua decomposição (máximo de 5\%).

Pode-se assumir que os $\alpha$ 's de vesículas injetadas com clorofórmio são iguais aos de vesículas injetadas com diclorometano, pois a distribuição dos tamanhos (determinada por microscopia eletrônica) destes dois tipos de preparação é praticamente igual.

O $\mathrm{K}_{\mathrm{Br} / \mathrm{Cl}}$ de micelas de $\mathrm{CTACl}$, determinado através da reação do TMD (figura 19), está bem próximo ao obtido por Loughlin e Romsted (1990), utilizando uma sonda de sal de diazônio que é sensível aos haletos ligados. Em CTAX 0,01 M e $\mathrm{HX} 0,2 \mathrm{M}\left(\mathrm{X}=\mathrm{Cl}^{-}\right.$ou $\left.\mathrm{Br}^{-}\right)$com concentração total de haletos igual a $0,21 \mathrm{M}$ e com proporção $\mathrm{Br}^{-} / \mathrm{Cl}^{-}=1$ foi obtido $\mathrm{K}_{\mathrm{Br} / \mathrm{Cl}}$ de 2,55. 
Os valores de $\alpha$ determinados através da reação do TMD foram utilizados no ajuste das curvas $k_{\Psi} v s . C_{d}$ para a reação de descarboxilação do NBOC e hidrólise alcalina do DTNB em presença de vesículas e micelas. Nas tabelas II e III estão resumidos os parâmetros utilizados no ajuste.

Os $\alpha_{e}$ e $\alpha_{i}$ para vesículas de DODAC são valores próximos, possivelmente iguais dentro do erro experimental. Portanto. para o ajuste das curvas de $k_{\Psi}$ vs. $C_{d}$ da hidrólise alcalina de DTNB para vesículas injetadas de DODAC pode ser obtido assumindose um único valor de $\alpha$ para as duas superfícies $\left(\alpha_{\mathrm{e}}\right.$ ou $\left.\alpha_{\mathrm{i}}\right)$.

A diferença obtida entre vesículas aquecidas e vesículas não aquecidas na catálise dos diferentes substratos confirma o acesso à superfície interna de vesículas através de aquecimento a uma temperatura acima da temperatura de transição de fase.

Através dos parâmetros obtidos com o ajuste de $k_{\Psi}$ vs. $C_{d}$ verificou-se se as equações podiam prever o perfil de $k_{\Psi}$ vs.[substrato].para uma concentração fixa de anfifílico. Para os resultados de $k_{\Psi}$ vs [NBOC] (figura 31) a diferença entre o valor experimental a baixas concentrações de NBOC o calculado pode ser explicada assumindo-se a existência de dois tipos de sítios em que o NBOC pode se ligar. Um, mais hidrofóbico, catalisando melhor a reação, e de maior afinidade ao NBOC., ao qual 0 substrato se liga preferencialmente em baixas concentrações. Com o aumento da concentração de NBOC, o sítio de maior afinidade é saturado, ocorrendo aumento da fração 
Tabela II: Resumo de parâmetros obtidos no ajuste de $\mathrm{k}_{\Psi}$ vs. $\mathrm{C}_{\mathrm{d}}$ para decomposição do NBOC.

\begin{tabular}{|c|c|c|c|c|}
\hline Agregado & $k_{m}\left(s^{-1}\right)$ & $\bar{\alpha}$ & $K_{\mathrm{NBOC} / Y}$ & $k_{\text {NBOC/borato }}$ \\
\hline \multicolumn{5}{|l|}{ micelas } \\
\hline CTACl & $6,20 \times 10^{-4}$ & 0,29 & 8 & 80 \\
\hline CTAB & $7,15 \times 10^{-4}$ & 0,26 & 4 & 80 \\
\hline vesículas & & & & \\
\hline $\begin{array}{l}\text { DODAB injetadas } \\
\text { superfície interna e } \\
\text { externa }\end{array}$ & $1,43 \times 10^{-3}$ & 0,11 & 3,5 & 100 \\
\hline $\begin{array}{l}\text { DODAB injetadas } \\
\text { superfície externa }\end{array}$ & $1,29 \times 10^{-3}$ & 0,11 & 3,5 & 100 \\
\hline DODAC sonicadas & $4,35 \times 10^{-3}$ & 0,20 & 7,0 & 20 \\
\hline $\begin{array}{l}\text { DODAC injetadas } \\
\text { superfície interna e } \\
\text { externa }\end{array}$ & $3,35 \times 10^{-3}$ & 0,11 & 7,0 & 10 \\
\hline $\begin{array}{l}\text { DODAC injetadas } \\
\text { superfície externa }\end{array}$ & $2,20 \times 10^{-3}$ & 0,11 & 7,0 & 80 \\
\hline
\end{tabular}


Tabela III: Resumo dos parâmetros utilizados no ajuste de $\mathrm{K}_{\Psi} \mathrm{Vs} . \mathrm{C}_{\mathrm{d}}$ para a hidrólise alcalina do DTNB.

\begin{tabular}{|c|c|c|c|c|c|}
\hline Agregado & $k_{2 m}\left(M^{-1} S^{-1}\right)$ & $\alpha_{e}$ & $\alpha_{i}$ & $\overline{K_{\mathrm{OH} / \mathrm{Cl}}}$ & $K_{\text {OH/DTNB }}$ \\
\hline vesículas & & & & & \\
\hline DODAC sonicadas & $8,8 \times 10^{-1}$ & 0,20 & & 0,15 & $1,70 \times 10^{-2}$ \\
\hline $\begin{array}{l}\text { DODAC injetadas } \\
\text { superfície interna }\end{array}$ & 2,2 & & 0,07 & 0,16 & $1,70 \times 10^{-2}$ \\
\hline $\begin{array}{l}\text { DODAC injetadas } \\
\text { superfície externa }\end{array}$ & $8,0 \times 10^{-1}$ & 0,11 & & 0,16 & $1,70 \times 10^{-2}$ \\
\hline
\end{tabular}


de NBOC ligada a este sítio, diminuindo o $k_{\Psi}$. Em concentrações altas de NBOC a fração de substrato ligado é alta, mascarando a catálise exercida pelo sítio de maior afinidade e $k_{\Psi}$ passa a ser independente da concentração de substrato.

Para os resultados de $k_{\Psi}$ vs [DTNB] para vesículas injetadas de DODAC (figura 35) houve concordância entre os valores teóricos e os dados experimentais na faixa de concentração de DTNB de $1,5 \times 10^{-5}$ a $1,0 \times 10^{-4} \mathrm{M}$. Os desvios observados fora da faixa acima podem ser explicados se for também assumido que existam no mínimo dois tipos de sítio onde o DTNB se liga, sendo que no sítio de maior afinidade, a ligação é somente hidrofóbica, não ocorrendo troca iônica. Este sítio é menos acessivel ao ataque pelo hidróxido e é a este sítio que o DTNB se liga preferencialmente em concentraçōes abaixo de $1,5 \times 10^{-5} \mathrm{M}$. Com o aumento da concentração de DTNB o sítio hidrofóbico é saturado e o substrato vai se ligar agora, mediante troca iônica, num sítio de menor afinidade e com $k_{\Psi}$ maior, por ser este sítio mais acessível ao hidróxido. Aumentando-se a concentração de DTNB este expulsa o hidróxido mediante troca, restando apenas a hidrólise alcalina do DTNB ligado nos sítios hidrofóbicos, dando um patamar a concentrações relativamente altas de DTNB.

A catálise da hidrólise alcalina do DTNB pela superfície interna de vesículas (figura 31) é difícil de interpretar. Visto que o DTNB se liga fortemente à superfície da vesícula (em todas as 
concentrações de vesículas a incorporação foi de 50\%), a concentração interna de DTNB variou com a concentração de anfifilico. O DTNB incorporado está sempre em presença de uma mesma concentração interna de anfifílico, independente da concentração analítica de detergente. No entanto, à medida que é aumentada a concentração analítica de anfifílico, a quantidade de DTNB por vesícula diminui. Para uma concentração fixa de anfifílico, a equação de ajuste prevê que a redução na concentração de DTNB provoca sempre um aumento no $k_{\Psi}$ (figura 35), o que pode explicar o aumento no $k_{\Psi}$ da figura 33, mas não a sua diminuição, a qual pode ser devida à ligação do DTNB no sítio hidrofóbico da vesícula, ficando menos acessível ao hidróxido, conforme descrito no parágrafo anterior. Os pontos experimentais da catálise pela superfície interna foram ajustados com $\alpha=0.07$ e parâmetros iguais aos utilizados no ajuste da catálise da superfície externa. Contudo, só ocorre o ajuste com uma concentração de sal da ordem de $1 \times 10^{-4} \mathrm{M}$, que compensa o problema da dificuldade de acesso do hidróxido ao DTNB em altas concentrações de vesículas, como se fosse uma troca cloreto/hidróxido. $\mathrm{O}$ valor de $\mathrm{k}_{2 \mathrm{v}}$ comparado aos obtidos para os outros ajustes é cerca de 3 vezes maior.

Visto que $k_{\Psi}$ vs [NBOC], para uma concentração fixa de vesículas injetadas (fig.31), apresentou uma variação de $40 \%$ no $k_{\Psi}$, era esperada uma variação maior de $k_{\Psi}$ vs [NBOC] para uma concentração de CTACI próxima à de DODAC (figura 26), pois 
suas cabeças polares não estão muito compactadas como nas vesículas.

O aumento na concentração de substrato pode alterar a compactação, como ocorre com tosilato e benzoato (Bunton et al, 1971), modificando a densidade de carga na superfície da micela e, consequentemente, seus parâmentros de catálise. A adição de sais orgânicos aumenta a catálise de descarboxilação do NBOC por micelas de CTAB em concentrações de sal na faixa de 0 a $0,1 \mathrm{M}$, caindo acentuadamente em concentrações maiores, sugerindo que os ânions orgânicos, ao mesmo tempo que modificam a compactação micelar, também competem com o substrato. Já a adição de sais inorgânicos aumenta a catálise, atingindo um patamar.

A faixa de concentração de NBOC utilizada na figura 26 foi muito pequena para se observar o aumento da catálise. Comparando-se com as vesículas, estas são muito mais sensíveis à variação da concentração de substrato nesta faixa estudada do que as micelas.

A catálise da descarboxilação do NBOC por vesículas de DODAB foi aproximadamente metade da obtida com DODAC (comparando-se os máximos), enquanto que micelas de CTAB catalisam cerca de $12 \%$ mais que micelas de CTACI. Esta inversão no contra-íon mais favorável à catalise pode ser relacionada novamente ao empacotamento das cabeças polares dos anfifílicos. $\mathrm{O} \mathrm{Br}^{-}$, por ligar mais às micelas e vesículas provoca um empacotamento maior que o provocado pelo $\mathrm{Cl}^{-}$. 
Este empacotamento aumenta a catálise no caso de micelas, como observado por Bunton et al (1971) e diminui, no caso de vesículas.

Dados obtidos com hidrólise alcalina e tiólise de octanoato de p-nitrofenila (Kawamuro et al, 1991) com vesículas sonicadas e injetadas de DODAC (DODAB) mostram que as diferenças de catálise entre vesículas pequenas (menor empacotamento da bicamada) e vesículas grandes (bicamada mais empacotada) são devido principalmente à variação na capacidade da bicamada de solubilizar o substrato e dissociar os contra-íons.

Com um maior empacotamento da bicamada, determinadas maneiras do substrato se ligar devem ser afetadas, por exemplo, se o substrato se liga com sua parte apolar mergulhada na parte apolar do agregado, um maior empacotamento da bicamada pode favorecer a interação anfifílico-substrato, mudando seu micro-ambiente e afetando a catálise.

Comparando-se $k_{m}$ vesicular com $k_{m}$ micelar conclui-se que o local onde o NBOC se liga na vesícula é muito mais apolar e/ou menos capaz de fazer pontes de hidrogênio do que o local onde o substrato se liga nas micelas.

\subsection{Conclusões}

Demonstramos, neste trabalho, que a decomposição do TMD é viável na determinação do $\alpha_{\mathrm{e}}$ de micelas e vesículas, do $\alpha_{\mathrm{i}}$ de vesículas e da constante de troca $\mathrm{Br}^{-} / \mathrm{Cl}^{-}$. 
O efeito de micelas e vesículas na decomposição do NBOC e na hidrólise alcalina do DTNB podem ser tratados quantitativamente usando o modelo de pseudofase com troca iônica e os valores de $\alpha$ determinados. 


\section{$\underline{\text { Referências bibliográficas }}$}

Barry, B.W.; Russel, F.J.,Prediction of micellar molecular weights and thermodinamics of micellization of mixtures of alkyltrimethylammonium salts. J.Coll.I.Sci.,40,174,1972.

Berezin, I.V.; Martinek, K.; Yatsimirski, A.K.,Physicochemical foundations of micelar catalysis, (1973) Russ.Chem.Revs. (English transl.),42,787.

Bunton, C.A.; Minch, M.J., Micellar catalysed decarboxilation of 6nitrobenzisoxazole-3-carboxilate ion ,Tetrahedron lett.,3881, (1970).

Bunton, C.A.; Minch, M.J.; Sepúlveda,L.,Enhancement of micelar catalysis by added eletrolytes, (1971) J.Phys.Chem,75,2707.

Carmona-Ribeiro, A.M.;Chaimovich, H., Preparation and characterization of large dioctadecyldimethylammonium chloride lipossomes and comparison with small sonicated vesicles,(1983) Biochim.Biophys.Acta, 733,172.

Carmona-Ribeiro, A.M.; Yoshida, L.S.; Sesso, A.; Chaimovich, $\mathrm{H}$.,Permeabilities and estabilities of large dihexadecylphosphate and dioctadecyldimethylammonium chloride vesicles, (1984) J.Colloid.Int.Sci.,100,433. 
Carmona-Ribeiro, A.M., Yoshida, L.S., Chaimovich, H., Salt effects of dioctadecyldimethylammonium chloride and sodium dihexadecyl phosphate vesicles, J.Phys.Chem.,2928,89,1985.

Carmona-Ribeiro, A.M., Chaimovich, H., Salt induced aggregation and fusion of dioctadecyldimethylammonium chloride and sodium dihexadecylphosphate vesicles, Biophys.J.,50, 621,1986 .

Carmona-Ribeiro, A.M., Synthethic amphiphile vesicles, Chem. Soc.Revs.,209,1992.

Chaimovich, H., Troca iônica em micelas, São Paulo, Departamento de Bioquímica, Instituto de Química da USP, 1979 (Tese de doutorado).

Chaimovich, H.; Bonilha, J.B.S.; Zanetti, D.; Cuccovia, I.M., Analysis of the effect of micelles and vesicles on the reactivity of nucleophiles derived from dissociation of weak acids, (1984) "Surfactans in Solution", Mittal, K.L. and Lindman,B.;Eds, Plenus, New York, vol 2, 1121.

Chaudhuri, A.; Romsted, L.S., Simultaneous determination of counterion, alcohol, and water concentrations at a three component microemulsion interface using product distributions 
from a dediazoniation reaction, J.Am.Chem.Soc.,113,5052, (1991).

Chaudhuri, A; Loughlin, J.A.; Romsted, L.S.; Yao, J.H., Arenediazonium salts: New probes of the interfacial compositions of association colloids.1. Basic aproach, methods, and illustrative aplications (1991) J.Am.Chem.Soc.,115,8351.

Chaudhuri, A; Romsted, L.S.; Yao, J.H., Arenediazonium salts: New probes of the interfacial compositions of association colloids.2. Binding constants of butanol and hexanol in aqueous three-component cetyltrimethylammonium bromide microemulsions, (1993) J.Am.Chem. Soc.,115,8362.

Corrin, M.L.; Harkins, W.D., The effect of salts on the critical concentration for the formation of micelles in colloidal electrolytes, J.Am.Chem.Soc.,69,683,1947.

Cuccovia, I.M.; Schroter, E.H.; Batista, R.C.; Chaimovich, H., Effect of hexadecyltrimethylammonium bromide on the thiolysis $\mathrm{O}$ p-nitrophenyl acetate, (1977) J.Org.Chem.,42,3400

Cuccovia, I.M.; Schroter, E.H.; Monteiro, P.M.; Chaimovich, H., Effect of hexadecyldimethylammonium bromide on the thiolysis of p-nitrophenyl acetate, (1978) J.Org.Chem.,43,2248. 
Cuccovia, I.M., Quina, F.H.; Chaimovich, H., Effect of dialkyldimethylammonium vesicles on the thiolysis of $p$-nitrophenil acetate, (1979) Tetrahedron Letters, 3065.

Cuccovia, I.M., Quina, F.H. e Chaimovich, H., A remarkable enhancement of the rate of ester thiolysis by sythethic amphiphile vesicles, Tetrahedron,38,917,1982.

Cuccovia, I.M.; Kawamuro, M.K.;Krutman, M.A.K.;Chaimovich, H.,Control of reaction rates in vesicular systems, (1989) J.Am.Chem.Soc., 111,365.

Cuccovia, I.M., Feitosa, E., Chaimovich, H., Sepúlveda, L. E Reed, W.F., Size, eletroforetic mobility and ion dissociation of vesicles prepared with synthetic amphiphiles, J.Phys.Chem., $94,3722,1990$.

Elamrani, K.; Blume, A.; Effect of lipid phase transition on the kinetics of $\mathrm{H}^{+} / \mathrm{OH}^{-}$diffusion across phosphatidic acid bilayers, (1983) Biochim.Biophys.Acta,727,22.

Fabre, H.; Kamenka, N.; Khan, A., Self diffusion and NMR studies of chloride and bromide ion binding in aqueous hexadecyltrimethylammonium salt solutions, (1980) J.Phys. Chem.,84, 3428. 
Fendler, J.H.; Fendler, E.J.(1975) "Catalysis in micellar and macromolecular systems", Academic Press, New York.

Fendler, J.H.;Hinze, W.L., Reactivity control in micelles and surfactant vesicles. Kinetics and mechanism of base-catalysed hydrolysis of 5,5'-dithiobis(2-nitrobenzoic acid) in water, hexadecyltrimethylammonium bromide micelles, and dioctadecyldimethylammonium chloride surfactant vesicles, (1981) J.Am.Chem.Soc.,103,5439.

Fendler, J.H. (1982) "Membrane Mimetic Chemistry", WileyInterscience, New York.

Feitosa, E.; Agostinho-Neto, A.; Chaimovich, H., Integration of the nonlinear Poisson-Boltzmann equation for charged vesicles prepared with synthethic amphiphiles, J.Phys,Chem.,94,3722, 1990.

Frankel, D.A.; Lamparki, H.; Liman, V.; O'Brien, D.F., Photoinduced destabilization of bilayer vesicles, J.Am.Chem. Soc.,111,9262, 1989.

Fuhrhop, J.; Liman, U.; Koesling, V., A macrocyclic tetramer bolaamphiphile and oligoamino $\alpha, \omega$-dicarboxilate combine to form monolayered, porous vesicle membranes, which are 
reversibly sealed by EDTA and other bulky anions, J.Am.Chem.Soc.,6840, 110,1988.

Fuhrhop, J. E Mathieu, J., Routes to functional vesicles membranes without proteins, Angew.Chem. Int.Ed.Engl. ,23, 100, 1984.

Geer, R.D.; Eylar, E.H.; Anaker, E.W., Dependence of micelle agregation number on polar head structure I. Light scattering by aqueous solutions of decylammonium salts and related surfactants, J.Phys.Chem.,75,369,1971.

Grunhagen,H.H., Chemical relaxation of cetylpyridinium iodide micelles in high eletric fields, J.Colloid Interface Sci.,53,282,1975.

Ishiwatari, T.e Fendler, J.H., Polymerized surfactant vesicles: effects of polimerization on intravesicular ester hydrolysis, J.Am.Chem.Soc.,106,1908,1984.

Israelachvili, J.N., "Intermolecular and surface forces", Academic Press, 1991.

Jaeger, D.A.; Clennan, M.W.;Jamrozik, J., Monohalogenation of alkyl phenyl ethers in micellar and vesicular media, J.Am.Chem.Soc.1171,112,1990. 
Jayasuriya, N.; Bosak, S.; Regen, S.L., Supramolecular surfactants:polymerized bolaphiles exhibiting extraordinarily high membrane-disrupting activity, J.Am.Chem.Soc.,112,5851,1990.

Jenks, W.J., Catalysis in chemistry and enzimology, New York, 1987.

Jones, M.N.; Piercy, J., Light scattering studies on $\mathbf{n}$ dodecyltrimethylammonium bromide and $\mathrm{n}$-dodecylpiridinium iodide. Faraday Soc.Trans.I,68,1839,1972.

Kano, K.; Romero, A.; Djermouni, B.; Ache, H.; Fendler, J.H., Characteriation of surfactant vesicles as membrane mimetic agents .2. Temperature-dependent changes of the turbidity, viscosity, fluorescence polarization of 2-methylanthracene, and positron annihilation in sonicated dioctadecyldimethylammonium chloride, (1979) J.Am.Chem.Soc.,101,4030.

Kawamuro, M.K.; Chaimovich, H.; Abuin ,E.B.; Lissi, E.A.; Cuccovia, I.M..Evidence that the effects of synthetic amphiphile vesicles depend on vesicle size, (1991) J.Phys.Chem.,95,1458.

Kemp,D.S.; Paul, K.G., The physical organic chemistry of benzisoxazoles.III.The mechanism and the effects of solvents on rates of the decarboxilation of benzisoxazole-3-carboxilic acids,(1975) J.Am.chem.Soc.,97,7305. 
Kosower, E.M.; Patton, J.W., The products and kinetics of hydrolysis of cyanopyridinium ions, Tetrahedron,22,2081,1966

Kunitake, T. E Sakamoto, T., Catalytic Hydrolysis of phenyl esters in aqueous didodecyldimethylammonium vesicles. Remarcable rate diference between intra and intervesicle reactions, J.Am.Chem.Soc., 100,4615,1978.

Kunitake, T.; Okahata, Y.; Ando, R.; Shinkai, S.; Hirakawa, S., Descarboxylation of 6-nitrobenzisoxazole-3-carboxylate catalyzed by ammonium bilayer membranes. A comparison of the catalytic behavior of micelles, bilayer membranes, and othe aqueous aggregates, J.Am.Chem.Soc.,102,7877,1980.

Larsen, J.W.; Magid, L.J., Calorimetric and counterion binding studies of the interactions between micelles and ions.The observation of lyotropic series, J.Am.Chem.Soc.,96,5774,1974.

Lasic, -D.D., The mechanism of vesicle formation, Biochem.J.,256,1,1988.

Lasic, D.D.; Papahadjopoulos, D., Liposomes revisited, Science,267,1275,1995. 
Lim,Y.Y.; Fendler, J.H., Characterization of surfactant vesicles as membrane mimetic agents.1. Interactions and reactions of sodium 2,2,5,5-tetramethyl-1-pyrrolidinyloxy-3-carboxylate spin probe in sonicated dioctadecyldimethylammonium chloride, (1979) J.Am.Chem.Soc., 101,4023.

Lindman, B.; Brun, B.,Translational motion in aqueous sodium noctanoate solution,. J.Coll.I.Sci.,42,388,1973.

Loughlin, J.A.; Romsted, L.S., A new method for estimating counter-ion selectivity of a cationic association colloid: Trapping of interfacial chloride and bromide counter-ions by reaction with micellar bound aryldiazonium salts, (1990) Colloids and Surfaces, 48,123 .

Maeda, M.; Kumano, A.; Tirrele, D.A., $\mathrm{H}^{+}$induced release of contents of phosphatidylcholine vesicles bearing surface-bound polyeletrolyte chains, J.Am.Chem.soc.,110,7455,1988.

Madani, H., Kaler, E.W., Aging and stability of vesicular dispersions, Langmuir,6,125,1990.

Mathews, W.K.; Larsen, J.W.; Pikal,M.J., The effect of solubilization on counter ion binding to micelles. Tetrahedron Letts.,513,1972. 
Menger, F.M.; Davis, D.S.; Persichetti, R.A.; Lee, J., Synthetic flux-promoting compounds. Exceeding the ion-transporting ability of gramicidin, J.Am.Chem.Soc.,112,2451,1990.

Moss, R.A. e Bizzigotti, G.O., Fully functionalized thiol vesicles:structure and estereolitic properties, J.Am.Chem.Soc., $103,6512,1981$.

Moss, R.A. e Bizzigotti, G.O., Examples of transvesicular reations, Tetrahedron Lett.,23,5235,1982.

Moss, R.A.; Dix, F.M.; Romsted, L., Micellar dediazoniation:Dramatic diretive effects on the course of reaction, J.Am.Chem.Soc.,104,5048,1982.

Moss, R.A. e Hui, Y., The screening of endovesicular reactions by cholesterol, Tetrahedron Lett.,24,3961,1983.

Moss, R.A.;Schreck, R.P., The reactivity of substrate functionalized surfactant vesicles, (1985) J.Am.Chem.Soc., 107, 6634.

Moss, R.A.; Swarup, S., Surface-specific phosphate clevage of a substrate-functionalized vesicular surfactant, J.Am.Chem.Soc., $5341,108,1986$. 
Moss, R.A.; Hendrickson, T.F.e Bizzigotti, G.O., Esterolytic Chemistry of a vesicular thiocholine surfactant, J.Am.Chem. Soc., $108,5520,1986$.

Moss, R.A., Bhattacharya, S., Scrimin, P.e Swarup, S., Surface specific-cleavage of a cationic carbonate-functionalized vesicular surfactant, J.Am.Chem.Soc.,109,5740,1987.

Moss, R.A. e Swarup, S., Transvesicular reactions of thiols with Ellman's reagent, J.Org.Chem.,53,5860,1988.

Moss, R.A., Swarup, S.; Zhang, H., Reactivity control by microencapsulation in simple ammonium ion vesicles, J.Am. Chem. Soc.,110,2914,1988.

Moss, R.A.; Bhattacharya, S.; Chatterjee, S., Chemical differentiation of bilayer surfaces in functional dialkylammonium ion vesicles: observation of surfactant flip-flop, J.Am.Chem.Soc.,3680, 111,1989.

Moss, R,A.; Fujita, T.; Ganguli, S., Dynamics of surfacedifferentiated alkylammonium ion vesicles, Langmuir, 6, 1197, 1990.

Moss, R.A.; Fujita, T.; Okumura, Y., Effect of unsaturation on lipid dynamics within synthetic lipid membranes, Langmuir,7,440,1991. 
Murakami, Y.; Kikuchi, J.; Shiratori, N., Multifunctional catalysis for transamination reaction of $\alpha$-amino acids with glyoxilic acid in synthethic bilayer membrane, J.Phys.Org.Chem.,2,110,1989.

Pansu, R.B., Arrio, B., Roncin, J. E Faure, J., Vesicles versus membrane fragments in DODAC suspensions, J.Phys. Chem., $94,796,1990$.

Politi, M.J.; Cuccovia, I.M.; Chaimovich, H.;Almeida, M.L.C.; Bonilha, J.B.S.; Quina, F.H., Effect of hexadecyltrimethylammonium bromide on the hydrolisys of $n$ alkyl-4-cyanopyridinium ions, Tetrahedron Letters, 115,1978.

Quina, F.H.; Chaimovich, H.,Ion exchange in micelar solutions.I.Conceptual framework for ion exchange in micelar solutions, (1979) J.Phys.Chem.,83,1844.

Quina, F.H.; Politi, M.J.; Cuccovia, I.M.; Baumgarten, E.; MartinsFranchetti, S.M.; Chaimovich, H., lon exchange in micellar solutions.4. "Buffered" systems, (1980) J.Phys.Chem,84,361.

Ramesh,V.; Labes,M.M., Influence of disc-rod-sphere phase transition in nematic lyotropics on unimolecular isomerization reaction, (1987) J.Am.Chem.Soc.,109,3228. 
Ramesh, V.; Labes, M.M., Dramatic influence of the nature of the surfactant aggregate on the rate constant for hydrolysis of phosphinate esters in aqueous nematic lyotropic liquid crystals, (1987) J.Am.Chem.Soc., 110,738.

Reed, W.R.; Guterman, L.;Tundo, P.; Fendler, J.H., Polymerized surfactant vesicles: kinetics and mechanism of photopolymerization, J.Am.Chem.Soc.,106,1897,1984.

Regen, S.L.; Yanaguchi, K.; Samuel, N.K.P.; Singh., M., Polymerized-depolymerized vesicles. A reversible prosphatidylcholine-based membrane, J.Am.Chem.Soc.,105, 6354, 1983.

Romsted, L.R., Kinetic treatment of micellar catalysis, Bloomington, Indiana, 1975.( PhD Thesis, Indiana University).

Schales, O.; Schales, S.S., A simple and accurate method for the detemination of chloride in biologic fluids, (1941), J.Biol.Chem. 140,879.

Souza, S.M.B., Efeito de aditivos nas propriedades de monocamadas de anfifílicos carregados, Dissertação de mestrado, Instituto de Química-USP,1994. 
Stefely, J.; Malkowitz, M.A.; Regen, S.L., Permeability characteristics of lipid bilayers from lipoic acid derived phosphatidyl cholines:comparison of monomeric, cross-linked and non-cross-linked polymerized membranes, J.Am.Chem.Soc., $110,7463,1988$.

Stelmo. M.; Chaimovich, H.; Cuccovia, I.M., Quantitative determination of alkylammonium amphiphiles using neutral detergents, J.Colloid Interface Sci.,200,117,1987.

Stigter, D., On the adsorption of counterions at the surface of detergent micelles, J.Phys.Chem.,68,3603,1964.

Vogel, A.I.,Química orgânica, Análise orgânica qualitativa, $3^{\mathrm{a}}$ ed (1971), Editora Ao livro técnico, página 633. 